\title{
Diagnosing hypertension : contributions from primary care
}

Citation for published version (APA):

Brueren, M. M. M. (1998). Diagnosing hypertension : contributions from primary care. [Doctoral Thesis, Maastricht University]. Datawyse / Universitaire Pers Maastricht. https://doi.org/10.26481/dis.19980116mb

Document status and date:

Published: 01/01/1998

DOI:

10.26481/dis.19980116mb

Document Version:

Publisher's PDF, also known as Version of record

\section{Please check the document version of this publication:}

- A submitted manuscript is the version of the article upon submission and before peer-review. There can be important differences between the submitted version and the official published version of record.

People interested in the research are advised to contact the author for the final version of the publication, or visit the DOI to the publisher's website.

- The final author version and the galley proof are versions of the publication after peer review.

- The final published version features the final layout of the paper including the volume, issue and page numbers.

Link to publication

\footnotetext{
General rights rights.

- You may freely distribute the URL identifying the publication in the public portal. please follow below link for the End User Agreement:

www.umlib.nl/taverne-license

Take down policy

If you believe that this document breaches copyright please contact us at:

repository@maastrichtuniversity.nl

providing details and we will investigate your claim.
}

Copyright and moral rights for the publications made accessible in the public portal are retained by the authors and/or other copyright owners and it is a condition of accessing publications that users recognise and abide by the legal requirements associated with these

- Users may download and print one copy of any publication from the public portal for the purpose of private study or research.

- You may not further distribute the material or use it for any profit-making activity or commercial gain

If the publication is distributed under the terms of Article $25 \mathrm{fa}$ of the Dutch Copyright Act, indicated by the "Taverne" license above, 


\title{
DIAGNOSING HYPERTENSION Contributions from primary care
}

\author{
PROEFSCHRIFT \\ ter verkrijging van de graad van doctor \\ aan de Universiteit Maastricht, \\ op gezag van de Rector Magnificus \\ Prof. dr. A.C. Nieuwenhuijzen Kruseman, \\ volgens het besluit van het College van Decanen, \\ in het openbaar te verdedigen \\ op vrijdag 16 januari 1998 om 14.00 uur
}

door

Mark Brueren

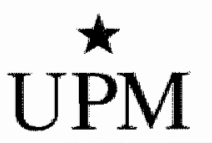

UNIVERSITAIRE PERS MAASTRICHT' 


\section{Promotores}

Prof.dr. J.W. van Ree

Prof.dr. P.W. de Leeuw

Prof.dr. C. van Weel (Katholieke Universiteit Nijmegen)

\section{Beoordelingscommissie}

Prof.dr. P. Pop (voorzitter)

Prof.dr. P. van den Brandt

Prof dr. J.A. Knottherus

Prof.dr. B. Meyboom-de Jong (Rijksuniversiteit Groningen)

Prof.dr. Th. Thien (Katholieke Universiteit Nijmegen)

The study presented in this thesis was supported by a grant from the Netherlands Organization for Scientific Research (NWO), Grant number 900.715.169.

Publication of this thesis was also made possible by a grant fiom:

The Nethertands Heart Foundation. Roche Nederland BV, Pfizer BV, Zeneca Farma BV 
'Het is werkelijk raar spul: het is koud en loopt weg, altijd onrustig, maar als het stil staat kun je je er beter in spiegelen dan in een spiegel."

Uit het verhaal 'Kwik' van Primo Levi. 


\section{Promotores}

Prof.dr. J.W. van Ree

Prof.dr. P.W. de Leeuw

Prof.dr. C. van Weel (Katholieke Universiteit Nijmegen)

\section{Beoordelingscommissie}

Prof.dr. P. Pop (voorzitter)

Prof.dr. P. van den Brandt

Prof.dr. J.A. Knottnerus

Prof.dr. B. Meyboom-de Jong (Rijksuniversiteit Groningen)

Prof.dr. Th. Thien (Katholieke Universiteit Nijmegen)

The study presented in this thesis was supported by a grant from the Metherlands Organization for Scientific Research (NWO). Gant number 900.715 .169$.

Publication of this thesis was also made possible by a grant from:

The Nethertands Heart Foundation. Roche Nederland BV, Pfizer BV. Zeneca Fama BV 
'Het is werkelijk raar spul: het is koud en loopt weg, altijd onrustig, maar als het stil staat kun je je er beter in spiegelen dan in een spiegel.'

Uit het verhaal "Kwik" van Primo Levi. 



\section{Contents}

Preface

\section{Chapter 1}

General background 11

\section{Chapter 2}

Methods

\section{Chapter 3}

Diagnosing hypertension in general practice: measurements according to the Dutch College of General Practitioners'

Protocol compared with ambulatory blood pressure measurements

Correspondence 1

\section{Chapter 4}

How many measurements are necessary in diagnosing mild to moderate hypertension?

\section{Chapter 5}

Are four duplicate remeasurements sufficient for diagnosing mild hypertension?

Correspondence 2

\section{Chapter 6}

Is a series of blood pressure measurements by the general practitioner or the patient a reliable alternative to ambulatory blood pressure measurement?

\section{Chapter 7}

Feasibility, acceptance and side effects of ambulatory blood pressure measurement and blood pressure self-measurement

\section{Chapter 8}

A series of self-measurements by the patient is a reliable aiternative to ambulatory blood pressure measurement 


\section{Chapter 9}

No relevant seasonal influences on office and ambulatory blood pressure: data from a study in borderline hypertensive primary care patients

Chapter 10

General discussion

Chapter 11

Summary

\section{Chapter 12}

Samenvatting

Dankwoord

Curriculum vitae 


\section{Preface}

In 1989, the Netherlands Organization for Scientific Research (NWO) decided to support a research proposal developed by clinical investigators of the University of Nijmegen (JW van Ree, Th Thien, C van Weel, H van den Hoogen, J Lenders, A Smits, M van Kruijsdijk, J van den Hoogen). The aim of the study was to improve the diagnostic procedure for hypertension, because there appeared to be a considerable risk of overdiagnosis and overtreatment, especially in borderline hypertensives. Since, at the same time, Van Ree was appointed as professor at Maastricht University, the research project moved to Maastricht, where it started in 1990. This thesis reports on the findings of the project.

\section{Structure of the thesis}

Chapter 1 provides the general background to the study: a brief history of blood pressure measurement and the difficulties in diagnosing hypertension. caused by, for instance, the phenomena of regression to the mean and white coat hypertension, and measurement errors.

Chapter 2 presents the methods used in the study.

In chapter 3, blood pressure measurements according to the guidelines of the Dutch College of General Practitioners are compared with ambulatory blood pressure measurements. The analysis is based on the first 102 patients who completed the study ( $83 \%$ of the entire study population).

Chapter 4 studies the number of blood pressure measurements by the general practitioner required for diagnosing mild hypertension with certainty. Findings are analyzed qualitatively after dichotomization (hypertension and normotension). This study is based on 114 patients (93\% of the entire study population).

The data from chapter 4 are analyzed quantitatively in chapter 5 .

Chapters 4 and 5 show a considerable overlap. Chapter 4 , which was published in an international journal for primary care physicians, can be read as an example of 'clinical reasoning'. Readers interested in the statistical foundations of the conclusions may prefer chapter 5 . In this thesis, these chapters mark the transition from clinical to statistical reasoning.

In chapter 6 the reproducibility of ambulatory blood pressure measurements is compared with that of a series of measurements by the general practitioner and the patient.

In chapter 7 the feasibility, acceptance and side effects of self-measurements and ambulatory measurements are presented. 
Chapter 8 compares series of blood pressures measured by the general practitioner, the practice nurse and the patient with ambulatory blood pressures.

Seasonal influences on blood pressure in borderline hypertensive primary care patients are studied in chapter 9.

In chapter 10 the studies are summarized and discussed in relation to methodological issues and practical consequences. Recommendations are made for health care and further research.

Chapter 11 provides a summary of the thesis, while chapter 12 consists of a summary in Dutch. 


\section{CHAPTER 1}

\section{General background}

\section{General background}

\subsection{Introduction}

In the Netherlands, the detection, diagnosis and treatment of mild to moderate hypertension are considered to be the task of general practitioners. ${ }^{1}$ Since Van der Feen described hypertension as 'a challenge to the general practitioner, a number of studies on this subject have been published by Dutch family physicians..$^{2-5}$ Several years before Van der Feen, Tudor Hart had already described case-finding of hypertensive patients as a feasible and effective intervention in primary care. ${ }^{6}$

Mild to moderate essential hypertension with or without target-organ damage is a risk factor for cardiovascular morbidity and mortality. The associations between blood pressure levels and incidence rates of stroke and coronary heart disease have been investigated in several prospective studies. in both sexes, the prevalence of hypertension increases with age, from five percent in the 18-25 age group to 60 percent in the $65-75$ age group. ${ }^{7,8}$ There is a continuous relationship between the height of blood pressure and cardiovascular risk: the higher the blood pressure, the greater the risk of stroke and coronary heart disease. Reductions in long-term average diastolic blood pressure of $5,7.5$ and $10 \mathrm{mmH}$ were found to be associated with at least $34 \%, 46 \%$, and $56 \%$ reduction in stroke and at least $21 \%, 29 \%$, and $37 \%$ reduction in coronary heart disease. ${ }^{9}$

\subsection{A brief history of blood pressure measurement}

A detailed review of the history of blood pressure measurement, beginning with the discovery of the circulation by William Harvey (1578-1657) and ending with the development and introduction of instruments for ambulatory blood pressure measurement, has been provided by $O^{\prime} B r i e n$ and Fitzgerald. ${ }^{10,11}$ In the introductory part of their review, the authors express their amazement over the virtual neglect of the discovery of blood pressure by the scientific community for almost a century. They end with skepticism over the tardiness with which scientific thinking grasps obvious science: 'Such are the lessons that may be learned from the study of history'. 
The first instrument for the indirect measurement of blood pressure was invented by Herisson in 1833. It was probably Karl Vierordt (1818-1864) who developed the sphygmograph. In 1880, Von Basch invented an apparatus which he called a 'sphygmomanometer', which was the first reasonably accurate device for clinical use. In an experimental model with cadaver arteries he showed that the pressure required for occlusion of an artery equalled the pressure within the vessel plus the pressure needed to exceed the rigidity of the wall.

An important step towards the modern mercury sphygmomanometer was made by Riva-Rocci in 1896. An inflatable cuff, encircling the upper arm, was connected to a glass tube filled with mercury. The $5-\mathrm{cm}$-wide cuff was inflated by a pump until the palpated pulse disappeared, and the (systolic) blood pressure was recorded as the level of mercury. Shortly afterwards, Hill and Barnard described an almost identical apparatus, using an aneroid gauge instead of a mercury manometer. In 1901, Von Recklinghausen demonstrated that the narrow cuff used by Riva-Rocci resulted in erroneously high blood pressure measurements. He recommended the use of a $12 \mathrm{~cm}$ wide cuff. ${ }^{10.11}$ In 1904, Janeway described the sources of measurement errors in detail and gave recommendations on the adequate technique of blood pressure measurement: the importance of a relaxed arm at heart level, slow deflation of the cuff, the allowance of an interval between measurements, and a cuff width of $12 \mathrm{~cm}$ 'for any but the most enormous arms'. ${ }^{12}$

In 1905, Korotkoff outlined the technique of auscultatory measurement of systolic and diastolic blood pressures: "At first no sounds are heard. With the falling of the mercury in the manometer down to a certain height, the first short tones appear; their appearance indicates the passage of part of the pulse wave under the cuff. It follows that the manometric figure at which the first tone appears corresponds to the maximal pressure. With the further fall of the mercury manometer one hears the systolic compression murmurs, which pass again into tones (second). Finally, all sounds disappear. The time of cessation of sounds indicates the free passage of the pulsewave; in other words, at the moment of the disappearance of the sounds the minimal blood pressure within the artery predominates over the pressure in the cuff. It follows that the manometric figures at this time correspond to the minimal pressure: ${ }^{13}$

In 1907, Ettinger described the 5 phases of Korotkoff sounds in the Wiener Klinischer Wochenschrift, and ten years later Cook and Taussig mentioned the phenomenon of the 'silent gap'. 14,15 In the decades after the description of the Korotkoff sounds, it was disputed whether the muffling (phase IV) or the disappearance of sounds (phase $W$ ) had to be regarded as the most accurate measure of diastolic blood pressure. It was not until fifteen years ago that this controversy was finally settled. ${ }^{16}$

An even greater controversy in relation to accurate blood pressure measurement concerned the optimal cuff dimensions. At present, it is generally agreed that an adequate cuff length is more important than the width, 
provided that the cuff is not too narrow. The ideal cuff width is $40 \%$ of arm circumference, and a cuff length of at least $80 \%$ of arm circumference is considered satisfactory. That means that for most adults, cuffs with a length of 30 to $32 \mathrm{~cm}$ and a width of at least $12 \mathrm{~cm}$ are considered to be adequate, while smaller cuffs should be used in children. Broader and longer cuffs are recommended for adults with thick upper arms. ${ }^{17}$

Janeway described the individual variability of blood pressure in 1904, and in later years blood pressures measured in the doctor's office were found to be higher than blood pressures measured at the patient's home or at work. This led to a growing interest in developing automated, and preferably ambulatory, techniques. In 1962, the first portable ambulatory system for non-invasive blood pressure measurement was described by Hinman and colleagues. ${ }^{18}$ The first study of intra-arterial blood pressure measurements in unrestricted subjects was published in 1969 by Bevan and co-workers. ${ }^{19}$ in addition to the development of instruments for ambulatory measurement, an immense number of instruments for home measurement was offered by manufacturers. Unfortunately, many of these devices have been shown to be inaccurate, and their widespread introduction into clinical practice has failed. 20 Over the last decade, however, several instruments for self-measurement have been validated and have been found to be adequate. ${ }^{21-23}$ In the future, self-measurement of blood pressure by the patient using a validated, easily available device may play an important role in the diagnosis of hypertension.

\subsection{Measurement errors}

Like many biological phenomena, blood pressure can change from one moment to the next, which is probably the most important source of measurement variations. A single blood pressure measurement may not represent the 'true' blood pressure. As a matter of fact, 'true' blood pressure is a rather theoretical concept, which might be best defined as 'the average of an infinite number of blood pressure measurements'.

in any type of measurement, differences between true values and measured values are caused by random and systematic errors. Minor sources of measurement variations are the design and construction of the instrument and the observer (that is the person conducting the measurement). ${ }^{24}$ The result of a measurement is affected in an unpredictable way by random errors, which are greater when variable phenomena are being measured. Augmenting the number of measurements is the best way to minimize random errors, as a large number of measurements reduces the average of all random errors to approximately zero.

Systematic errors may be stable or variable. Stable systematic errors influence all measurements in an identical way. Errors may be caused by the measurement instrument, by the observer or by the entity or person being 
measured. An example of observer bias in blood pressure measurements is digit preference: the observer chooses to record only to the nearest 0 or 5 $m m H$. To avoid this type of measurement error, guidelines advocate recording to the nearest $2 \mathrm{mmHg} . " 16,17$ Observer bias may also be caused by the presence of a silent or auscultatory gap, in which the sounds are absent at some point midway between the systolic and diastolic pressures. Palpating the brachial or radial pulse during inflation of the cuff may prevent misinterpretation of systolic pressure. The pathogenetic mechanism of this phenomenon is still unknown. ${ }^{25}$

\subsection{Blood pressure variability}

In 1880, Zadek was probably the first to observe the variability of blood pressure in different situations. ${ }^{10.11}$ Kapsammer discovered in 1899 that blood pressure tends to fall when the subject becomes more used to the measurement procedure. ${ }^{26}$ The concept of blood pressure as a variable entity, extensively described by Janeway in 1904, was elaborated in later years by Kilgore, Alvarez and Addis. Addis studied blood pressure levels under fixed conditions, as well as changes in pressure induced by alteration of the conditions. 27 The drop in blood pressure during sleep was first described by Hill in $1898 .^{28}$

A detailed review of factors influencing blood pressure levels has been given by Thomas Pickering. ${ }^{29}$ He made a distinction between short-term changes (within half an hour) and long-term variability of blood pressure (diumal and seasonal changes). Short-term blood pressure variability, which can be assessed by means of intra-arterial recording, is mainly caused by respiratory fluctuations. ${ }^{30}$ Dornhorst et al. described a number of interesting observations on the relation between respiration and blood pressure. ${ }^{31}$ Abdominal and thoracic breathing proved to have similar effects on blood pressure whereas the amplitude of blood pressure swings was found to increase with decreasing respiratory rate. Fluctuations in the blood pressure were more marked in standing than in supine position. ${ }^{32}$ The most important source of long-term blood pressure variability is the sleep-wake rhythm. ${ }^{29}$ Invasive and non-invasive ambulatory measurements have shown that blood pressure tends to be highest in the morning. decreases in the course of the day, and reaches its lowest level during the night. ${ }^{33}$ However, a study of Littler and Watson found no early morning rise in blood pressure, but blood pressures remaining relatively stable during the hours before waking, and rising at the moment of waking. 34 since the drop in blood pressure during sleep (nocturnal 'dip') may be absent in hypertensive patients, 'non-dipping" possibly is of diagnostic and prognostic interest. ${ }^{29}$ In temperate climates, ambulatory (systolic and diastolic) and office (diastolic) blood pressures have been shown to be about $5 \mathrm{mmHg}$ higher in winter than in summer. ${ }^{35}$ 


\subsection{Regression to the mean}

Regression to the mean, a term introduced by Galton in 1866, is the phenomenon that an extreme outcome on a first measurement will tend to be closer to the center of the distribution on later measurements. ${ }^{36}$ The concept of regression to the mean is important in studies where subjects are selected on the basis of high or low measurement values relative to the clinically relevant threshoid. The results of clinical trials may be biased by this phenomenon, which is to be considered a methodological artefact (selection effect). In measuring blood pressure, regression to the mean is usually greatest in subjects with the highest or lowest initial blood pressures. ${ }^{37-39}$

Table 1 lists the findings of a number of non-intervention and placebo-controlled blood pressure studies, indicating the degree of regression to the mean. Although formal comparison of these studies is difficult because of different time intervals, the table shows that the largest regressions were found in the studies with the highest initial values.

Table 1. Studies of non-treated or placebo-treated hypertensive patients. Reference 44 reported medians instead of means.

\begin{tabular}{|c|c|c|c|}
\hline initial blood pressure & $N$ & interval & blood pressure fall \\
\hline $155 / 100$ & 49 & 1 manth & $7 / 6 \quad 40$ \\
\hline $158 / 102$ & 1943 & 3 years & $14 / 11^{41}$ \\
\hline $144 / 87$ & 32 & 12 weeks & $7 / 5 \quad 42$ \\
\hline $159 / 99$ & 19 & 4 weeks & $6 / 2 \quad 43$ \\
\hline $159 / 94$ & 386 & 3 years & $8 / 5$ \\
\hline $181 / 97$ & 17 & 4 weeks & $19 / 4 \quad 45$ \\
\hline
\end{tabular}

\subsection{White coat hypertension}

The simple definition of white coat hypertension is a persistently elevated blood pressure measured in a clinical setting with a normal pressure outside the clinic. Studies of the prevalence of white coat hypertension have used different definitions. Using a cut-off point of $90 \mathrm{mmHg}$ diastolic pressure for the clinical pressure, compared with ambulatory blood pressure, Pickering et al. found white coat hypertension in 21 percent of patients with clinical diastolic blood pressures between 90 and $104 \mathrm{mmHg}{ }^{46}$ Patients with diastolic blood pressures above $105 \mathrm{mmHg}$ showed a much lower prevalence of white coat hypertension ( 5 percent), while in normotensive subjects the phenomenon was almost absent. ${ }^{46}$ The use of other criteria (diastolic office pressure at least 10 
$\mathrm{mmHg}$ higher than daytime ambulatory blood pressure), resulted in 23 percent ${ }^{47}$ and 39 percent ${ }^{48}$ of patients showing white coat hypertension. In a unselected population ( 387 men, 350 women, average age 31.5 years) white coat hypertension was found to be present in 7 percent. ${ }^{49}$ Table 2 lists the findings of a number of studies on the prevalence of this phenomenon in borderline hypertensive patients.

Table 2. Studies of white coat effect in borderline hypertensive patients.

\begin{tabular}{lll}
\hline office blood pressure & $N$ & percentage with white coot effect \\
\hline $150 / 96$ & 292 & $21^{46}$ \\
$155 / 100$ & 60 & $38^{50}$ \\
$>150 / 90$ & 20 & $30^{51}$ \\
$151 / 96$ & 110 & $23^{47}$ \\
$164 / 104$ & 159 & $34^{52}$ \\
\hline
\end{tabular}

$N=$ number of patients

\subsection{Guidelines on blood pressure measurement}

Measuring blood pressure is a simple diagnostic procedure. However, a correct diagnosis cannot be based on a single measurement. The large withinperson variability of blood pressure, the statistical phenomenon of regression to the mean, the clinical phenomenon of 'white coat hypertension' and the risk of measurement errors necessitate multiple measurements. The Fifth Report of the Joint National Committee on Detection, Evaluation, and Treatment of High Blood Pressure states that elevated initial readings should be confirmed on at least two subsequent occasions over a period of one to several weeks. ${ }^{53}$

The management quidelines of the British Hypertension Society recommend two or more blood pressure measurements in the sitting position during each visit, on up to four separate occasions. ${ }^{54}$ The 'NHG-Standaard Hypertensie', a guideline published by the Dutch College of General Practitioners, proposes at least five duplicate measurements in patients whose diastolic blood pressures are between 95 and $105 \mathrm{mmHg}$ initially. ${ }^{55}$

\subsubsection{Misclassification, overdiagnosis, overtreatment}

In three studies of patients diagnosed as mild hypertensives, one third to one half of all of those taking placebo were later found to have normal blood pressures. ${ }^{56-58}$ Comparable percentages of overtreatment were found in a 
recently published study by Myers et al. ${ }^{59}$ These results reflect the risk of incorrect diagnosis, misclassification and overtreatment. Anthypertensive treatment in normotensive patients should be avoided, since labeling and treatment may induce illness behavior. ${ }^{60}$ Furthermore, there is a risk of side effects of drug therapy, and lifelong drug treatment and regular checkups by the doctor are expensive.

\subsubsection{Difference between office and home blood pressure}

Home measurements by the doctor, by some member of the household or the patient have become more important since Ayman and Golshine demonstrated that in every one of 34 hypertensive patients, blood pressure readings taken at home were lower than those taken at the clinic by the doctor. ${ }^{61}$ Since that discovery, many instruments for home measurement of blood pressure have been promoted by manufacturers and introduced into clinical practice.

With the introduction of intra-arterial and non-invasive instruments for ambulatory blood pressure measurement, the "ideal' instrument that G.W. Pickering called for came within reach for investigators and clinicians: "In epidemiological studies the ideal is to have a single observer to make measurements under as natural conditions as possible'. 62 Since ambulatory blood pressure measurement is relatively expensive and the added value for diagnosing and treating hypertension is still unclear, the widespread introduction of ambulatory monitors in general and clinical practice is still a matter for debate. ${ }^{63-68}$

\subsection{Diagnosing hypertension in general practice}

Given the large within-person variability of blood pressure, as well as the methodological artefact of regression to the mean, the clinical phenomenon of white coat hypertension, and the risk of measurement errors, there is a considerable risk of misclassification. This may resuit in unjustified, probably lifelong treatment, or in an incorrect withholding of treatment. Blood pressures near the threshold, in the borderline region between 'hypertensive' and 'normotensives, may easily lead to misclassification. ${ }^{39}$ This dilemma is particularly experienced in general practice, where the majority of hypertensive patients are detected, and where most hypertensive patients have blood pressure values around the threshold level for treatment.

Data on sensitivity and specificity of a test., for instance blood pressure measurement, are usually based on small numbers of measurements. The precision of estimates of sensitivity and specificity of blood pressure measure. ments increases with the number of measurements on which the estimate is based. ${ }^{69}$ This phenomenon has been clearly demonstrated in the study by Perry 
and Miller. ${ }^{39}$ The positive predictive value of a test is high in populations with a high prevalence of hypertension (internist, cardiologist), but relatively low in populations with a low prevalence (general practitioner). ${ }^{70}$ for this reason, there is a considerable risk of misclassification and unjustified treatment in general practice. This has been shown in the three studies already mentioned. $56-58$

The aim of the present study was to detect which blood pressure measurement procedure, feasible in general practice, reduces the risk of misclassification to an acceptable level.

The research questions are:

How many blood pressure measurements by the general practitioner are necessary for a diagnosis of hypertension?

What is the reproducibility of a series of measurements by the general practitioner and self-measurements by the patient in comparison to that of ambulatory blood pressure measurement?

What are the feasibility, acceptance and side effects of blood pressure self-measurement and ambulatory blood pressure measurement?

Is the white coat effect less pronounced when blood pressure is measured by the practice nurse instead of the dactor?

Is a series of measurements by the general practitioner or the patient a reliable alternative to ambulatory blood pressure measurement?

Are there seasonal influences on blood pressure in borderline hypertensive primary care patients, necessitating caution in diagnosis and adaptation of treatment according to the season?

\section{References}

1. Gezondheidsraad. Advies inzake hypentensie. Den Haag: Staatsuitgeverij, 1983

2. Van der Feen IAE. Hypertensie. Een uitdaging voor de huisarts. Thesis Rotterdam, 1977.

3. Boot CPM. Risicofactoren voor coronaire hartziekten. Screening en interventie in een huisartspraktijk. Thesis, Leiden, 1979

4. Van Ree JW. Nijmeegs Interventie Project. Thesis, Nijmegen, 1981.

5. Van Weel C. Aniciperende geneeskunde in de praktiik. Thesis, Rotterdam, 1981.

6. Hart JT. The management of high blood pressure in general practice. JR Coll Gen Pract 1975; 25: $160 \cdot 92$.

7. Kaplan M. Clinical hypertension. Williams \& Wilkins, Baltimore, USA 1994.

8. Bennet NE. Hypertension in the elderly. Lancet 1994; 344: 447-9.

9. MaciMahon S. Peto R. Cutler J, et al. Blood pressure, stroke, and coronary heart disease. Part 1. prolonged differences in blood pressure: prospective observational studies corrected for the regression dilution bias. Lancet $1990 ; 335: 765-74$. 
10. OBrien $E_{x}$ Fitzgerald $\mathrm{D}$. The history of indirect blood pressure measurement, in: $\mathrm{O} B$ rien $\mathrm{E}$. OMalley K (eds): Handbook of Hypertension. Volume 14: Blood pressure measurement. Elsevier, Amsterdam, 1991, pp 1-54.

11. O'Brien E, Fitzgerald D. The history of indirect blood pressure measurement. J Hum Hyppertens 1994; 8: 73-84.

12. Janeway TC. The clinical study of blood pressure. New York: Appleton, 1904, in: Swales JD (ed). Textbook of Hypertension. Blackwell Scientific Publications, Oxford, 1994, pp 989-1008.

13. Laher M, O'Brien E. In search of Korotkoff. BMJ 1982; 285: 1796-8.

14. Ettinger $W$. Auskultatorische Methode der Blutdruckbestimmung und ihr praktischer Wert. Wien Klin Wochenschr 1907; 20: 992-6.

15. Cook JE, Taussig AE. Auscultatory blood pressure determination. JAMA 1917; 68: 1088.

16. O'Brien $E_{\text {。 }} \mathrm{O}^{\prime}$ Malley $K$, in: $A B C$ of hypertension. British Medical Association, London, 1981: pp 10-2.

17. Anonymous. American Heart Association recommendations for human blood pressure determination by sphygmomanometers, in: O'Brien $\mathbb{E}$, O'Malley $K$ (eds): Handbook of Hypertension. Volume 14: Blood pressure measurement. Elsevier. Amsterdam, 1991, pp 399-420.

18. Himman AT, Engel BT, Bickford AF. Portable blood pressure recorder. Accuracy and preliminary use in evaluating intradaily variations in pressure. Am Heart 1 1962; 63: 663-8.

19. Bevan A.T, Honour AJ, Stott FD. Direct arterial pressure recording in unrestricted man. Clin Sci 1969: 36: 329-44.

20. O'Brien $E$, Atkins $N$, Mee $F$, et al. Inaccuracy of seven popular sphygmomanometers for home-measurement of blood pressure. J Hypertens 1990; 8: 621-34.

21. Jamieson MJ. Webster J, Witte $K$, et al. An evaluation of the A\&D UA-751 semi-automated cuff-oscillometric sphygmomanometer. J Hypertens 1990; 8: 377-81.

22. Walma EP, Van Dooren C, Van der Does. E, et al. Accuracy of an oscillometric automatic blood pressure device: the Omron HEM403C. I Hum Hypertens 1995; 9: 169-74.

23. O'Brien $E$, Mee $F$. Atkins $N$. An accurate automated device for home blood pressure measurement at last! The Omron HEM705CP. J Hypertens 1994; 12: 1317-8.

24. Fletcher $\mathrm{RH}_{x}$ Fletcher $5 \mathrm{~W}$, Wagner $\mathrm{EH}$. Clinical epidemiology: the essentials. Willams \& Wilkins, Baltimore, 1988, pp 23-35.

25. Messerli FH, Schmieder SW, in: O'Brien E, O'Malley K (eds): Handbook of Hypertension. Volume 14: Blood pressure measurement. Elsevier, Ansterdam, 199\%, pp 148-54.

26. Kapsammer $G$. Blutdruckmessungen mit dem Gärtner'schen Tonometer. Wien Klin Wochenschir 1899; 12: 1279.

27. Addis $T$. Blood pressure and pulse rate levels: the levels under basal and daytime conditions. Arch Intern Med 1922; 29: 539-53.

28. Hill $\mathrm{L}$. On rest, sleep, and work and the concomitant changes in the circulation of the blood. Lancet 1898; i: 282-5.

29. Pickering TG. Ambulatory Monitoring and Blood Pressure Variability. Science Press, London, $1991: 4.1-5.15$.

30. Mancia G. Ferrani A, Gregorini L, et al. Blood pressure and heart rate variabilities in normotensive and hypertensive human beings. Circ Res 1983; 53: 96-104 
31. Dornhorst AC, Howard P, Leathant GL. Respiratory variations in blood pressure. Circulation $1952: 6: 553-8$.

32. Millar-Craig MW, Bishop $C N$, Raftery EB. Circadian warkation of blood pressure. Lancet 1978; i: 795-7.

33. Clark LA, Denby $L$, Pregibon D, et al. The effects of activity and time of day on the diumal variations of blood pressure. J Chron Dis 1987; 40:671-81.

34. Littler WA, Watson RDS. Circadian variation in blood pressure. Lancet 1978; $1: 995-6$.

35. Giaconi S, Palombo C. Genovesi-Ebert $A_{\text {, }}$ et al Long-term reproducibility and evaluation of seasonal influences on blood pressure monitoring. J Hypertens 1988; 6 (suppl 4): 564-566.

36. Davis CE. The effect of regression to the mean in epidemiologic and clinical studies. Am J Epidemiol 1976; 104: 493-8.

37. Armitage $P$, Rose GA. The variability of measurements of casual blood pressure I. A laboratory study. Clin Sci 1966: 30:325-35.

38. Armitage $P$, Fox W. Rose GA, Tinker CM. The variability of measurements of casual blood pressure II. Survey experience. Clin Sci 1966; 30:337-44.

39. Perry HM, Miller JP. Difficulties in diagnosing hypertension: implications and alternatives. J Hypertens 1992; 10: 887-96.

40. Lauginlin KD, Fisher $\mathrm{L}$, Sherrard DJ. Bload pressure reductions during self-recording of home blood pressure. Am Heart 1979; 98: 629-34.

41. Australian National Blood Pressure Study Management Committee. Untreated mild hypertension, Lancet 1982; i: 185-91.

42. Watson RDS, Lumb $R$, Young MA, et al. Variation in cuff blood pressure in untreated outpatients with mild hypertension. Implications for initiating antihypertensive treatment. J Hypertens 1987; 5: 207-11.

43. Kenny RA, Brennan $M$, O'Malley $K$, et al. Blood pressure measurements in borderline hypertension. J Hypertens 1987; 5 (suppl 5): \$483-5485.

44. Mant D, McKinlay C, Fuller A, et al. Three year follow up of patients with raised bllood pressure identified at health checks in general practice. BMJ 1989;298: 1360-2.

45. Jyothinagaram SG, Rae L, Campbell A, et al. Stability of home blood pressure over time. J Hum Hypertens 1990; 4: 269-71

46. Pickering TG, James GD, Boddie $C$, et al. How common is white coat hypertension? JAMA $1988 ; 259: 225-8$.

47. Veerman DP, Van Montfrans GA. Nurse-measured or ambulatory blood pressure in routine hypertension care. J Hypertens $1993 ; 11: 287-92$.

48. Lerman CE, Brody DS, Hui T, et al. The white-coat hypertension response: prevalence and predictors. J Gen Intern Med 1989; 4: 225-31.

49. Julius 5 . Mejia $A$, Jones $K_{0}$ et al. White coat versus sustained borderline hypertension in Tecumseh, Michigan. Hypertension 1990; 16: 617-23.

50. Krakoff $L R$. Eison $H$, Phillips $R H$, et al. Effect of ambulatory blood pressure monitoring on the diagnosis and cost of treatment for mild hypertension. Am Heart $₫ 1988 ; 116: 1152-4$.

51. Gourlay SG, MCNeil Jj, Marriner T, et al. Discordance of mercury sphygmomanometer and ambulatory blood pressure measurements for the detection of untreated hypertension in a population study. J Hum Hypertens 1993; 7: 467-72. 
52. Høegholm $\mathrm{A}_{\mathrm{a}}$ Kristensen $\mathrm{KS}_{0}$ Madsen $\mathrm{NH}_{i}$ et al. White coat hypertension diagnosed by $24-\mathrm{H}$ ambulatory monitoring. Am I Hypertens 1992; 5: 64-70.

53. Anonymous. The fifth repont on the Joint National Committee on Detection, Evaluation and Treatment of High Blood Pressure (INC-V). Airch Intern Med 1993; 153: 154-83.

54. Sever $P$, Beevers $G$, Bulpitt $C$, et al Management guidelines in essential hypertension: report of the second working party of the British Hypertension Society. BMJ 1993; 306: 983-7.

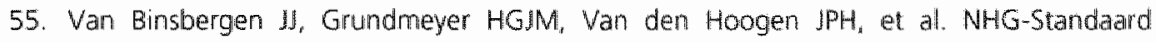
Hypertensie. Huisarts Wet 1991; 34(8): 389-95.

56. Management Committee of the Australian therapeutic trial on mild hypertension. Untreated mild hypertension. Lancet 1982; i: 185-91.

57. Medical research council working party. MRC trial on treatment of mild hypertension: principal results. BMJ 1985; 291: 97-104.

58. Van Kruijsdijk MCM. Hypertensie opnieuw gemeten [proefschriftl. Krips Repro, Meppel, 1991. Nijmegen: Universiteit van Nijmegen, 1991.

59. Myers MG, Reeves RA, Oh PI, et all Overtreatment of Hypertension in the Community. Am J Hypertens 1996; 9:419-25.

60. Haynes RB, Sackett DL, Taylor DW, et al. Increased absenteeism from work after detection and labeling of hypertensive patients. N Engl I Med 1978; 299: 741-4.

61. Ayman D, Goldshine AD. Blood pressure determinations by patients with essential hypertension: difference between clinic and thome readings before treatment. Am. I Med Sci 1940; 200; 465-74.

62. Pickering GW. High blood pressure. Churchill, London, 1968, p 17 .

63. Cox.P. O'Malley K, O'Brien ET. Ambulatory blood pressure measurement in general practice. BrJ Gen Pract 1992; 42:402-3.

64. Webb DI, Stewart MJ, Padfield PL. Monitoring ambulatory blood pressure in general practice. BMJ 1992; 304: 1442 (30 May).

65. Silagy $C$, Lawrence $M$, Ebbs $D$, et al. Monitoring ambulatory blood pressure in generat practice. BMJ 1992; 305: 181-2 (18 July).

66. Webb DJ, Stewart MJ, Padfield PL. Monitoring ambulatory blood pressure in general practice. EMJ 1992; 305: 716-7 (19 September).

67. Appel L. Stason WB. Ambulatory blood pressure monitoring and blood pressure self-measurement in the diagnosis and management of hypertension. Ann Intern Med 1993: 118: 876-82.

68. Anonymous. Automated ambulatory blood pressure and self-measured blood pressure monitoring devices: their role in the diagnosis and management of hypertension. Ann intern Med 1993; 118: 889-92.

69. Fletcher RH, Fletcher 5 W. Wagner EH. Clinical epidemiology: the essentials. Williams \& Wilkins, Baltimore, 1988, p 54-61.

70. Knottnerus JA. Interpretation of diagnostic data: an unexplored field in general practice. I A Coll Gen Pract 1985; 35: 270-4. 



\section{CHAPTER 2}

\section{Methods}

\section{Methods}

Design

Comparative, prospective study over 7 months in potentially hypertensive primary care patients.

\section{General practices}

General practitioners and their practice nurses were asked to participate in the study. All of them were given instructions on adequate techniques of bllood pressure measurement. ${ }^{1}$ Phase $V$ of the Korotkoff sounds was recorded as the level of diastolic pressure.

\section{Patients}

Patients were selected on the basis of an initially elevated office blood pressure during normal practice routine (case-finding).

Inclusion criteria were:

- mean of two systolic values (measured in one visit) between 160 and 200 $\mathrm{mmHg}$ and/or mean of two diastolic measurements between 95 and 115 $\mathrm{mmHg}$

- age between 20 and 75 .

Exclusion criteria were:

- known hypertension or antihypertensive treatment in the year preceding the study

- suspicion of secondary hypertension

- congestive heart failure or unstable angina

- pregnancy.

After inclusion all patients received a code. The general practitioner noted the following data: blood pressure (duplicate), pulse, length $(\mathrm{cm})$, age, sex, profession, reason of blood pressure measurement, medication, special remarks. During the first and last month of the study, the weight $(\mathrm{kg})$ was measured.

\section{Measurement procedures}

After inclusion by the general practitioner, all patients underwent four procedures of blood pressure measurement:

Procedure 1 consisted of duplicate office measurements in one visit by the general practitioner in weeks 2,3 and 4 , and months $2,3,4,5,6$ and 7 . 
Table. Time-schedule of measurements by GP (general practitioner). PN (practice nurse), HP (home-measurements by patient), and ABPM (ambulatory blood pressure measurements).

\begin{tabular}{|c|c|c|c|c|c|c|c|c|c|c|}
\hline & \multicolumn{4}{|c|}{ werk } & \multicolumn{6}{|c|}{ month } \\
\hline & 1 & 2 & 3 & 4 & 2 & 3 & 4 & 5 & 6 & 7 \\
\hline GP & 1,2 & 3,4 & 5,6 & 7,8 & 9,10 & 11,12 & 13,14 & 15,75 & 17.18 & 19,20 \\
\hline PN & & 1,2 & 3,4 & 5,6 & & & & & & \\
\hline $\mathrm{HP}$ & & $1-8$ & $9-16$ & & & & & & & \\
\hline ABPM & & & & $\Uparrow$ & & & & & & 2 \\
\hline
\end{tabular}

$1,23,4$ etc two measurements on one occasion. 1-89-16: self-measurements by patient on two separate days in week 2 and 3 (wwo measurements in the morning, two in the evening).

Procedure 2 consisted of duplicate measurements in one visit (on other days than the measurements by the general practitioner) by the practice nurse in weeks 2,3 and 4.

Procedure 3 consisted of home-measurements by the patient (two measurements in the morning and two in the evening on two working-days) in week 2 and week 3.

Procedure 4 consisted of ambulatory blood pressure measurement on one working-day in week 4 and month 7 . On the days after both ambulatory measurements the following data were collected: weight ( $\mathrm{kg}$ ), use of salt, liquorice and alcohol, smoking, amount of nuisance by ambulatory measurement during the day and the night.

The time-schedule of the study is given in the table.

\section{Measurement instruments}

The general practitioner and the practice nurse measured blood pressures with a calibrated mercury sphygmomanometer, provided with a standard-sized cuff $(12 \times 35 \mathrm{~cm})$. Home-measurements by the patient were made using a BOSO-Oscillomat. The BOSO-Oscillomat (Bosch LTD, Jungingen, Germany) is a battery-powered cuff-oscillometric measuring device which is triggered by the patient. It is driven by an automatic internal pump. The apparatus has been extensively validated, and has been described as an acceptable alternative to a conventional sphygmomanometer ${ }^{2-4}$ The patients were asked to record 16 blood pressure readings according to the schedule mentioned before. In addition, the blood pressure values were stored in the memory of the apparatus (maximum capacity 14 readings). The stored readings were printed out at the 
general practitioner's office, and were compared with the values written down by the patient.

Ambulatory blood pressure was measured using a Spacelabs 90207 (SpaceLabs Inc., Hillsboro, Oregon, USA) automatic cuff-oscillometric monitor. This monitor received a $\mathrm{B}$ rating for both systolic and diastolic blood pressure according to the criteria of the British Hypertension Society, and satisfies the criteria of the Association for the Advancement of Medical Instrumentation. 5.6 Blood pressures were recorded automatically every 15 minutes from 6.00 AM till 10.00 PM, and every 30 minutes during the night.

The data were analyzed using SPSS (Statistical Package Social Sciences).

The study was approved by the Ethic Committee of the University Hospital of Maastricht. All subjects were asked for written informed consent for participation in the study.

At the start of the study handbooks on hypertension and review articles were studied. From 1990 till 1995 there was a subscription to the current awareness service of the University Library, assuring that every month a list of relevant articles was received. The literature search was based on the key words 'blood pressure', "blood pressure determination', 'white coat hypertension', 'circadian rhythm', 'general practice', 'family physician', 'ambulatory blood pressure monitoring', 'home blood pressure' and 'basal blood pressuret. From the monthly offer of articles a selection was made by the investigator. Bibliographies of the handbooks and articles were also used.

\section{References}

1. British Hypertension Society recommendations on bload pressure measurement, in: O'Brien E, O'Malley K (eds): Handbook of Hypertension. Volume 14: Blood pressure measurement. Amsterdam, Elsevier, 1991, p 387-95.

2. Jamieson MJ, Webster J, Witte K, et al. An evaluation of the A\&D UA.751 semi-autonated cuffoscillometric sphygmomanometer. J Hypertens 1990; 8: 377-81.

3. Imai $Y$, Abe K, Sasaki, et al. Clinical evaluation of semiautomatic and automatic devices for home blaod pressure measurement: comparison between cuff-oscillometric and microphone methods. J Hypertens 1989; 7: 983-90.

4. Johnston DW. Shah D. An evaluation of the Takeda UA.751 automatic sphygmomanometer. Behav Res Ther 1989; 27: 203-4

5. O'Brien $E_{*}$ Mee F. Atkins $N$, et al. Accuracy of the SpaceLabs 90207 determined by the British Hypertension Society Protocol. J Hypertens 1991; 9ksuppl 5): 525-531.

6. Association for the Advancement of Medical Instrumentation. American National Standard for Electronic or Automated Sphygmomanometers. Washington DC, AMMI. 1987 



\section{CHAPTER 3}

\section{Diagnosing hypertension in general practice}

Measurements according to the Dutch College of General Practitioners' protocol compared with ambulatory blood pressure measurements

Published as: Brueren MM, Dinant GI, Schouten B, Van Ree IW. Hypertensiediagnostiek door de huisarts: metingen volgens de NHG-standaard vergeleken met ambulante bloeddrukmeting. Ned Tijdschr Geneeskd 1995; 139: 278-82. 


\section{Abstract}

Objective. To compare the procedure for diagnosing hypertension described in the protocol published by the Dutch College of General Practitioners (NHG) with the results of ambulatory blood pressure measurements (ABPM).

Design. Prospective diagnostic study.

Setting. Practices of 17 general practitioners (GP) in central and southern Limburg, The Netherlands.

Methods. Of the 102 patients with suspected hypertension, eight dropped out for various reasons. The remaining 94 patients were examined on the basis of the NHG's 'Hypertension' protocol. In addition to this, 24-hour indirect ambulatory measurements were carried out on the same patients, by way of reference.

Results. The correlation between the results of the two methods was relatively poor $(r=0.51)$. On average, measurements using the NHG protocol were higher. Sensitivity and specificity of the NHG protocol measurements were 0.67 and 0.52 respectively. As regards the clinical decision of hypertension or no hypertension, the NHG procedure correlated much better with the ABPM for patients with a 'high' initial measurement result (diastolic pressure $105-115 \mathrm{mmHg}$ ) than for those with a 'low' initial measurement result (diastolic pressure $95-105 \mathrm{mmHg}$ ).

Conclusion. The difference between blood pressures measured in clinical settings and those measured at home ('white coat effect') is also found in the GP's practice. The results of the present study support the NHG protocol's recommendation of different procedures for 'high' and 'low' initial values.

\subsection{Introduction}

There is a large intra-individual variability in blood pressure, even more so among hypertensive than among normotensive persons. ${ }^{12} \mathrm{~A}$ study in a number of Dutch general practices has shown that $43 \%$ of patients in whom essential hypertension had been diagnosed were able to stop using antihypertensive medication without their biood pressure rising above the level regarded as the lower limit for treatment, even in the long term. ${ }^{3}$ Two other studies reported comparable percentages. ${ }^{45}$

This implies that hypertension may be overdiagnosed and that drug treatment is being initiated unnecessarly. The Hypertension Protocol published by the Dutch College of General Practitioners (Nederlands Huisartsen Genootschap. NHG) recommends that subjects with diastolic blood pressures of $95-104 \mathrm{mmHg}$ should be remeasured on at least five occasions within 3-6 months, with two blood pressure measurements at each visit. Blood pressure values $\geq 105 \mathrm{mmHg}$ necessitate at least three consultations within a period of some weeks to months, each consultation once again involving two measure- 
ments. The mean of these values, excluding the value of the first measurement, determines whether the diagnosis of hypertension should be made. In this protocol, the systolic blood pressure is not used in the diagnostic decision. ${ }^{6}$

The literature on hypertension distinguishes between 'clinical' blood pressure, measured in a clinical setting, and 'real' blood pressure. Clinical blood pressure is often higher than that measured at the patient's home? Ambulatory blood pressure, measured over a period of 24 hours, would seem to be a better measure of the 'real' blood pressure than the clinical measurement made with a mercury sphygmomanometer: it avoids the influence of the observer, and the measurements are made in the patient's own familiar surroundings. Moreover, ambulatory measurement provides a large number of values. ${ }^{8}$ Ambulatory blood pressure has been found to correlate better with left-ventricular hypertrophy than 'clinical' blood pressure. ${ }^{910}$ Insufficient hard evidence, based on ambulatory measurements, is available on the relation between blood pressure and cardiovascular morbidity and mortality. The first study to look for such evidence found that this correlation was stronger for ambulatory measurement than for conventional blood pressure measurements. ${ }^{11}$

Quality and feasibility of ambulatory blood pressure measurement have increased considerably since the first experiments 30 years ago. ${ }^{12-14}$ Some of the instruments are now sufficiently reliable and user-friendly to deem them adequate for scientific research in general practice. This allowed us to compare the procedure for diagnosing 'hypertension' described in the NHG protocol with the results of ambulatory, indirect 24-hour measurements.

We have investigated to what extent blood pressure measurements according to the NHG protocol coincide with ambulatory blood pressure measurements used as reference values, and have determined the sensitivity and specificity of the procedure recommended in the protocol.

\subsection{Methods}

\section{Patients}

The study took place in 1992 and 1993 in 17 general practices in southern and central Limburg (The Netherlands). Prior to the study the general practitioners (GP) were instructed about the correct method of blood pressure measurement. It was agreed that phase $V$ of the Korotkoff tones reflected the level of the diastolic blood pressure and that readings were to be made with an accuracy of $2 \mathrm{mmHg} .{ }^{15}$ Patients with suspected hypertension were traced during normal practice routine (so-called 'case finding'). Patients eligible for the study were those, aged 20 or over, with a diastolic blood pressure (DBP = mean of two measurements during 1 consultation) between 95 and 115 $\mathrm{mmHg}$. They were not known to suffer from hypertension, were not using 
anthypertensives, did not have secondary hypertension, congestive heart failure or unstable angina and were not pregnant.

\section{Measurements by the GPS.}

in accordance with the NHG protocol's guidelines, participating patients with initial measurements showing $95 \leq \mathrm{DBP}<105 \mathrm{mmHg}$ were called in for consultation five times during the three months after the initial measurement, each consultation comprising two measurements; those with $105 \leq \mathrm{DBP} \leq 115$ $\mathrm{mmHg}$ were called in three times for two measurements. During the fourth week of the study, all patients underwent a noninvasive ambulatory 24 hour measurement. Height and weight were measured in order to determine the Quetelet index (in $\mathrm{kg} / \mathrm{m}^{2}$ ). Measurements at the GPS' office were made using the practice's own mercury sphygmomanometer. All sphygmomanometers had been tested before the start of the study and had been provided with a standardized cuff. (inner cuff size $12 \times 35 \mathrm{~cm}$ ).

\section{Ambulatory measurements.}

The ambulatory measurements were taken on work days. A research assistant explained the procedure, instructed the patients (Table) and installed the instrument. The GPS remained unaware of the results of the ambulatory measurements during the study. Measurements were made using an automatic, cuff-oscillometric blood pressure device, the Spacelabs 90207 (Spacelabs Inc., Hillsboro, Oreg., USA). This instrument consists of an inflatable cuff (inner cuff size $12 \times 22 \mathrm{~cm}$ ), connected via a rubber tube to a small monitor ( $3 \times 9 \times$ $11 \mathrm{~cm}$ ) which can be attached to the patient's belt. The instrument has been described as reliable and valid. ${ }^{16-18}$ The test-retest reliability of ambulatory blood pressure measurement has been shown in a number of studies to meet requirements. ${ }^{19-21}$

Table. Patient instructions for 24 -hour ambulatory blood pressure measurement

- The cuff will remain around your upper arm for 24 hours; you will not be able to take a shower.

- You should try to keep up your normal everyday activities as much as possible.

- Your blood pressure will be measured every 15 minutes during the daytime (0600h - 2200h), and every 30 minutes at night $(2200 \mathrm{~h}-0600 \mathrm{~h})$.

- While the measurement is being taken during the daytime, it is best to stand or sit still and to relax your arm alongside your body.

- You will not be able to engage in sports activities.

- In the unlikely event that a blood pressure measurement causes you excessive inconvenience, you can press the 'stop' button.

- You will only be able to read the first 5 measurements for yourself.

- If the instrument inconveniences you excessively during the night, largely or totally depriving you of sleep, you can turn it off. 


\section{Analysis}

The analysis was based on the mean diastolic blood pressure values of the GPs' follow-up measurements. A scatterplot was used to compare the GPS' measurements with the mean of the ambulatory blood pressure measurements for the daytime hours $(0600$ to $2200 \mathrm{~h})$. The correlation coefficient and linear regression coefficient were calculated using the SPSS statistical program (Statistical Package Social Sciences International BV., Gorinchem, The Netherlands).

The lower limit for hypertension in the ambulatory measurements was set at a daytime mean of $91 \mathrm{mmHg}$; values below this limit were not regarded as hypertensive. The limit was based on a meta-analysis of 22 studies, with the daytime mean of a total normotensive population of 2638 persons raised by twice the standard deviation. ${ }^{22}$ A 'receiver operating characteristic' curve (ROC-curve) was plotted, showing the sensitivity and specificity of the two measurement methods at 'high' ( $105 \leq \mathrm{DBP} \leq 115 \mathrm{mmHg}$ ) and 'low' ( $95 \leq \mathrm{DBP}$ $<105 \mathrm{mmHg}$ ) initial measurement values in the NHG protocol, for ten different cut-off points.

The study design had been approved by the Ethic Committee of the University Hospital of Maastricht. All participating patients gave their written informed consent.

\subsection{Results}

The stuidy population comprised 102 patients, of whom eight dropped out, for various reasons: three patients started antihypertensive drug treatment during the study, one patient was unable to sustain the measurements, one patient had a heart attack, the ambulatory blood pressure measurement failed for technical reasons in one patient, and two patients 'lost interest'. This left us with 94 patients who could be evaluated: 45 women and 49 men. The mean age of the women was 47 (SD: 13; median: 47); that of the men 47 (SD: 11; median: 47). The mean Quetelet index was 25.8 (range: 18.9 - 3.4.8; SD: 3.3), which meant that the cuffs used in the study had the required size. The group with high initial measurements included 30 patients, who had a mean blood pressure of $107.7 \mathrm{mmHg}$ (SD: 2.6; median: 107.3), while the group with low initial measurements included 64 patients, with a mean blood pressure of 100.2 (SD: 2.5; median: 100.0).

The correlation between the GPs' diastolic measurements and the ambulatory diastolic measurements is depicted in Figure 1. This figure illustrates that the mean of the GPS' measurements was higher than the mean of the ambulatory measurements. The correlation coefficient was $0.51(p<0,001)$, while the regression coefficient was 0.49 ( $p<0.001)$, using the ambulatory measurements as the independent variable and the GPs" measurements as the dependent variable (intercept: 51.8 ). 


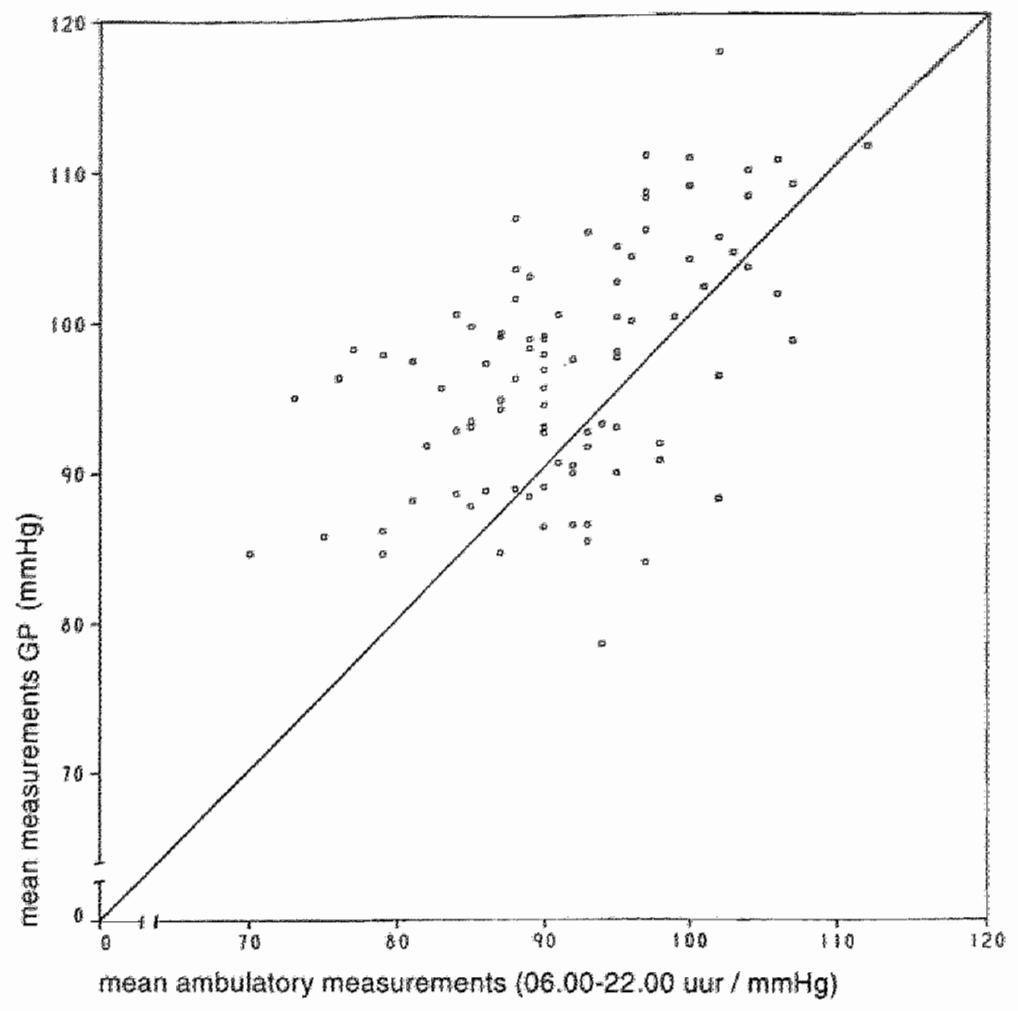

Figure 1. Correlation between mean diastolic measurements by the GP5 and the daytime mean of 24 armbulatory diastolic measurements in 94 patients (some points overlap). mean measurements $G^{P}$ (mmHg); mean ambulatory measurements (mm $\mathrm{Hg}$ ).

At the lower limit of $95 \mathrm{mmHig}$ as recommended by the NHG protocol, agreement was found for 56 of the 94 patients (32 were hypertensive according to both methods, while 24 were normotensive), corresponding to a sensitivity of 0.67 and a specificity of 0.52 (for the GPs" measurements relative to the ambulatory measurements). In 22 cases, the GPs' measurements showed patients to be hypertensive, while the ambulatory measurements showed them to be normotensive (false-positive hypertension), corresponding with $23 \%$ of the patients having white coat hypertension in this population. The opposite was found in 16 cases (false-negative normotension). At the upper limit of 105 $\mathrm{mmHg}$, agreement was found for 59 patients (14 were hypertensive according to both methods, while 45 were normotensive). At this limit, ambulatory measurements showed 34 patients to be hypertensive while the GP's measurements resulted in normotension; the opposite was found in one case. 
Using ten cutoff points of measurements according to the NHG protocol, sensitivity and specificity of the procedures were calculated for the 'high' ( $n=$ 30) and "low" $(n=64)$ initial measurement values, and depicted in a ROC curve (Figure 2). Figure 2 illustrates that the correlation between the two methods was higher for the group with 'high' initial values than for the other group. The larger the area under the curve, the better the correlation between that measurement and the reference measurement.

\subsection{Discussion}

On average, blood pressure measurements by GPS according to the NHG Protocol were higher than ambulatory blood pressure measurements. The correlation coefficient was in agreement with that found in one of the first comparative studies. ${ }^{23}$

For initial values between 105 and $115 \mathrm{mmHg}$, there was good agreement between the GPS' measurements and the ambulatory measurements. The agreement was much poorer for initial measurements between 95 and 105 $\mathrm{mmHg}$, that is those initial values for which the NHG protocol recommends measurements on at least five occasions. Other studies have recommended that blood pressures in this region should be remeasured on at least six visits, with two measurements per visit. ${ }^{24}$

In our study, 48\% (22/46) of patients with normal ambulatory blood pressures were found to be hypertensive by their GPs. This finding is in good agreement with the overdiagnosis reported in the three studies referred to above ${ }^{3-5}$ Two other studies have reported lower percentages of false positive findings. ${ }^{2526}$ These differences can probably be attributed to different inclusion criteria and a different definition of 'white coat effect'. The white coat effect in general practice proved to be as strong as it was found in hospital based studies.

On the other hand, 16 patients were classified as false-negative on the basis of the GP' measurements, which is in agreement with the findings of a previous study. ${ }^{27}$ We did not find an explanation for these false-negative results in the literature. A possible explanation could be the variability of blood pressure and its consequences for the measurements. If one takes enough measurements, blood pressure values show a normal distribution. This means that a number of blood pressure measurements taken by the GP can be regarded as a sample taken from the 'population' of possible blood pressure values. The mean value for this sample may correspond well with the mean value for the larger number of ambulatory measurements (as was the case in 56 of our 94 patients), or it may be higher than that mean value (in 22 patients) or lower (in 16 patients). This approach sheds new light on the phenomenon of the white coat effect. We hypothesize that the white coat effect partly can 


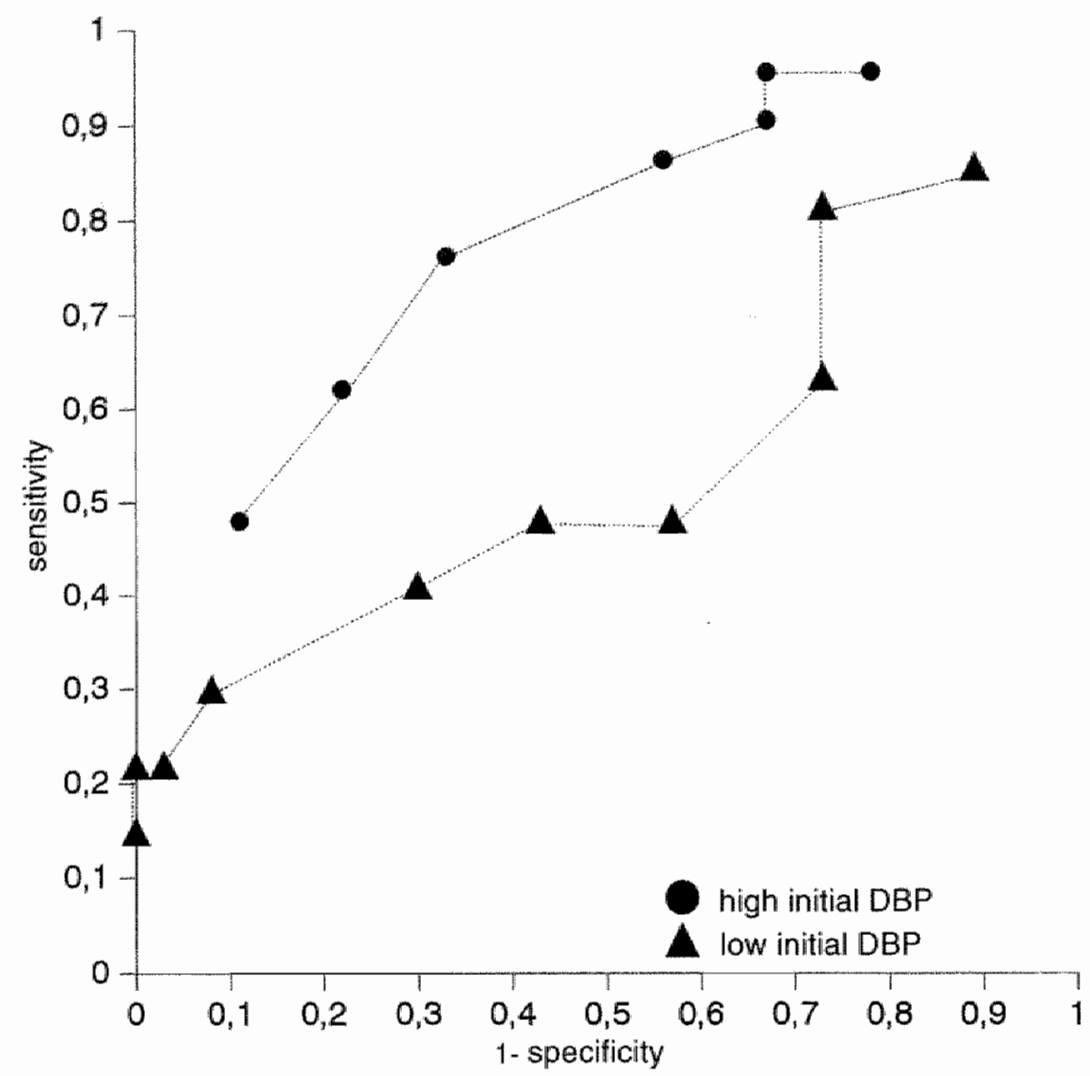

Figure 2. Sensitivity and specificity of blood pressure measurements by the GP, using 24h ambulatory blood pressure measurements as a reference, at ten different cut-off points for diastolic blood pressure, in two groups of patients: patients with high initial measurement values $(105 \leq D 8 P \leq 115$ mmHg; $n=30)$ and patients witl low hitial measurement values $(95 \leq D B P<$ $105 \mathrm{mmHg}: \mathrm{n}=64 \mathrm{4}$; , the cutoff point for hypertension in the ambulatory measurements was a daytime mean of $91 \mathrm{mmHg}$; DBP = diastolic blood pressure, that is the mean of two measurements during one and the same consultation.

be attributed to the lack of representativeness of the sample of blood pressure measurements.

The study population included roughly equal numbers of men and women. The mean and range of the patients' ages were almost the same for both groups. In view of the mean and range of the initial values, the study population, which was assembled via case-finding, can be regarded as representative of what the literature often calls "borderline hypertensives". The measurements were made in a standardized fashion. It was not investigated 
whether there were any systematic differences between blood pressures measured by GPs and ambulatory blood pressures. We do, however, believe that the study design is a fair reflection of the normal routine in general practice.

The present study shows that the diagnosis of "hypertension" is indeed most problematic for blood pressure values between 95 and $105 \mathrm{mmHg}$. If the limit value recommended by the NHG protocoll is used, this will lead to a relatively high percentage of patients being incorrectly diagnosed as hypertensive, compared with ambulatory measurements. If, on the other hand, a higher limit value is used, more people will be incorrectly classified as normotensive. Which of these two possibilities is the least desirable can in many cases only be indicated at the level of the individual patient. ${ }^{28}$ The presence of other cardiovascular risk factors, which have been ignored in the present study, may be decisive in the therapeutic decision. American research has shown that, in treating hypertension, GPS are more aware of the concurrent presence of other risk factors than medical specialists. ${ }^{29}$ We do not know whether this is also true for the Dutch situation.

So far, there is not enough evidence to justify the introduction of ambulatory blood pressure measurements into general practice as an instrument for diagnosing hypertension. The feasibility of ambulatory blood pressure measurements in general practice has not been sufficiently studied, and data from cost-benefit analyses are lacking. In the scientific research on the diagnostics of hypertension, however, ambulatory blood pressure measurement has become indispensable.

The present study was based on the conviction that the average, 'real' blood pressure is more closely approximated by the large number of measurements of an ambulatory 24-hour measurement than by a smaller number of office measurements. Our study revealed a considerable discrepancy between the "hypertensive/normotensive' condlusions on the basis of ambulatory measurements and those based on GPs measurements, especially in the group with "low' diastolic initial measurement values. The number of three visits for initial values $\geq 105 \mathrm{mmHg}$, as recommended by the NHG protocol, turned out to be sufficient for the purpose of the clinical decision. The decisions based on five visits for initial values between 95 and $105 \mathrm{mmHg}$, however, showed rather poor correlation with those based on ambulatory measurements. In our view, diagnosing hypertension in the latter group deserves further research. Perhaps ambulatory blood pressure measurements will prove to be particor ure diagnostics in this borderline group. 


\section{References}

1. Millar-Craig M, Bishop CN, Faftery EB. Circadian wariations of blood pressure. Lancet 1978 ; i: $107-9$.

2. Pickering GW. High blood pressure. New York, Churchill Livingstone, 1955: p 25.

3. Van Kruijsdijk MCM. Hypertersie opnieuw gemeten [proefschrift]. Meppel, Krips Repro, 1991. Mijmegen: Uniwersiteit van Nimmegen 1991.

4. Management Committee of the Australian therapeutic trial on mild hypertension. Untreated mild hypertension Lancet 1982; i: 185-91.

5. Medical research council working party. MRC trial on treatment of mild hypertension: principal results. BMJ 1985; 291:97-104.

6. Van Binsbergen J, Grundmeyer HGIM, Van den Hoogen JPH, et al. NHG-Standaard hypertensie. Huisarts Wet 1991; 34: 389-95.

7. Ayman D, Goldshine AD. Blood pressure determinations by patients with ressential hyperiension: difference between clinic and home readings before treatment. Am I Med Sci 1940; 200: 465-74.

8. Cox JP, OMalley K, O'Brien E. Ambulatory blocod pressure measurement in general practice. BrJ Gen Pract 1992; $42: 402-3$.

9. Kleinert HD, Harshfield GA, Pickering TG, et al. What is the value of home pressure measurement in patients with mid hypertension? Hypertension 1984: 6:574-8.

10. Parati $G$, Pomidossi $G$. Albini $F$, et al. Relationship of 24-hour blood pressure mean and variability to severity of target-organ damage in hypertension. $J$ Hypertens 1987; 5: $93-8$.

11. Perloff $D$, sokolow M, Cowan R. The prognostic value of ambulatory blood pressures. IAMA 1983; 249: 2792-8.

12. Hinman AT, Engel BT, Bickford AF. Portable blood pressure recorder: accuracy and preliminary use in evaluating intradaily variations in pressure. Am Heart I 1962: 63: 663-8.

13. Kain HK, Hinman AT, Sokolow M. Arterial blood pressure measurements with a portable recorder in hypertensive patients. I. Variability and correlation with "casual" pressure. Circulation 1964; 30; 882-92

14. Meyer-Sabellek WA. Non-iwasive blood pressure measurement, in: O'Brien E, O'Malley K (eds): Handbook of Hypertension. Volume 14: Blood Pressure Measurement. Elsevier. Ansterdan: 1991, pp 184-217.

15. Gezondheidsrad. Advies inzake hypertensie. Den Haag. Staatsuitgeverij, 1983

16. Graettinger WF, Lipson $U$, Cheung DG, et al. Validation of portable noninvasive blood pressure monitoring devices: comparisons with intra-arterial and sphygmomanometer measurements. Am Heart J 1988; 116: 1155-60.

17. O'Bthen E, Mee E. Atkins N, et al. Accuracy of the Spacelabs 90207 determined by the British Hypertension Society prolocol. I Hypertens 1991; 9: 573-4.

18. Cates EM, Schlussel YR, James GO, et al. A validation study of the Spacelabs 90207 ambulatory blood pressure monitor. I Amb Mon 1990; 3: 149-54.

19. Conway J, Coats A. Value of ambulatory blood pressure monitoring in clinical pharmacology. J Hypertens, 3989; 7 (suppl 3): S29-532.

20. Höting B, Gehring J. Heinbuch 5 , et al. 24-Stunden-Blutdruckprofil: Reproduzierbarkeit bei ambulanter automatischer Messung. Dtsch Med Wochenschr 1991: 116: 1337-41. 
21. Fotherby MD, Potter JF. Reproducibility of ambulatory and clinic blood pressure measurements in elderly hypertensive subjects. I Hypertens 1993; 11: 573-9.

22. Staessen 1 , Fagard $R_{r}$ Lijnen $P$, et al. Reference values for ambulatory blood pressure: a meta-analysis. J Hypertens 1990; 8 (suppl 6): 557-564.

23. Sokolow M. Werdegar D, Kain HK, et al. Relationship between level of blood pressure measured casually and by portable recorders and severity of complications in essential hypertension. Circulation 1966; 34: 279.98.

24. Watson RDS, Lumb $R$, Young $M A$, et al. Variation in cuff blood pressure in untreated outpatients with mild hypertension: implications for initiating antihypertensive treatment. J Hypertens 1987; 5: 205-11.

25. Floras 15 . Hassan MO, Sever PS, et al Cuff and ambulatory blood pressure in subjects with essential hypertension. Lancet 1981; i: 107-9.

26. Pickering TG, James GD, Boddie $C$, et al. How common is white coat hypertension? JAMA 1988; 259:225-8.

27. Gourlay SG, McNeil JJ, Marriner T, et all. Discordance of mercury sphygmomanometer and ambulatory blood pressure measurements for the detection of untreated hypertension in a population study. J H.tum Hypertens 1998; 7: 467-72.

28. Knottnerus $J A$. Interpretation of diagnostic data: an unexplored field in general practice. $J \mathrm{R}$ Coll Gen Pract 1985; 35: 270-4.

29. Cloher TP, Admin M, Whelton PK. Physician approach to the recognition and initial management of hypertension. Arch Intern Med 1986; 146: 529-33. 



\section{Correspondence 1}

The paper by Brueren et al. does justice to the difficult problem of diagnosing hypertension. On the one hand, it points out once again the risk of overdiagnosing. while indicating on the other hand that the introduction of new diagnostic techniques should be undertaken with great caution.

The discrepancy between blood pressure values measured in the conventional way in the doctor's office and those found in ambulatory measurements has been widely publicized. Although factors such as the 'white-coat effect' and 'cuff response' can be regarded as partly responsible for this phenomenon, a large proportion of this discrepancy can in my opinion also be explained by the variability of blood pressure. Although ambulatory blood pressure measurement is superior to conventional measurements, it is still only moderately reproducible, partly because of differences in patients" daily activities. ${ }^{12}$ Hence, a single ambulatory measurement can only provide a rough indication of the value of conventional measurements in an individual patient. This has no bearing on the rejection or acceptation of the diagnosis of 'hypertension. We therefore support the authors' view that ambulatory blood pressure measurements. do not yet deserwe a place as a diagnostic tool in general practice. A number of additionall method-specific points should be made. Ambulatory measurements have added a new dimension to the white-coat effect and cuff response. Looking at a patient's ambulatory pressure profile, it is not uncommon to find clearly falling blood pressure values during the first hour of measurement, implying that it might be better to disregard the values measured during that first hour. Increasing the measuring period to, say, 26 hours might be worth considering. In addition, in estimating average daytime pressure, it would be better to consider the actual moments of getting up and going to bed if the average daytime blood pressure is to be estimated.

Finally, I should like to say that the omission of systolic blood pressure from diagnostic considerations is fundamentally incorrect, since an elevated systolic blood pressure can be regarded as an important risk factor for cardiovascular complications, even more so than an elevated diastolic blood pressure.

Mastricht, March 1995

\section{References}

1. Mansoor GA, MlCCabe EJ, White WB. Long-term reproducibility of ambulatory blood pressure. J Hypertens 1994; 12: 703-8.

2. Gerin W. Rosofsky M, Pieper C, et al. A test of reproducibility of blood pressure and heart rate variability using a controlled ambulatory procedure. J Hypertens 1993; 11:1127-31.

3. Stamler J Neaton JD. Wentworth DN. Blood pressure (systolic and diastolic) ard risk of latal coronary heart disease. Hypertension 1989; 13 (suppl 5): 133-35. 
The letter by our esteemed colleague or. Lavrijsen provides a valuable addition to our paper. He righty observes that a single ambulatory measurement cannot be regarded as a 'gold standard'. At this point in time, a definitive solution to the problem of the gold standard in blood pressure measurements does not appear to be in sight. On the other hand, the noninvasive ambulatory measurement method has in recent years acquired an important position in the unexplored territory between the 'physiological gold standard' (i.e., intramarterial measurement) and the sepidemiological goid standard' (cinical measurement. using the sphygmomanometer). The moderate reproducibility of ambulatory measurements highlights the large variability of blood pressure, not only within one day but also between warious days. The reproducibility depends nat only on patient-related variables such as physical exertion, stress and partly unknown physiological factors, but aiso on the number of measurements performed; the larger the number of measurements, that is, the shorter the intervals between the measurements, the greater the reproducibility. in any case, indirect ambulatory blood whessure measurements do satisfy the 'ideal' of adequate blood pressure measurement. which was phrased by Pickering as follows: "In epidemiological observations the ideal 15 to have a single observer to make measurements under as natural conditions as
possible."

As regards the second point made by Lavrijssen, we would like to make the following comment. Whether one should use the average value over 24 hours, the 'daytime' average or the average over the hours between getting up and going to bed depends be elevated, so the suggestion answer. In many people, initial measurements tend to rather than only 24 hours to disregard the first hour and to measure for 25 or 26 rather than only 24 hours would seem to be a useful one. Our paper, however. compared the findings of ambulatory measurements with those made by the general practitioner using a sphygmomanometer. Of the two measurements on one occasion, first was found to be generally higher than the second. If we were to disregard the the hour of ambulatory measurements, considerations of fainess were to disregard the first disregard the first of the two measurements by the GPS. That would he us also to counter to the NHG quidelines as well as to international guidelines? 2 , however, run

We fully agree with the comment about the predictive value of

pressure values for cardiovascular risk ascesment the predictive value of systolic blood guidelines on hypertension should put greater emt. A future revised version of the NHG however, was designed to evaluate the cuter emphasis on systolic pressure. Our paper,

MM Brueren, GJ Dinant.

B Schouten, JW van Ree

Maastricht, March 1995

\section{References}

1. Pickering GW. High blood pressure. 2nd ed Churchill, London, 1968.

2. Varn Binsbergen J., Grundmeyer HGJM, Van den Hoogen JPH, et al. NHG-standaard

The Dutch versions of these letters were published in: Ned Tijdschr Geneeskd 1995.
139: 902 (29 April). 
CHAPTER 4

\section{How many measurements are necessary in diagnosing mild to moderate hypertension?}

Published as: Brueren MM, Petri H, Van Weel C, Van Ree JW. How many measurements are necessary in diagnosing mild to moderate hypertension? Fam Pract 1997; 14: 130-5. 


\section{Summary}

Objective: The aim of this study was to investigate how many blood pressure measurements are necessary in diagnosing mild to moderate hypertension.

Methods: The subjects were 99 outpatients who were included on the basis of elevated diastolic ( $95 \leq \mathrm{DBP} \leq 45 \mathrm{mmHg}$ ) and/or systolic (160 $\leq 5 \mathrm{SP} \leq 200$ $\mathrm{mmHg}$ blood pressure. After the initial measurement all patients underwent nine subsequent blood pressure measurements over a period of seven months. None of the patients received antihypertensive drug treatment during the study.

Results: Between the first (initial) and second measurements, there was a significant reduction in systolic $(161.0$ to $152.5 \mathrm{mmHg}$ ) and diastolic (101.5 to $97.1 \mathrm{mmHg}$ ) blood pressures $(p<0.01)$. The differences between pairs of subsequent measurements were not statistically significant. The average of the last five assessment sessions (two readings per session) was regarded as the "conceptual average blood pressure". Comparing the blood pressure at repeat measurement with the conceptual average blood pressure revealed misclassification in 19\% of cases, even after four repeat measurements (threshold value $95 \mathrm{mmH}$ ). Analysis of the subgroups $(95 \leq \mathrm{DBP}<105 \mathrm{mmHg}$ and $105 \leq \mathrm{DBP} \leq 115 \mathrm{mmHg}$ ) revealed that the proportion of misclassification greatly depended on the initial value and the accepted threshold value. At a threshold value of $95 \mathrm{mmHg}$, patients with 'high' initial diastolic blood pressures (105 $\leq \mathrm{DBP} \leq 115 \mathrm{mmHg}$ ) required only two repeat measurements (misclassification in $7 \%$ of cases after four repeat measurements). Of those with 'low' initial diastolic blood pressure values ( $95 \leq \mathrm{DBP}<105 \mathrm{mmHg}$ ), $24 \%$ were misclassified even after four repeat measurements.

Conclusions: For these 'borderline' diastolic values, we propose larger numbers of measurements than are recommended in international guidelines. Our advice for values in this borderline region is to be reticent in starting antihypertensive drug treatment. The presence or absence of other cardiovascular risk factors should be taken into account when deciding whether treatment is required or not.

Keywords: Blood pressure determination, essential hypertension, general practice, office blood pressure.

\section{Introduction}

High blood pressure found incidentally, defined as a blood pressure above a certain level, tends to be lower when it is measured on subsequent occasions. "This can be attributed to the phenomenon of regression towards the mean on the one hand, and to the cuff response effect on the other. Regression towards the mean is a statistical phenomenon: it also occurs, in the opposite direction, with low initial values. ${ }^{2}$ Cuff response is a type of defence 


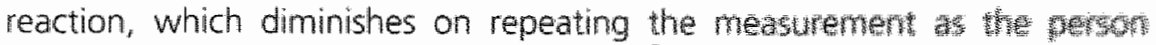
becomes more familiar with the procedure. ${ }^{3}$

If there is a large distance between the blood pressure megumed clinically relevant threshold, the probability of misdasshication whe whe Blood pressures near the threshold, in the borderline region beween high and low, may easily lead to misclassification." In view of these phenomend, an important question relates to the number of measurements necessay for correct diagnosis.

There are no general guidelines with regard to the minimum number of measurements. The guidelines of the WHO/ISH Meeting in 1993 say that if the initial diastolic pressure averages between 90 and $104 \mathrm{mmHg}$. measurements should be repeated on at least two further occasions during the next 4 weeks If the initial diastolic values lie between 95 and $105 \mathrm{mmHg}$, the consensusmeeting of Dutch physicians recommended three measurements during the next weeks or months, with three measurements per session. ${ }^{6}$ The 1993 Report of the American Joint National Committee on Detection. Evaluation and Treatment of High Blood Pressure states that an initial elevated measurement should be confirmed on at least two subsequent visits. ${ }^{7}$ The 'NHG-Standard Hypertension', a guidelime published by the Dutch College of General Practitioners (GP), proposes different numbers of measurements for patients with initial diastolic readings between 105 and $115 \mathrm{mmHg}$ (three visits) and patients with initial values between 95 and $105 \mathrm{mmHg}$ (five visits). In this guideline, the diagnosis is based on the average of all diastolic readings, with the exception of the initial value. ${ }^{8}$ The BHS (British Hypertension Society) recommends that two or more blood pressures should be measured at each visit on up to four separate occasions. ${ }^{9}$

There is no generally accepted threshold level of blood pressure for drug treatment. The BHS guidelines recommend a diastolic threshald of $100 \mathrm{mmHg}$ for drug treatment, whereas others prefer 90 or $95 \mathrm{mmHg} .^{357}$ The guideline of the Dutch College of General Practitioners recommends $105 \mathrm{mmHg}$ as the threshold walue for drug therapy, unlless there are two or more other cardiovascular risk factors. ${ }^{8}$

The objective of the present study was to investigate the number of measurements required for diagnosing imild to moderate hypertension with sufficient certainty. The importance of a correct diagnosis arises from the consequent long-term treatment, including the risks and side effects of potent drugs. Misclassification may inflict unjustified treatment, or may incorrectly withhold treatment. This dilemma is particularly experienced in general practice where the majority of hypertensive patients are diagnosed and many patients have blood pressures which are hovering near the thresholl level for treatment. 


\section{Patients and methods}

Seventeen GPS participated in the study. Participating physicians were given instructions on adequate techniques of blood pressure measurement. ${ }^{10}$ Phase $\checkmark$ of the Korotkoff sounds was recorded as the level of diastolic pressure.

The patients were selected for this study on the basis of an initially elevated blood pressure. Inclusion criteria were (i) mean of two systclic values (measured in one visit) between 160 and $200 \mathrm{mmHg}$ and/or mean of two diastolic measurements between 95 and $115 \mathrm{mmHg}$; and (ii) age between 20 and 75 years. Exclusion criteria were (i) known hypertension or antihypertensive treatment in the year preceding the study; (ii) secondary hypertension; (iii) congestive heart failure or unstable angina; and (iv) pregnancy.

After inclusion, nine visits were arranged over the next 7 months. At each visit, the blood pressure was measured twice. Visits 1, 2 and 3 took place during the 4 weeks after inclusion; subsequent visits over the next 6 months.

Blood pressures were measured by the GP in the office with a conventional calibrated mercury sphygmomanometer, provided with a standard-sized cuff $(12 \times 35 \mathrm{~cm})$.

\section{Analysis}

Results were reported as mean \pm SD (standard deviation). Differences between the means of two successive readings (systolic and diastolic) were analyzed using Student's paired t-test. The average DBP (diastolic blood pressure) of the five visits ( 10 blood pressure measurements) during the last 5 months of the study was regarded as the 'conceptual average blood pressure", a compromise between the mean value of four measurements used by Armitage et $a l^{11}$ as the reference value and the mean of six measurements used by Watson et al. ${ }^{12}$

The study was approved by the ethics review committee of the University Hospital of Maastricht, the Netherlands. All subjects gave written informed consent for participation in the study.

\section{Results}

One hundred and fourteen patients were included in the study. Fifteen dropped out (10 men and 5 women, mean initial SBP $164.7 \mathrm{mmHg}$, mean initial DBP $105.1 \mathrm{mmHg}$ ): six patients started antihypertensive drug treatment, one suffered a heart attack and the other eight withdrew because of nonmedical reasons. Ninety nine patients thus completed the study, 49 men and 50 women (mean age 48 years). The mean initial SBP was $161.0 \mathrm{mmHg}$ and the mean DBP $101.5 \mathrm{mmHg}$. The mean systolic and diastolic values of the initial $(I=$ inclusion/initial) and subsequent $(S 1,52, \ldots \ldots, 59)$ readings are shown in Figure 1. There was a significant difference between the systolic $(8.5 \mathrm{mmHg})$ 


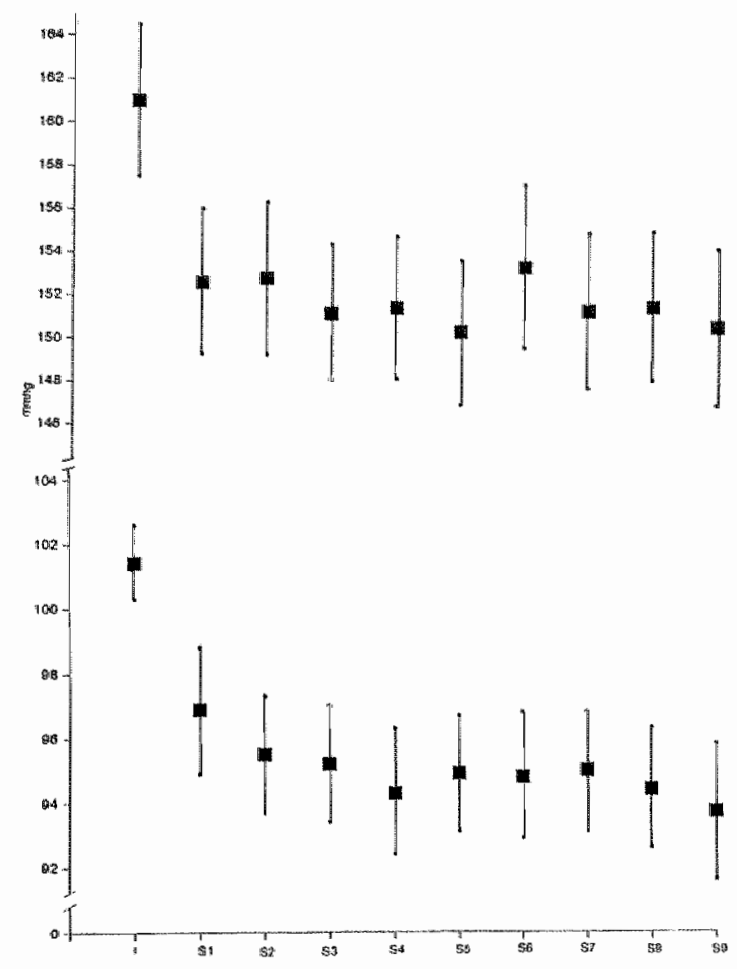

Figure 1. population meanis and 95\%-confidence intervals of SBP and DBP $(n=99) .1$ = Initial measurement; $S=$ subsequent measurement; 1-51, 51-52, 52-53: one week intervals; \$3-54, 54-55, 55-56, 56-57, 57-58, 58-59: one month intervals.

and diastolic $(4.5 \mathrm{mmHg})$ readings I and $S 1(p<0.001)$. The differences between the mean values of the subsequent readings were not statistically significant. As can be seen from Figure 1 the effect of regression had almost disappeared after the second measurement (S1). In patients with initial diastolic values between 105 and $115 \mathrm{mmHg}(n=28)$ the averages for first and tenth measurements were 171 and $154.5 \mathrm{mmHg}$ (SBP) and 107.7 and $98.3 \mathrm{mmHg}$ (DBP), a systolic fall of $16.5 \mathrm{mmHg}$ and a diastolic fall of $9.4 \mathrm{mmHg}$. The patients who were included only on the basis of systolic blood pressure $(n=9)$ showed an even greater regression ( 170.6 to $152.1 \mathrm{mmHg}$ ) between the first and last measurements (Figure 2). If we regard $95 \mathrm{mmHg}$ as the diastolic threshold value for starting drug treatment, $19 \%$ ( $11 \%$ false-positive, $8 \%$ false-negative) of the patients with initial diastolic blood pressure values between 95 and 115 $\mathrm{mmHg}(n=90)$ would have been misclassified after four repeat measurements. The proportion of misclassifications in this group at threshold values of 100 


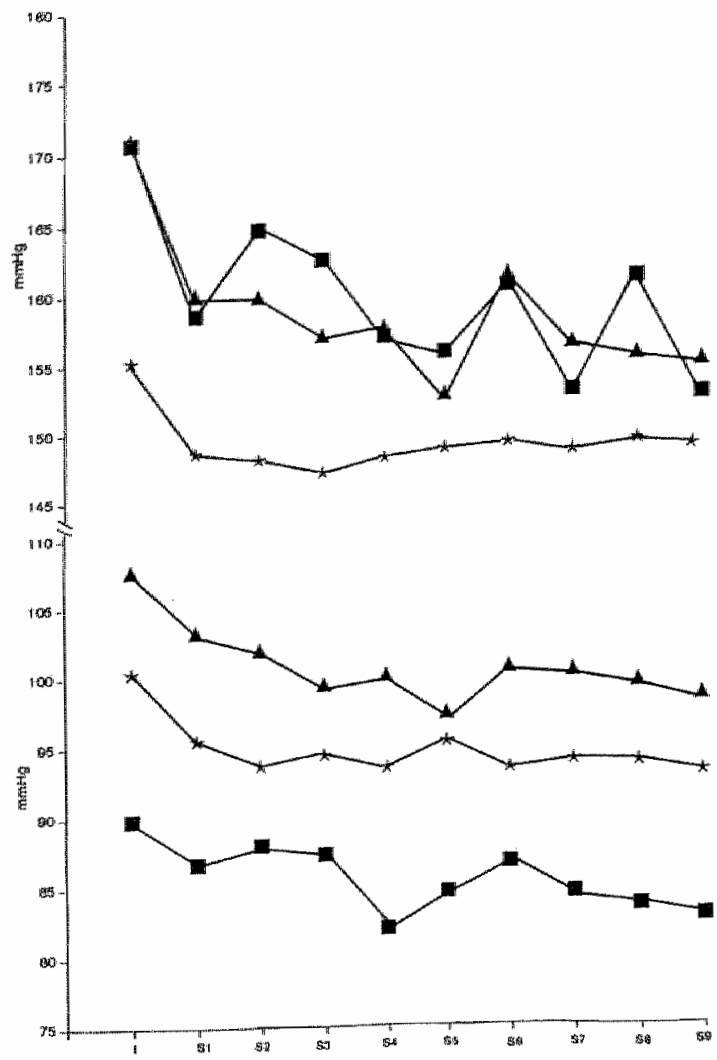

Figure 2. Subgroup means of $5 B P$ and $D B P$ at initial and subsequent measurements. initial $D B P<95 \mathrm{mmHg}(n=9)$; $\$ 95 \leq$ initial $D B P<$ $105 \mathrm{mmHg}(\mathrm{n}=62) ; \boldsymbol{A} 105 \leq$ initial DBP $\leq 115 \mathrm{mmHg}(\mathrm{n}=28)$.

and $105 \mathrm{mmHg}$ were comparable (Figure 3a). In the patients with initial diastolic values between 95 and $105 \mathrm{mmHg}(n=62)$ the proportion of misclassifications on all subsequent measurements was lower at higher threshold values. If we use a threshold value of $105 \mathrm{mmHg}$, the proportion of misclassifications in this study population was low: in this case one single measurement seemed to be sufficient (Figure 3b). At higher initial diastolic values $(105<\mathrm{DBP} \leq 115 \mathrm{mmHg})$ the misclassifications consist for the greater part of false-positives and the most serious misclassification refers to a threshold value of $105 \mathrm{mmHg}$ (Figure 3c). All groups with initial diastolic blood pressures near the relevant threshold value showed a considerable proportion of misclassifications, $20-30 \%$, even after four repeat measurements. 


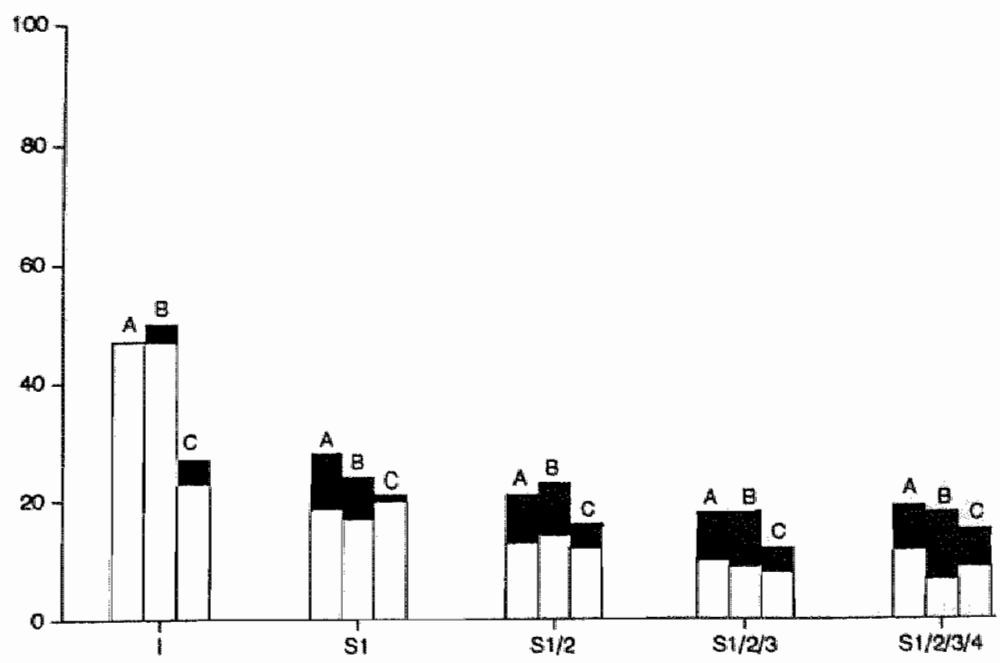

Figure 3a. Percentages of misclassifications in subgroup with $95 \mathrm{mmHg} \leq$ initial DBP $\leq 115 \mathrm{mmHg}$ $(n=90)$ at 3 threshold values $(A=95 \mathrm{mmHg}, B=100 \mathrm{mmHg}, C=105 \mathrm{mmHg}$ ). I = initial measurement; $51 / 2 / 3 / 4=$ average of subsequent measurements $1,2,3$ and $4 ; \mathbf{m}=$ false negative classification; $\square=$ false positive classification.

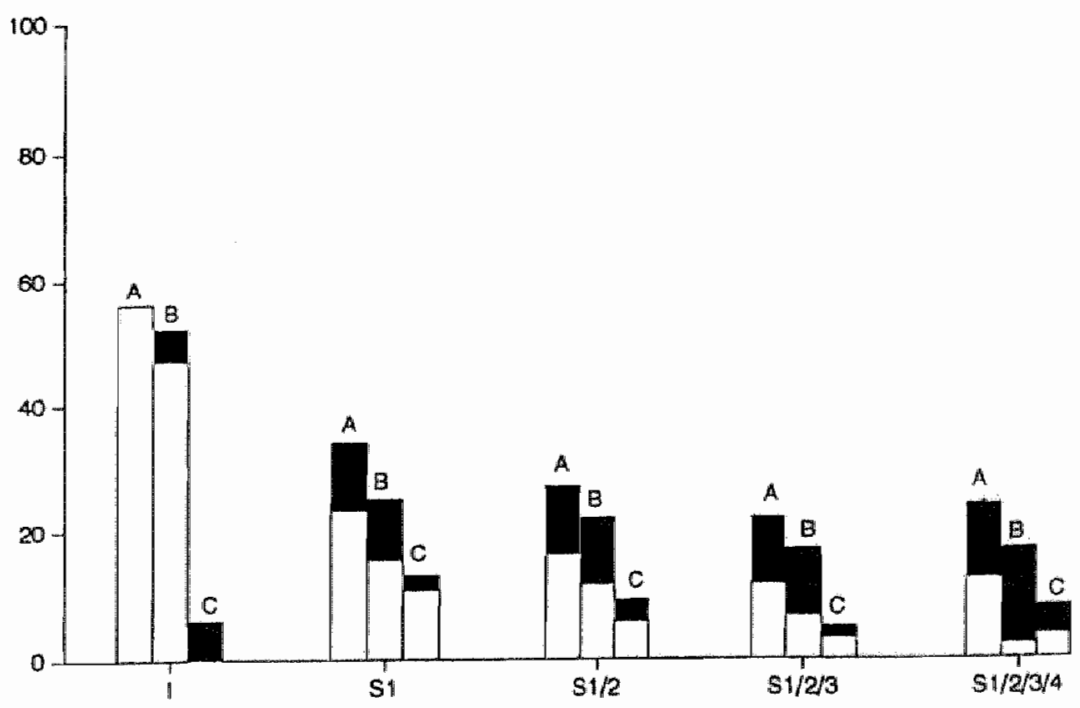

Figure 3b. Percentages of misclassification in subgroup with $95 \mathrm{mmHg} \leq$ initial DBP $<105 \mathrm{mmH}$. $(\mathrm{n}=62)$ at 3 threshold values $(A=95 \mathrm{mmHg}, B=100 \mathrm{mmHg}, C=105 \mathrm{mmHg}$ ) I = initial measturememt; $51 / 2 / 3 / A=$ average of subsequent measurements $1,2,3$ and $4 ; \mathbf{m}=$ false negative classification: $\mathrm{I}=$ false positive classification. 


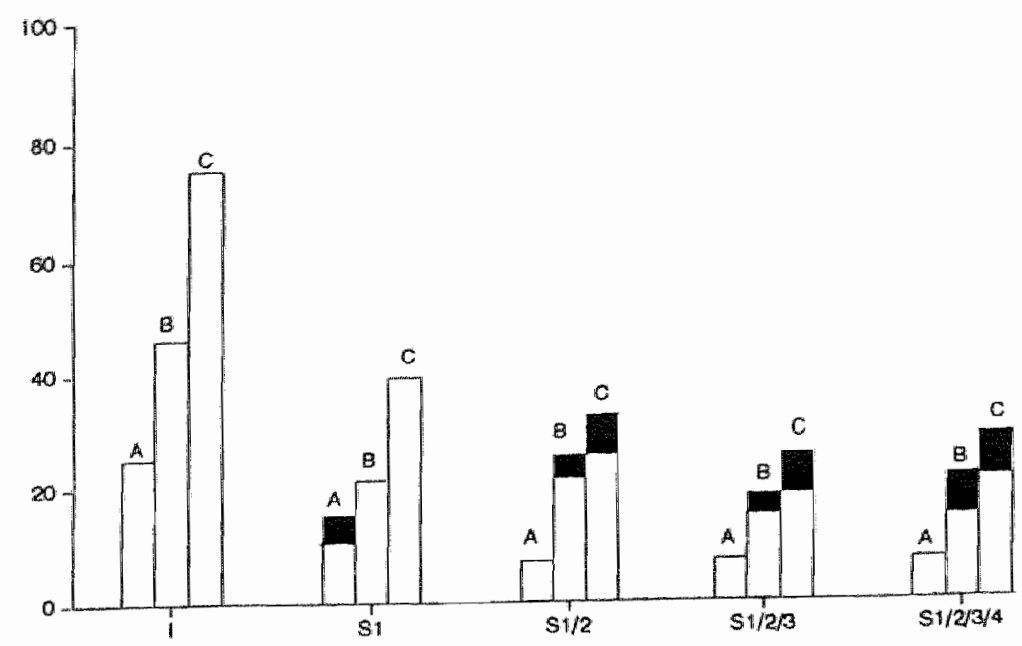

Figure 3c. Percentages of misclassifications in subgroup with $105 \mathrm{mmHg} \leq$ initial $D B P \leq 115$ mmitg $(n=28)$ at 3 threshold walues $(A=95 \mathrm{mmHg}, B=100 \mathrm{mmHg}, C=105 \mathrm{mmHg}) .1=$ initial measurement; $51 / 2 / 3 / 4=$ average of subsequent measurements $1,2,3$ and $4 ;=$ false negative classification; $\square=$ false positive classification.

\section{Discussion}

In the present study we defined the means of 10 measurements made at the last five of a series of 10 visits as the 'conceptual average blood pressure'. Given the enormous variability of blood pressure one might question this as a plausible standard. On the other hand, the numbers of measurements at later points in time should yield a standard that is relatively free of regression towards the mean and of cuff-responding effects.

The effects of 'regression towards the mean' and 'accommodation to the measurement ' were almost entirely restricted to the first and second measurements. After the second measurement, there was a random fluctuation around a mean value. Within each of the three subgroups (initial DBP $<95 \mathrm{mmHg}, 95$ $\leq$ initial DBP $<105 \mathrm{mmHg}$ and $105 \mathrm{mmHg} \leq$ initial DBP $\leq 115 \mathrm{mmHg}$ ) there was a strong decline in SBP and DBP between the initial measurement (1) and the final measurement (S9). This is in agreement with the results reported by Millar and Lever. ${ }^{13}$ The very small group of patients who were only included on the basis of SBP $(n=9, \mathrm{DBP}<95 \mathrm{mmHg})$ showed the greatest decline in systolic values over time. This corresponds with the results reported by Van Loo et al. ( $n=5999$ ), indicating that isolated systolic hypertension should not be diagnosed too readily. ${ }^{14}$

of the studied group of potentially hypertensive patients and the two subgroups studied, $20-30 \%$, depending on the threshold value chosen, were 
still misclassified after four repeat measurements. This could explain the reduction in blood pressure following placebo treatment of mildly hypertensive patients which has been found in two randomized controlled clinical trials. 15,16

In the study population as a whole, the probability of misclassification after two, three or four repeat measurements, using 95,100 and $105 \mathrm{mmHg}$ as threshold values, was almost $20 \%$. Different patterns were found in the subgroups $(95 \mathrm{mmHg} \leq \mathrm{DBP}<105 \mathrm{mmHg}$ and $105 \leq \mathrm{DBP} \leq 115 \mathrm{mmHg}$ ). Figures 1-3 illustrate what can be intuitively grasped: the proportion of misclassifications is low at relatively low initial values and higher threshold values, and the same applies to relatively high initial values and lower threshold values. If, for instance, a GP measures a blood pressure below $105 \mathrm{mmHg}$ at the first consultation, is only interested in the question 'should I start drug treatment?', and accepts a threshold of $105 \mathrm{mmHg}$ for this decision, that single blood pressure measurement is sufficient. If the physician measures a blood pressure between 105 and $115 \mathrm{mmHg}$ and accepts $105 \mathrm{mmHg}$ as the relevant threshold value, the decision should be based on at least three subsequent measurements, thereby reducing the probability of misclassification from 3 in 4 to 1 in 4 . The 3 in 4 probability of misclassification after the first measurement is even worse than what a 'flip coin' random choice would generate, which highlights the rather misleading phenomenon of 'being selected' on the basis of blood pressure measurement on one single occasion.

The answer to the question how many blood pressure measurements are required for diagnosis depends on the initial blood pressure and the threshold that is considered relevant for the diagnostic decision. If one considers 95 $\mathrm{mmHg}$ as the relevant diastolic threshold value in patients with an initial diastolic blood pressure between 105 and $115 \mathrm{mmHg}$, two repeat measurements appear to be sufficient. Using the same threshold value in patients with initial diastolic values between 95 and $105 \mathrm{mmHg}$, a $24 \%$ misclassification rate should be taken into account, even after four repeat measurements. More measurements are necessary if blood pressure is hovering near a diagnostic threshold value. If the measured blood pressure is far from this threshold, fewer measurements are required for confident classification. ${ }^{4}$ Like Jackson et al. ${ }^{17}$ we recommend that for these borderline values, other cardiovascular risk factors should be taken into account in the decision whether to treat or not. Our results and conclusions support the statement by Reeves in his detailed review: "In the future, individualized assessments of absolute risk incorporating other relevant information, such as age, sex, concomitant risk factors, and coexisting target organ damage, along with the patient's tolerance for risk and history of drug side effects may replace arbitrary cut points in determining when blood pressure elevation becomes treatable ${ }^{18}$ In comparison with their colleagues in internal medicine and specialty practices, GPs have been found to be more cautious in starting antihypertensive drug treatment, and GPs also paid more attention to other cardiovascular risk factors. ${ }^{19}$ The present study substantiates this approach by GPs. 


\section{References}

1. Beevers DG. Blood pressures that fall on rechecking. BM 1982; 284:71-2.

2. Davis CE. The effect of regression to the mean in epidemiologic and dinical studies. Am J Epidemiol 1976; 104: 493-9.

3. Pearce KA, Grirrim RA, Rao S, et all. Population-derived comparisons of ambulatory and office blood pressures: implications for the determination of casual blood pressiure and the concept of white coat hypertension. Arch Intern Med 1992; 152:750-6.

4. Perry HM, Miller IP. Difficulties in diagnosing hypertension: implications and alternatives. I Hypertens 1992; 10: 887-92.

5. Guidelines Sub-Committee of the WHO/5H Mild Hypertension Liaison Committee. 1993 Guidelines for the management of mild hypertension; memorandum from a World Health Organization/nternational Sociely of Hypertension meeting. IHypertens 1993; 11: 905-18.

6. Struyvenberg A. Hypertensie-consensus in Nederland. Ned Tijdschr Geneeskd 1990; 134: 2086-93.

7. Joint National Committee on Detection, Evaluation and Treatment of High Blood Pressure. The iffth report of the Joint National Committee on Detection, Evaluation and Treatment of High Blood Pressure (.INC-W). Arch intern Med 1993; 153: 154-83.

8. Van Binsbergen $\mathrm{JJ}$, Grundmeyer HGM, Van den Hoogen JPH, et al. NHG-Standaard Hypertensie. Huisarts Wet 1991; 34: 389-95.

9. Sever $P$, Beevers $G$, Bulpitt $C$, et al. Management guidelines in essential hypertension: report of the second working party of the British Hypertension Society. BMI 1993; 306: 983-7.

10. British Hypertension Society recommendations on blood pressure measurement, in: $O^{\prime} B r i e n$ E, O'Malley K (eds): Handbook of Hypertension. Volume 14: Blood pressure measurement. Elsevier, Amsterdam, 1991, pp 387-95.

11. Armitage $P_{r}$ Fox W, Rose GA, et al. The variability of measurements of casual blood pressure. 11. Survey experience. Clin Sci 1966; 30: 337-44.

12. Watson ROS, Lumb $R$, Young MA, et al. Variation in cuff blood pressure in untreated outpatients with mild hypertension: implications for initiating antihypertensive treatment. J Hypertens 1987; $5: 207-11$.

13. Millar JA, Lever AF. Effect of sexwelated changes in blood pressure at entry to the MRC Trial on prediction of cardiovascular risk. Clin Exp Pharmacol Physiol 1994: 21:167\%9.

14. Van Loo JM, Peer PG, Thien TA. Twenty-five minutes between blood pressure readings: the influence on prevalence rates of isolated systolic hypertension. J Hypertens 1986; 4: 631-5.

15. Management Committee of the Australian Therapeutic Trial on Mild Hypertension. Untreated mild hypertension. Lancet 1982; i: 185-91.

16. Medical Research Council Working Party. MRC trial on treatment of mild hypertension: principal results. BMJ 1985; 291: 97-104.

17. Jackson R, Barham P. Bills J, et al. Management of raised blood pressure in New Zealand: a discussion document. BMJ 1993; 307: 107-10.

18. Reeves RA. Does this patient have hypertension? How to measure blood pressure. IAMA 1995; $373: 1211-8$.

19. Cloher TP, Admin M. Whelton PK. Physician approach to the recognition and initial management of hypertension. Arch Intern Med 1986; 146: 529-33. 


\section{Are four duplicate remeasurements sufficient for diagnosing mild hypertension?}

Published as: Brueren $M$, Petri H, Schouten $H$, Van Weel C, Van Ree J. Are four duplicate remeasurements sufficient for diagnosing mild hypertension? J Hum Hypertens 1996; 10: 349-52. 


\section{Summary}

The aim of this study was to investigate if four duplicate blood pressure (BP) remeasurements are sufficient for diagnosing hypertension in potentially hypertensive subjects. The subjects were 99 autpatients who were included on the basis of elevated diastolic $(95 \leq 115 \mathrm{mmHg})$ or systolic $(160 \leq 200 \mathrm{mmHg})$ $B P$. After inclusion all patients underwent nine subsequent duplicate BP measurements over a period of seven months.

None of the patients received hypotensive drug treatment during the study. Between the first (initial) and second measurements there were significant reductions in systolic $(161.0$ to $152.5 \mathrm{mmHg})$ and diastolic $(101.5$ to 97.1 $\mathrm{mmHg})$ BPs $(p<0.01)$. Differences between the subsequent measurements were not statistically significant. A linear regression analysis proved that the 'conceptual average $\mathrm{BP}^{\prime}$ (the average of the last five visits) which was chosen as the reference value was stable. The decline of standard deviations of differences between two, three and four duplicate remeasurements on one hand and the reference value on the other was found to be strikingly small. After four duplicate remeasurements, there was misclassification in $56 \%$ (systolic) and $38 \%$ (diastolic). We conclude that the numbers of two, three or four blood pressure measurements recommended by international guidelines for diagnosing hypertension are too low. Even after four duplicate remeasurements a considerable amount of misclassification remains.

\subsection{Introduction}

Given the enormous within-person variability of blood pressure (BP), the phenomenon of "white-coat hypertension" and measurement errors, one might wonder whether the few repeated measurements recommended by guidelines are enough for diagnosing hypertension. The Fifth Report of the Joint National Committee on Detection, Evaluation, and Treatment of High Blood Pressure states that initial elevated readings should be confirmed on at least two subsequent occasions over a period of one to several weeks. ${ }^{1}$ The management guidelines of the British Hypertension Society recommend two or more BP measurements in the sitting position on each visit on up to four separate occasions. ${ }^{2}$ The 'NHG-Standard Hypertension', a guideline published by the Dutch College of General Practitioners, proposes at least five duplicate remeasurements in patients with diastolic initial blood pressures between 95 and $105 \mathrm{mmHg} .^{3}$

In two studies in patients diagnosed as mild hypertensives, one third to one half of all those taking placebo were later found to have diastolic pressures below $90 \mathrm{mmHg} .4,5$ This raises the question of the correctness of the initial diagnosis. 
In the 1940s, Smirk and co-workers investigated the differences between $\mathrm{BP}$ measured in the doctor's office (casual BP) and BP measured under highly standardized conditions after a period of rest (basal BP). ${ }^{6-9}$ However, there are two problems with the concept of basal BP: (1) it is almost impossible to measure in general and clinical practice; (2) the prognostic value and clinical relevance remain unclear.

The objective of the present study is to answer the question if four duplicate remeasurements are sufficient for diagnosing hypertension in potentially mildly to moderately hypertensive outpatients. In other words is, in these patients, the average of four duplicate remeasurements a solid basis to start a probably lifelong, drug treatment? This question is relevant since the importance of a correct diagnosis and classification is in the subsequent treatment. Misclassification may result in unjustified treatment, or in an incorrectly withholding of treatment. This dilemma is particularly experienced in general practice, where the majority of hypertensive patients are diagnosed, and where most hypertensives have BP values around the threshold level for treatment.

\subsection{Patients and methods}

The study was approved by the ethical review committee of the University Hospital of Maastricht, The Netherlands. All subjects gave written informed consent for participation in the study.

Seventeen general practitioners participated in the study. All of them were given instructions on the correct technique of measuring BP. ${ }^{10}$ Phase $\mathrm{V}$ of Korotkoff tones was recorded as the level of diastolic blood pressure (DBP). Patients were selected on the basis of an elevated initially BP.

Inclusion criteria:

- mean of two systolic values measured in one visit between 160 and 200 $\mathrm{mmHg}$ or mean of two diastolic measurements between 95 and $115 \mathrm{mmHg}$

- age between 20 and 75 years.

Exclusion criteria:

- known hypertension or hypotensive treatment in the year preceding the intendied inclusion

- secondary hypertension

- congestive heart failure or unstable angina

- pregnancy

After inclusion ( $\left.V_{1}\right)$, nine visits (V2, V3,...V10) were arranged over the next 7 months. At each visit, the BP was measured twice. $V_{2}, V_{3}$ and $V 4$ took place during the four weeks following $V 1$, while $V 5, V 6, V 7, V 8, V 9$ and $V 10$ were made over the subsequent period of 6 months. BP was measured by the general practitioner in the office using a conventional calibrated mercury sphygmomanometer, provided with a standard-sized cuff $(12 \times 35 \mathrm{~cm})$. 


\section{Analysis}

Results were reported as systolic and diastolic means, standard errors of the mean and standard deviations of all patients at $V 1, V_{2}, \ldots . V 10$. Differences between the means of two successive readings $(V 1$ versus $V 2$, $V 2$ versus $V 3$, ..) were analyzed using Student's paired t-test. The average systolic blood pressure (SBP) and DBP of V6, V7, V8, V9 and V10 (10 BP measurements) over the last five months of the study were regarded as the 'conceptual average $B P^{\prime}$ (CABP). This reference value is a compromise between the mean value of 8 measurements in four visits used by Armitage et al. ${ }^{11}$ and the mean of 12 measurements in six visits used by Watson et al. ${ }^{12}$

A linear regression analysis was done to provide a basis for the CABP. Therefore, the slope of $V 6, V 7, V 8, V 9$ and $V 10$ was calculated for each participating subject. A Student's paired t-test between the mean slope and zero was used to assess the stabillty of the CABP. Mean differences and SDDs standard deviations of the differences (SDD) were calculated between CABP and $V 2 N 3, C A B P$ and $V 2 N 3 N 4, C A B P$ and $V 3 N 4 / 5$ and $C A B P$ and V2N3N4N5.13

Finally, the percentages of misclassification were calculated on the basis of one (V2), two (V2N3), three (V2N3N4) and four $(V 2 N 3 N 4 N 5)$ duplicate remeasurements. Misclassification was defined as $5 \mathrm{mmHg}$ or more difference between the initial remeasurements and the CABP, using the same definition as Watson et al. ${ }^{12}$

\subsection{Results}

One hundred and fourteen patients were included in the study of which 15 dropped out (10 men and 5 women; mean systolic $V 1164.7 \mathrm{mmHg}$, mean diastolic V1 $105.1 \mathrm{mmHg}$ ): six patients started antihypertensive drug treatment, one patient had a heart attack and the other eight withdrew for personal, non-medical reasons.

Ninety-nine patients completed the study, 49 men and 50 women (mean age 48 years). Mean systolic $V 1$ was $161.0 \mathrm{mmHg}$ and mean diastolic $V 1101.5$ $\mathrm{mmHg}$. The dropouts had higher average BPS when entering the study. Systolic and diastolic means, standard errors (s.e.) and standard deviations are given in Table 1. There were significant differences between systolic $V 1$ and $V 2 / 8.5$ $m \mathrm{mHg} . P<0.001)$ and between diastolic $V 1$ and $V 2(4.5 \mathrm{mmHg} . P<0.001)$. Differences between the mean values of the other pairs of successive measurements (V2 ws. V3, V3 vs. V4, ..) were not statistically significant (Table 1).

The mean slope of systolic CABP was -0.04 (s.e. of mean 0.4 ), that of diastolic CABP - -0.11 (s.e. of mean 0.2). Student's paired t-test showed no significant differences between these mean slopes and zero $(P=0.9$ resp $P=0.6)$. This indicates that our conceptual average BP can be regarded as a stable reference value. There is a minor decline in mean differences and SDD5 (SBP 
Table 1. Means, standard errors and standard deviations, of systolic and diastolic blood pressures at $V 1, V 2, \ldots V 10$, and $P$-values of the paired sample $t$-tests of successive readings.

\begin{tabular}{|c|c|c|c|c|}
\hline & inean & standard error & standard deviation & p-value \\
\hline \multicolumn{5}{|c|}{ Systolic blood pressure } \\
\hline$V_{1}$ & 161.0 & 1.8 & 17.4 & $0.00(\mathrm{~V} / \mathrm{ws} . \mathrm{V} 2)$ \\
\hline V2 & 152.5 & 1.7 & 16.8 & $0.91(\mathrm{~V} 2$ vs. V3) \\
\hline$\sqrt{3}$ & 152.8 & 1.8 & 17.3 & 0.24 (V3 ws. V4) \\
\hline V4 & 151.2 & 1.6 & 15.6 & 0.81 (V4 vs. V5) \\
\hline V5 & 151.5 & 1.7 & 16.4 & 0.40 (V5 vs. V6) \\
\hline V6 & 150.4 & 1.7 & 16.7 & 0.05 (V6 vs. V7) \\
\hline V7 & 153.4 & 1.9 & 18.9 & $0.21(\mathrm{~V} 7 \mathrm{vs} . \mathrm{v} 8)$ \\
\hline V8 & 150.8 & 1.7 & 16.9 & 0.88 (V8 vs. v9) \\
\hline v9 & 151.7 & 1.8 & 17.3 & 0.64 (v9 v5.V10) \\
\hline V10 & 150.7 & 1.8 & 17.0 & \\
\hline \multicolumn{5}{|c|}{ Diastolic blood pressure } \\
\hline V1 & 101,4 & 0.6 & 5.6 & $0.00(v 1$ ws. V2) \\
\hline V/2 & 96.9 & 1.0 & 9.6 & $0.06(\mathrm{~V} 2 \mathrm{vs} . \mathrm{v} 3)$ \\
\hline V3 & 95.5 & 0.9 & 8.9 & $0.79(\sqrt{ } 3$ ws. $/ 4)$ \\
\hline V4 & 95.2 & 0.9 & 8.8 & $0.31\left(v / 4 w_{5} .15\right)$ \\
\hline V5 & 94.3 & 1.0 & 9.7 & 0.55 (V5 ws. V6) \\
\hline$v_{6}$ & 94.9 & 0.9 & 8.9 & 0.98 (V6 ws. V7) \\
\hline V7 & 94.8 & 1.0 & 9.7 & 0.89 (V7 ws. V8) \\
\hline V8 & 94.8 & 0.9 & 9.0 & 0.55 (V8 ws. V9) \\
\hline 19 & 94.4 & 0.9 & 9.3 & 0.95 (V9 vs.V10) \\
\hline V10 & 93.7 & 1.1 & 9.9 & \\
\hline
\end{tabular}

$V x$ : average of duplicate measurements on visit $x$.

from 11.4-9.6 mmHg, DBP from 6.4-5.3 $\mathrm{mmHg}$ ) of systolic and diastolic CABP vs V2N3, CABP vs V2N3N4, CABP and V3N4N5 and CABP vs V2N3N4N5 (Table 2). The percentages of misclassification after one, two, three and four duplicate remeasurements show a decline. However, after four remeasurements there is still misclassification in 56\% (SBP) and 38\% (DBP) of the subjects (Table 3). 
Table 2. Mean differences (mean), standard errors (SE) and standard deviations of mean differences (SDO) between conceptual average blood pressure and $V / 3, V 2 / 3 / 4, V 3 / 4 / 5$ and v2/3/45

\begin{tabular}{|c|c|c|c|c|c|c|}
\hline & \multicolumn{3}{|c|}{ Systolic blood pressure } & \multicolumn{3}{|c|}{ Diastolic blood pressure } \\
\hline & meam & SE & SDO & mean & SE & SDD \\
\hline$\sqrt{2 / 3}$ & -4.1 & 1.1 & 11.4 & -1.6 & 0.6 & 6.4 \\
\hline$\sqrt{2} / 3 / 4$ & -0.6 & 1.0 & 10.3 & -1.2 & 0.6 & 5.8 \\
\hline$\sqrt{3 / 4 / 5}$ & -0.3 & 1.0 & 10.0 & -0.3 & 0.6 & 5.5 \\
\hline $4 / 2 / 3 / 4 / 5$ & -0.5 & 1.0 & 9.6 & -0.8 & 0.5 & 5.3 \\
\hline
\end{tabular}

Table 3. Proportion of misclassification, defined as a difference of $5 \mathrm{mmHg}$ or more between $C A B P$ and $V 2 / 3, V 2 / 3 / 4, V 2 / 3 / 4 / 5)$ after two, three and four duplicate remeasurements.

Systolic blood pressure

Diastiolic blood pressure

\begin{tabular}{llllll}
\hline$v 2 / 3$ & $v / 3 / 4$ & $v 2 / 3 / 4 / 5$ & $v / 3$ & $v 2 / 3 / 4$ & $v 2 / 3 / 4 / 5$ \\
0.67 & 0.55 & 0.56 & 0.40 & 0.39 & 0.38 \\
\hline
\end{tabular}

\subsection{Discussion}

A linear regression analysis proved that the 'conceptual average $\mathrm{BP}^{\prime}$ which was chosen as the reference value was stable. It was found that there was a statistically significant fall in systolic and diastolic BP between the first and second measurements. This can be regarded as a consequence of the selection process. It reflects the well known 'regression towards the mean' phenomenon, in addition to the causes mentioned in the introductory part. Using analyses of variance, Dunne ${ }^{1 / 4}$ also found highly significant differences between the first and second occasion, in contrast to the minor differences between subsequent occasions. After the second measurement there was a slight fall in mean DBP, without significant differences between two successive readings. After the second measurement, mean SBP seemed to oscillate around a mean value. The decline of the standard deviations of the differences between two, three and four duplicate remeasurements on the one hand and the reference value CABP on the other was found to be strikingly small. Excluding not only the first, but also the second measurement resulted in the best, though still disappointing agreement with the CABP. After four duplicate remeasurements, there was misclassification in $56 \%$ (systolic) and $38 \%$ of all patients. These results are even slightly worse than those found by Watson et 
al. ${ }^{12}$ in their study ( $50 \%$ misclassification after four remeasurements for SBP. $32 \%$ for DBP). This minor difference may have been caused by different inclusion criteria and different numbers of patients included. As we did not have more measurements, we could not calculate the misclassification after five and six remeasurements. Applying Cronbach's generalizability theory, Llabre ${ }^{15}$ and co-workers demonstrated that for normotensive subjects at least six readings of systolic and 6 to 10 readings of DBP are needed.

We conclude that the numbers of two, three or four BP measurements recommended by international guidelines for diagnosing mild hypertension are too low. ${ }^{1,2}$ Even after four duplicate remeasurements a considerable amount of misclassification remains.

\section{References}

1. Anonymous. The Fifth Report of the Joint National Committee on Detection, Evaluation, and Treatment of High Blood Pressure. Arch lintern Med 1993; 153: 154-83.

2. Sever $P, B e e v e r s ~ G, B u i p i t t C$, et al. Management guidelines in essential hypertension: report of the second working party of the Birtish Hypertension Society. BMJ 1993: 306: 983-7.

3. Van Binsbergen JJ, Grundmeyer HGJM, Van den Hoogen IPH, et al. NHG-Standaard Hypertensie. Huisarts Wet 1991; 34: 389-95.

4. Report of the Management Committee of the Australian Therapeutic Trial in Mild Hypertension. Untreated mild hypertension. Lancet 1982; i: 185-91.

5. Medical Research Council Working Party. MRC trial of treatment of mild hypertension: principal results. BMJ 1985; 291: 97-104.

6. Alam GM, Smirk JH. Casual and basal blood pressures. II. In British and Egyptian men. Br Heart 1 1943; 5: 152-5

7. Alam GM, Smirk FH. Casual and basal blood pressures. II. In essential hypertension. Br Heart J 1943; 5: 156-60.

8. Gatman M, Amin M, Smirk FH. Casual and basal blood pressures. llll, in renal hypertension. Br Heart I 1943; $5: 169-2$.

9. Smirk FH. Casual and basal blood pressures. IV. Their relationship to the supplemental pressure with a not on statistical implications. Br Heart J 1944; 6: 174-82.

10. British Hypertension Society recommendations on blood pressure measurement, in: O'Brien E, O'Malley K (eds): Handbook of Hypertension. Volume 14: Blood pressure measurement. Elsevier, Amsterdam, 1991, pp 387-95.

11. Armitage $P$, Fox W, Rose GA, et al. The variability of measurements of casual blood pressure. II. Survey experience. Clin Sci 1966; 30: 337-44

12. Watson RDS, Lumb $R$, Young MA, et all. Variation in cuff blood pressure in untreated outpatients with mild hypertension: implications for initiating antihypertensive treatment. I Hypertens 1987; 5: 207-11.

13. Bland $\mathrm{MM}$, Altman DG. Statistical methods for assessing agreement between two methods of dinical measurement. Lancet 1986; i: 307-10. 


\section{CHATER 5}

14. Dunne JF. Variation of blood-pressure in untreated hypertensive outpatients. Lancet 1969; i: $391-2$.

15. Llabre MM, fronson GH, Spitzer SB, et al. How many blood pressure measurements are enough? An application of generalizability theory to the study of blood pressure reliability. Psychophysiology 1988; 25: 97-106. 


\section{Correspondence 2}

EDITOR, Frank W Beltman and colleagues report the predictive value of seated and ambulatory blood pressure after withdrawal of antihypertensive drugs.' Their conclusion that seated blood pressure (defined as two measurements obtained during one visit) is a worse predictor of blood pressure in the long term than ambulatory blood pressure (multiple measurements obtained during one day) is not surprising.

The limited accuracy of blood pressure measured during a single visit was described almost 20 years ago. ${ }^{2}$ For that reason, the British Hypertension Society recommends that seated blood pressure should be measured at least twice at each visit on up to four separate occasions before drug treatment is started (or restarted). ${ }^{3}$ Given the large within person variability in blood pressure, the potential 'white coat effect', random measurement errors, and regression to the mean, the Dutch College of General Practitioners even proposes that at least five duplicate repeat measurements should be obtained in patients with initial diastolic pressure between 95 and $105 \mathrm{mmHg}{ }^{4}$ Comparison of the ambulatory blood pressure with a series of measurements of blood pressure obtained in the clinic, as recommended by international guidelines, would show better predictive values of seated blood pressure measured by a doctor. The equivalence of multiple measurements of blood pressure in the clinic and ambulatory measurement as a predictor of left ventricular mass has been described by Fagard et al, ${ }^{5}$ I hope that in a future double blind, placebo controlled study (as called for by Beltman and colleagues) the internationally recommended number of clinic measurements would be used. For the time being, the use of ambulatory monitoring should be restricted to scientific research.

\section{References}

1. Beltman FW, Heesen WF, Kok RHJ, et al. Predictive value of ambulatory blood pressure shortly after withdrawal of antihypertensive drugs in primary care patient5. BMJ 1996; 313: 404-6.

2. Rosner P, Hennekens $C H$, Kass EH, et al. Age-specific correlation analysis of longitudinal blood pressure data. Am J Epidemiol 1977; 106: 306-13.

3. Sever $P$, Beevers $G$, Bulpitt $C$, et al. Management guidelines in essential hypertension: report of the second working party of the British Hypertension Society. BMJ 1993; 306: 983 7.

4. Van Binsbergen 1$)$, Grundmeyer HGIM, Van den Hoogen JPH, et al. NHG-5tandaard hypertensie. Huisarts Wet 1991; 34: 389-95.

5. Fagard R, Staessen J, Thijs L, et al. Multiple standardized clinic blood pressures may predict left ventricular mass as well as ambulatory monitoring. Am J Hypertens 1995; 8: 533-40.

Published as: Brueren M. Ambulatory monitoring of blood pressure should be restricted to scientific research. BMJ 1996; $313: 1334$ (23 November). 
I was pleased to see your letter in the ENI of 23 November. This unit produced a Shot report which cane to the same conchsion as yourself. This has recewed some critich within sotiand. where a number of fundholdng pratices have purchased their own ambuaton 8 p neters from savings prescibing or referrats.

Isusper that part of the problem nay be that technology is seductive; and impresses. doctors and patiente.

Yours sincerely

Dr N Wagh, Sottish Heath Purchasing Information Centre, Aberdeen Scotland (published with permission from the athor). 
Is a series of blood pressure measurements by the general practitioner or the patient a reliable alternative to ambulatory blood pressure measure measurement?

Published as: Brueren MM, Van Limpt P, Schouten HJA, De Leeuw PW, Van Ree $M W$. is a series of blood pressure measurements by the general practitioner or the patient a reliable alternative to ambulatory blood pressure measurement? A study in general practice with reference to short-term and long-term between-visit variability. Am / Hypertens 1997; 10: $879-85$. 


\section{Summary}

We studied the reproducibility of a series of blood pressure measurements by GP (general practitioner) and patient in comparison with that of ABPM (ambulatory blood pressure measurement), with reference to short-term and long-term between-visit variability using a prospective, comparative, diagnostic study. The study group was 88 potentially hypertensive primary care patients (initial systolic blood pressure [SBP] between 160 and $200 \mathrm{mmHg}$ or with diastolic blood pressure [DBP] between 95 and $115 \mathrm{mmHg}$ ). ABPMs were measured on 2 separate days (at a 6 months interval). Two series of measurements by the doctor (at 1 to 6 months intervals), and the patient (at a 1 week interval) were measured. Mean differences and standard deviations of mean differences (SDD) between two successive series of measurements, and between two ABPMs were computed. The Wilcoxon signed-ranks test was used to compare these standard deviations. Mean initial office-blood pressures were 161 (SBP) and 102 (DBP) mmHg. Long-term between-visit variability (measurements by GP) was larger than short-term between-visit variability: SDDs were 16 vs $11 \mathrm{mmHg}(\mathrm{SBP})$, and $10 \mathrm{vs} 8 \mathrm{mmHg}$ (DBP). The differences in average SBP and DBP between successive ABPMs and between successive series of office measurements by GP and home measurements by patient were not statistically significant. Mean differences between two series of measurements by GP and patient, and between two ABPMs, were $0 \pm 1 \mathrm{mmHg}$. SDDs between successive $A B P M s$ and series of measurements by GP and patient ranged from 8 to $11 \mathrm{mmHg}$ (SBP), and were $6 \mathrm{mmHg}$ (DBP). No statistically significant differences were found between the SDDs of the studied measurement procedures (SBP and DBP). In our study the reproducibility of ambulatory blood pressure measurement was not found to be better than that of a series of four duplicate measurements by GP or patient. Long-term ( 6 months interval) between-visit variability was larger than short-term ( 1 week interval) betweenvisit variability.

keywords: blood pressure determination, general practice, essential hypertension, ambulatory blood pressure measurement.

\section{Introduction}

Like most biological phenomena, blood pressure changes from moment to moment, which we assume to be the most important source of measurement variation. A single blood pressure measurement may not represent the 'true' blood pressure. As a matter of fact, true blood pressure is a rather theoretical concept, which could probably best be defined as 'the average of an infinite number of blood pressure measurements'.

Generally speaking, differences between the true value and the measured value are caused by random and systematic errors. Minor sources of measure- 
ment variation are the design and construction of the instrument and the observer (the person conducting the measurement). ${ }^{1}$ The results of a measurement are affected in an unpredictable way by random errors, which are greater when variable phenomenona are being measured. Augmenting the number of measurements is the best way to minimize random errors: a large number of measurements reduces the average of all random errors to approximately zero.

Systematic errors may be stable or variable. Stable systematic errors influence all measurements in an identical way. Systematic errors may be caused by the measurement instrument, by the observer or by the entity or person being measured.

The variations in blood pressure measured on different occasions may be very large. ${ }^{2}$ For this reason, a number of measurements on different occasions are required to estimate the true blood pressure. Roughly, general practice uses three procedures to measure blood pressure: conventional office-measurements by the general practitioner (GP) in the office, home measurements by the patient and a relatively new technique, ambulatory blood pressure measurement (ABPM). Several studies have claimed the reproducibility of office blood pressure to be worse than that of ambulatory blood pressure ${ }^{3,4,5,6}$

This study compared the reproducibility of ABPM and a series of blood pressure measurements by the GP and by the patient at home in a group of subjects who were included on the basis of an initially elevated blood pressure.

\section{Methods}

Seventeen general practitioners participated in the study. All physicians were given instructions on adequate techniques of blood pressure measurement. ${ }^{7}$ Phase $V$ of the Korotkoff sounds was recorded as the level of diastolic pressure. Patients were selected on the basis of an initially elevated blood pressure.

Inclusion criteria were: the mean of two systolic values (measured in one visit) between 160 and $200 \mathrm{mmHg}$ or mean of two diastolic measurements between 95 and $115 \mathrm{mmHg}$ and age between 20 and 75 years.

Exclusion criteria were known hypertension or antihypertensive treatment in the year preceding the study, secondary hypertension, congestive heart failure or unstable angina, and pregnancy.

After inclusion by the GP, all patients underwent three procedures of blood pressure measurement:

1. GP: Duplicate office measurements by the general practitioner in weeks 2 , 3, 4 and month 2 (series 1) and months 3, 4, 5 and 6 (series 2). In month 7 there was another visit (last duplicate measurement) at the GPs office. The number of four duplicate measurements corresponds with the guidelines of the British Hypertension Society. ${ }^{8}$ 
2. HP (home by patient): Measurements at home by the patient ( 2 measurements in the morning and 2 in the evening on 2 working days) in week 2 (series 1) and in week 3 (series 2 ).

3. ABPM on one working day in week 4 (ABPM 1) and month 7 (ABPM 2). Table 1 presents the time schedule of the study.

Table 1. Time-schedule of measurements by general practitioner (GP), home-measurements by patient (HP) and ambulatory blood pressure measurements (ABPM).

\begin{tabular}{|c|c|c|c|c|c|c|c|c|c|c|}
\hline & wetk 1 & week 2 & wees 3 & week 4 & mointh 2 & month 3 & monith 4 & month is & month 6 & month? \\
\hline GP & 1,2 & 3,4 & 5,6 & 78 & 9,10 & 11.12 & 13,14 & 15,16 & 17.18 & 19,20 \\
\hline \multirow[t]{2}{*}{$H$} & & $M 1,2,5,6$ & $9,10,13,14$ & & & & & & & \\
\hline & & $E 3.47,8$ & $11,12: 15,16$ & & & & & & & \\
\hline ABPAM & & & & 1 & & & & & & 2 \\
\hline
\end{tabular}

M: morning; $E$ : evening; incl: inclusion; 1,2, 3,4 etc: 2 measurements an one occasion.

Conventional blood pressures were measured by the GP using a calibrated mercury sphygmomanometer, provided with a standard-sized cuff $(12 \times 35$ $\mathrm{cm}$ ). Home measurements (HP) took place using a BOSO-Oscillomat. The BOSO-Oscillomat (Bosch LTD, Jungingen, Germany) is a battery-powered, cuff-oscillometric measuring device that is triggered by the patient. It is driven by an automatic internal pump. The apparatus has been extensively validated and has been described as an acceptable alternative to a conventional sphygmomanometer. 9,10,11 The patients were asked to record the 16 blood pressure readings in a special diary. In addition, the blood pressure measurements were stored in the memory of the apparatus (maximum capacity 14 readings). The stored readings were printed out at the GPs office and compared with the readings written by the patient. ABPM was measured using a SpaceLabs 90207 (SpaceLabs Inc. Hillsboro, OR) automatic cuff-oscillometric monitor. The monitor was given a $B$ rating for both systolic and diastolic blood pressure according to the criteria of the British Hypertension Society protocol and satisfied the criteria of the Association for the Advancement of Medical Instrumentation. ${ }^{12}$ Blood pressures were recorded automatically every 15 minutes from 6:00 AM till 10:00 PM, and every 30 minutes during the night.

\section{Data analysis}

The averages of the first series of measurements (eight measurements on four occasions) by the GP and by the patient were compared with the averages of the second series of measurements. The daytime values of the ABPM were used, and the first hour was discarded. Nighttime pressure was not used, as we compared the reproducibility of ABPM with that of (daytime) measure- 
ments by GP and patient. Twenty successful ambulatory daytime readings were regarded as a minimum for anallysis. ${ }^{13}$ Using Student's paired $t$-test, the first series of measurements in each procedure was compared with the second series of measurements (SBP/systolic blood pressure and DBP/diastolic blood pressure). Means of individual differences (between first and second series of measurements) and standard deviations of the differences (SDD) were computed. We expect $95 \%$ of the individual differences to lie between mean -2 SDD and mean +2SDD. ${ }^{14,15}$ since SDD squared is a mean of squared differences, the Wilcoxon signed ranks test was used to compare SDDs, in order to compare the reproducibility of the measurement procedures.

We studied short-term and long-term between-visit variability by comparing the SDDs of the second and third GP measurements (1 week interval) with SDDs of the fourth and last GP measurement ( 6 months interval).

The study was approved by the Ethic Review Committee of the University Hospital. All subjects gave written informed consent for participation in the study.

\section{Results}

The study cohort included 122 patients. Thirty-four patients dropped out: eight were excluded because they started drug treatment during the study, one patient had a heart attack, one patient refused a second ABPM (the first measurement had been too painfull), 17 patients did not meet the criterion of the minimum number of measurements and seven withdrew for personal reasons. The population characteristics of the dropouts were: 18 men and 16 women, mean initial SBP $167 \mathrm{mmHg}$ (SD 19), mean initial DBP 102 (SD 7). mean age 52 years. Eighty-eight patients completed the study: 45 men and 43 women, with a mean age of 47 years (SD 12); mean initial SBP was $161 \mathrm{mmHg}$ (SD 17), mean initial DBP 102 (SD 5). The relatively small standard deviation of DBP indicates that most patients were included on the basis of DBP.

The first 14 readings stored in the apparatus and printed at the GPS office were compared with the 16 readings registered in the diary. There appeared to be no differences.

The differences in mean SBP and DBP between series 1 and 2 by GP and patient and between ABPM 1 and 2 were not statistically significant (Table 2).

As measures of short-term and long-term between-visit variability, SDDs were computed as follows: SBP 11 (1 week interval) versus $16 \mathrm{mmHg}$ ( 6 months interval), DBP 8 (1 week interval) vs $10 \mathrm{mmHg}$ ( 6 months interval).

The differences of first and second ABPM and series 1 and 2 by GP and patient were plotted against the averages. Plots of first and second ABPM are given in Figure $1 a$ for $S B P$ and Figure $1 b$ for DBP, and plots of first and second series of home measurements are presented in Figures $2 a(S B P)$ and $2 b$ (DBP). Mean differences between two series of measurements by GP and patient, and 
between two ABPMs were $0 \pm 1 \mathrm{mmHg}$. Standard deviations of mean differences between successive measurement procedures ranged from 8 to 11 $m m H g$ (SBP) and were $6 \mathrm{mmHg}$ (DBP). None of the procedures was found to have a test-retest-reliability that was significantly better than that of another (Table 3).

Table 2. Average systolic (SBP) and diastolic (DBP) blood pressures and standard deviations of measurements by the GP. home measurements and ambulatory measurements. Student's paired i-fest was used to detect statistically significant differences between series 1 and 2 (measurements by GP and patient at home) and ABPM 1 and 2. No statistically significant differences were found between series 1 and 2, resp. ABPM 1 and Z (SBP and DBP).

\begin{tabular}{|c|c|c|c|c|}
\hline & $\begin{array}{l}\text { series } 1 / \text { first } \\
\operatorname{sBP}(5 D)\end{array}$ & $\begin{array}{l}\text { series } 2 / \text { second } \\
\text { SBP(SD) }\end{array}$ & $\begin{array}{l}\text { series 1/first } \\
\mathrm{DBP}(\mathrm{SD})\end{array}$ & $\begin{array}{l}\text { series } 2 / \text { second } \\
\mathrm{DBP}(\mathrm{SD})\end{array}$ \\
\hline measurements by GP & $152(14)$ & $151(15)$ & $96(8)$ & $95(8)$ \\
\hline home measurement & $140(114)$ & $140(14)$ & $90(9)$ & $89(10)$ \\
\hline $\mathrm{ABPM}$ & $143(12)$ & $142(12)$ & $91(8)$ & $92(9)$ \\
\hline
\end{tabular}

Table 3. Standard deviations of differences (SDD) between successive series of measurements by GP and patient, and between successive ABPMs, and significance according to the Wilcoxon matched-pairs signed-ranks test.

\begin{tabular}{llllll}
\hline & \multicolumn{2}{l}{ SBP } & & \multicolumn{2}{l}{ DBP } \\
\cline { 2 - 3 } \cline { 5 - 6 } $\begin{array}{l}\text { Measurement } \\
\text { procedure }\end{array}$ & SDD & $P$ & & SDD & $P$ \\
\hline 1. by GP & 9 & NS (1 vs 2) & 6 & NS (1 vs 2) \\
2. home & 8 & NS (2 vs 3) & 6 & NS (2 vs 3) \\
3. ambulatory & 11 & NS (1 ws 3) & 6 & NS (1 vs 3) \\
\hline
\end{tabular}

series $=$ average of 8 measurements ( 4 occasions); $N S=$ not statistically significant $(P=.05)$. 

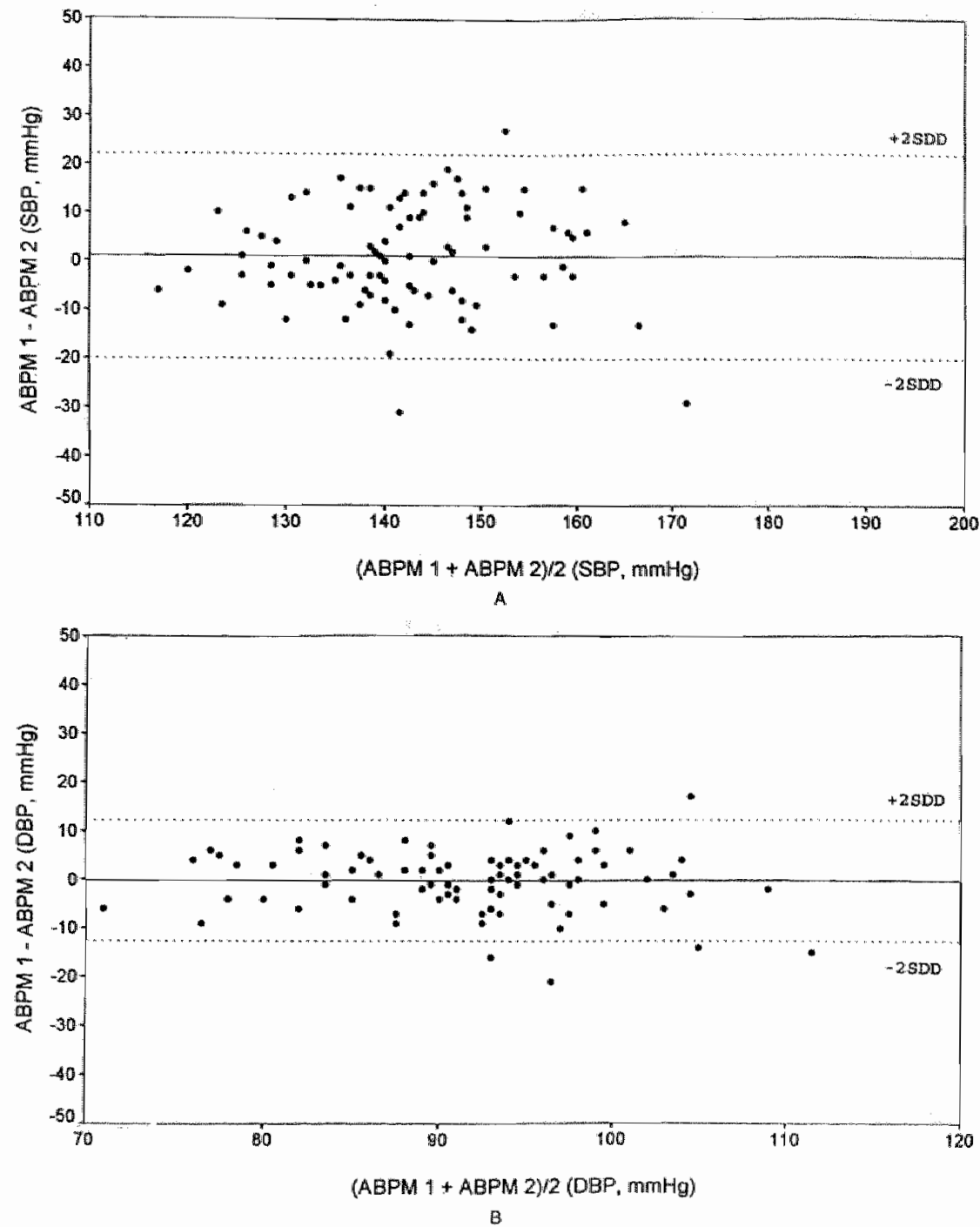

Figure 1a. Differences (SBP) between first and second ambulatory blood pressures (y-axis) versus their means $(x-a x i s)$. All values are in $\mathrm{mmHg}$. The mean difference(- - - , and the $95 \%$ limits of agreement (- . - ) are indicated. b. Differences (DBP) between first and second ambulatory biood pressures $(x-a x i s)$ versus their means $(y-a x i s)$. All values are in $m m H i g$. Mean difference $(-\longrightarrow)$, and $95 \%$ limits of agreement ( . . - ) are indicated. 


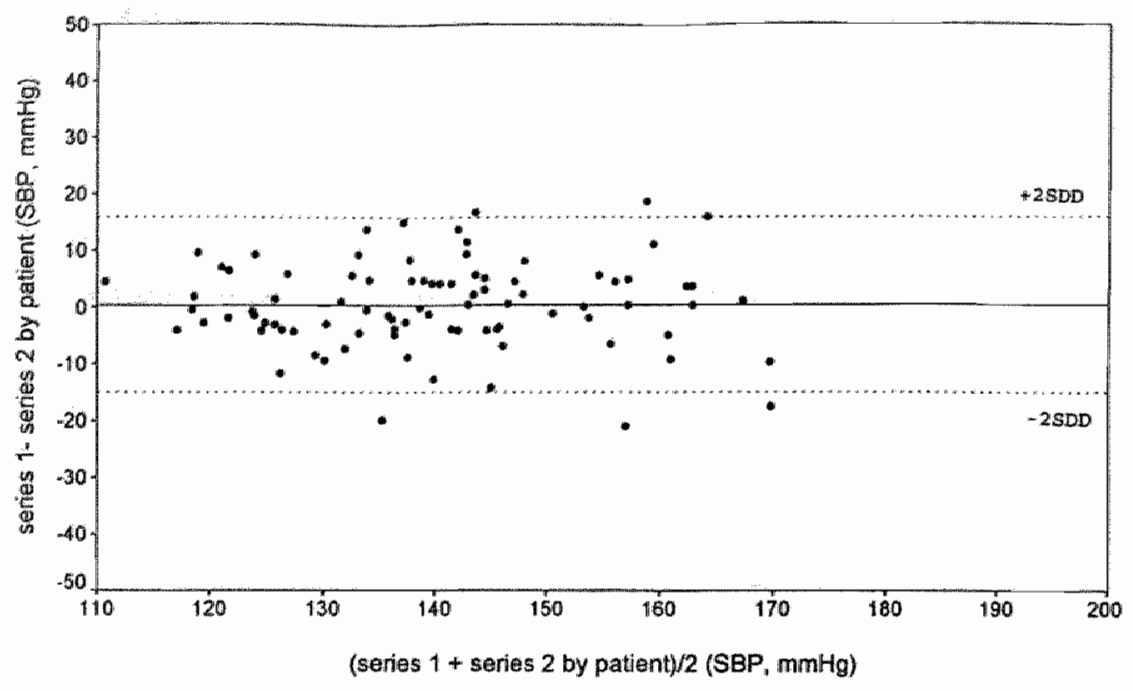

A

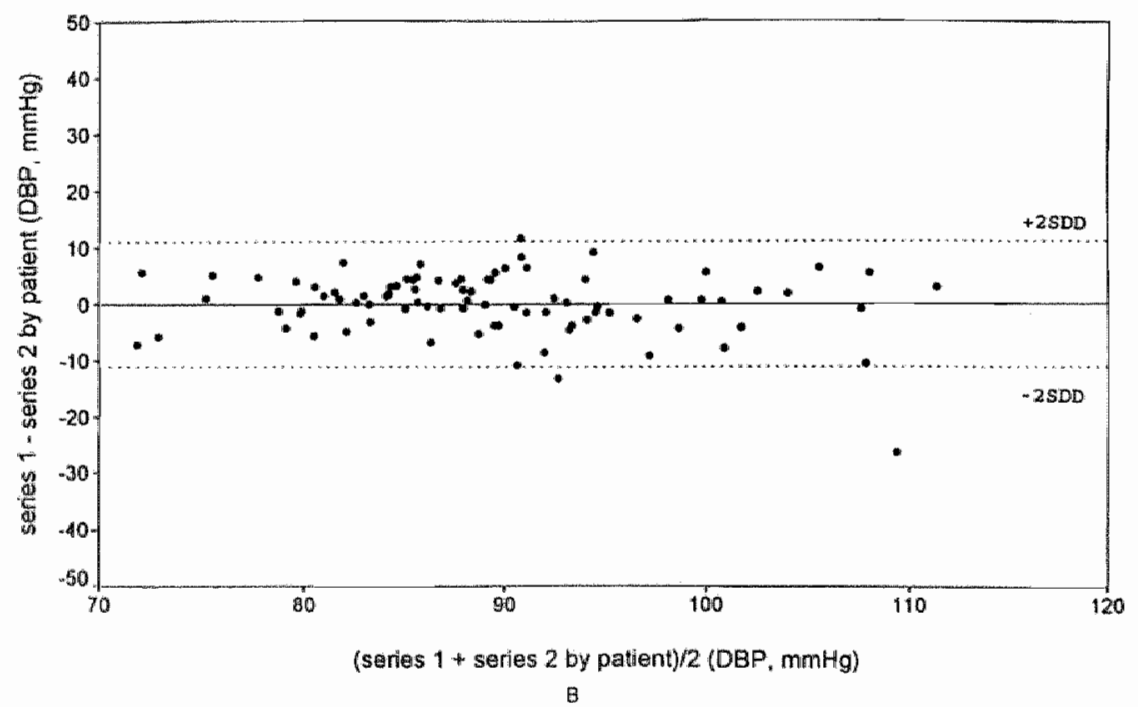

Figure 2a. Differences ( 58 P) between first and second series of blood pressure measurements by the patient ( $y$-axis) versus their means ( $x$-axis). All values are in $\mathrm{mmHg}$. Mean difference (and $95 \%$ limits of agreement (-..--) are indicated. b. Differences (DBP) between first and second series of blood pressure measurements by the patient ( $y$-axis) versus their means ( $x$-axis). All values are in mmH Mean difference (___ $)$, and $95 \%$ limits of agreement ( . . . - ) are indicated. 


\section{Discussion}

The most important purpose of the study was to determine the reproducibility of ambulatory blood pressure measurement compared with that of a series of measurements by the general practitioner and the patient. To gain insight in short-term and long-term between-visit variability, we also presented these data. We hypothesized that the worse reproducibility of clinical measurements found in other studies was not caused by shorter or longer intervals between measurements but by insufficient numbers of measurements. Moreover, measuring with exactly equal intervals in general practice is almost impossible.

The large drop out rate $(28 \%)$ is mainly caused by the long duration of this nonintervention study ( 7 months). The patients who dropped out were older and had higher initial SBPs. We did not analyze this group any further and do not know whether the drop out rate is related to age or initial SBP.

The long-term ( 6 months interval) between-visit variability was larger than the short-term variability ( 1 week interval). This may indicate that correctly diagnosing mild hypertension not only requires a sufficient number of measurements but also sufficient time (months rather than weeks).

The reproducibility of ambulatory blood pressure measurement was not found to be better than that of a series of measurements by the GP or the patient. The differences between conventional measurements (procedure 1) and measurements in a nonclinical environment (procedures 2 and 3 ) were in accordance with those found in other studies. ${ }^{16-20}$

Unlike previous studies, we investigated the reproducibility of a series of eight measurements on four occasions by the GP and the patient, which is a better approach to international guidelines on blood pressure measurement and diagnosing hypertension. ${ }^{8,21,22}$ We tried to gain insight into the reproducibility of the various procedures by computing the standard deviations of successive differences, which, for our purpose, we considered as more adequate than (Pearson's) correlation coefficients. ${ }^{14,15}$ The reproducibility of the three procedures was found to be comparable. No statistically significant differences were found.

Conway and Coats found SDDs of $12.3 \mathrm{mmHg}$ for the diastolic conventional measurement and of $6.3 \mathrm{mmHg}$ for the diastolic ambulatory measurement (1 month interval), but they compared single conventional measurements with multiple ambulatory measurements. ${ }^{13}$ Mansoor and associates ${ }^{23}$ found a comparable reproducibility of ambulatory blood pressure monitoring and noted that the less reproducible office blood pressure they had found might be caused by the small numbers of office measurements. Our results support this assumption. A study in a general population (average office blood pressure $123 / 74 \mathrm{mmHg}$ ) showed that a single ambulatory blood pressure monitoring was unlikely to improve blood pressure determination. ${ }^{24}$ 
A recent review demonstrates that multiple standardized clinical blood pressure measurements may predict left ventricular mass as well as ambulatory monitoring. ${ }^{25}$ A comparison between one single or only a few blood pressure measurements by doctor or patient and multiple ambulatory measurements seems to be unfair. Our results give an answer to the question raised by Bottini and co-workers for 'any methodology of indirect blood pressure measurements that may reduce the variability and improve repeatability of casual office blood pressure. ${ }^{26}$

In this study blood pressure measurements by the 17 general practitioners were treated as one procedure, and intra/interobserver variations were left out of consideration. The reproducibility of a series of blood pressure measurements by an individual physician may be even better than that found in our study. In all patients standard types of cuff's were used in all instruments. Because the focus of our study was on reproducibility and not on validity of measurements procedures, the main results were not biased. We conclude that the reproducibility of a series of measurements by GP or patient equals that of ambulatory blood pressure monitoring.

In accordance with the guidelines of the British Hypertension Society, for diagnosing mild hypertension we recommend four duplicate readings by the doctor on separate days. ${ }^{8}$ Four duplicate readings on two days by the patient at home appeared to be a reliable, and probably less expensive, alternative. The use of ABPM should be restricted to scientific research, to answer specific clinical questions, and to solve certain practical problems. Ambulatory measurement is useful in the reduction of required numbers of patients in randomized clinical trials with blood pressure as main dependent variable, in detecting circadian patterns, in studying factors influencing the blood pressure level (with the help of a diary), and in tracing white coat hypertension in patients unable to perform self-measurements.

\section{References}

1. Fletcher $\mathrm{RH}$, Fletcher $\mathrm{SW}$, Wagner $\mathbb{E H}$. Clinical epidemiology: the essentias. Williams \& Wilkins, Baltimore, 1988, pp 23-35.

2. Armitage $P$, Rose $G$. The variability of measurements of casual blood pressure. I. A laboratory study. Clin Sci 1966; 30: 325-35.

3. Drayer J, Weber MA. Reproducibility of blood pressure values in normotensive subjects. Clin Exp Hypertens 1985; 7: 417-22.

4. James $G D$. Pickering $T G$, Yee $L S_{x}$ et al. The reproducibility of average ambulatory, home, and clinical pressures. Hypertension 1988; 11: 545-9.

5. Fotherby MD. Potter JF. Reproducibility of ambulatory and clinic blood pressure measurements in elderly hypertensive subject5. J Hypertens 1993; 11: 573-9.

6. Thijs $\mathrm{L}$, Amery $\mathrm{A}_{1}$ Clement $\mathrm{D}$, et al. Ambulatory blood pressure monitoring in elderiy patients with isolated systolic hypertension. J Hypertens 1992; 10:693-9. 
7. British Hypertension Society recommendations on blood pressure measurement, in: $\mathrm{O}^{\mathrm{B}} \mathrm{Brien}$ E, O'Malley K (eds): Handbook of Hypertension, Volume 14: Blood pressure measurement. Elsevier. Amsterdam, 1991, pp 387-95.

8. Sever $P$, Beevers $G$, Bulpitt $C$, et al. Management guidelinies in essential hypertension: feport: of the second working party of the British Hypertension Society. BMI 1993; 306: 983-7.

9. Imai $Y$, Abe K, Sasaki $S$, et al. Clinical evaluation of semiautomatic and automatic devices for home blood pressure measurement: comparison between cuff-oscillometric and microphone methods. J Hypertens 1989; 7: $983-90$.

10. Johnston DW, Shah D. An evaluation of the Takeda UA-751 automatic sphygmomanometer. Behav Res Ther 1989; $27: 203-4$.

11. Jamieson MJ, Webster 1, Witte $K_{v}$ et al. An evaluation of the A\&D UA-751 semi-automated cuff-oscillometric sphygmomanometer. J Hypertens \%990; 8: 377-81.

12. O'Brien E, Mee F, Atkins N, et al. Accuracy of the SpaceLabs 90207 determined by the British Hypertension Society Protocol. J Hypertens 1991: 9: 573-4.

13. Conway J, Coats A. Value of ambulatory blood pressure monitoring in clinical pharmacology. J Hypertens 1989; 7 (suppl 3): 529-532.

14. Bland JM, Altman DG. Statistical methods for assessing agreement between two methods of dinical measurement. Lancet 1986; 说: 307-10.

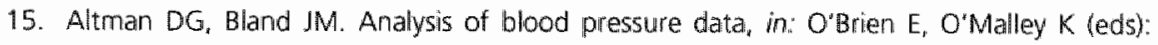
Handbook of Hypertension. Volume 14: Blood pressure measurement. Elsevier, Amsterdam, 1991. pp $287-314$.

16. Jacot des Combes $B_{*}$ Porchet $M$, Waeber $G_{n}$ et al. Ambulatory blood pressure recordings. Reproducibility and unpredictability. Hypertension 1984; 6: 110-5.

17. Kieinert $H D$, Harshfield $G A$, Pickering $T G_{n}$ et al. What is the value of home blood pressure measurernent in patients with mild hypertension? Hypertension 1984; 6: 574-8.

18. Kenny RA, Brennan $M$, O'Malley $K$, et al. Blood pressure measurements in borderline hypertension. J Hypertens 1987; 5 (suppl 5): \$483-\$485.

19. Flapan AD, Stewart SE, MCDougal F, et al. is self home-monitoring of blood pressure as good as 24-hour ambulatory monitoring? I Hypertens 1987; 5 (suppl 5): \$491-5493.

20. Marolf A., Hany S, Băttig B, et al. Comparison of casual, ambulatory and self-determined blood pressure measurement. Nephron 1987; 47 (suppl 1): 142-145.

21. Guidelines Sub-Committee of the WHO/SH Hypertension Liaison Committee. 1993 Guidelines for the management of mild hypertension: memorandum from a World Health Organisation/nternational Society of Hypertension meeting. J Hypertens 1993: 11: 905-18.

22. Joint National Committee on Detection, Evaluation and Treatment of High Blood Pressure. The fifth report of the loint National Committee on Detection, Evaluation and Treatment of High Blood Pressure. Arch Intern Med 1993; 153: 154-83.

23. Mansoor GA, MCCabe EJ, White WB. Long-term reproducibility of ambulatory blood pressure. JHHypertens 1994; 12: 703-8.

24. Pearce KA, Grimm RH, Rao S, et al. Population-derived comparisons of ambulatory and office blood pressures. Arch Intern Med 1992; 15:2: 750-6.

25. Fagard R, Staessen J. Thijs $\mathrm{L}$, et al. Multiple standardized dinic blood pressures may predict left wentricular mass as well as ambulatory monitoring. Am J Hypertens 1995; 8: 533-40.

26. Bottini $P B$, Carr AA, Rhoades RB, et al. Variability of indirect methods used to determine blood pressure. Arch Intern Med 1992; 152: 139-144. 



\section{CHAPTER 7}

Feasibility, acceptance and side effects of ambulatory blood pressure measurement and blood pressure self-measurement 


\section{Abstract}

Objective. The aim of this study was to investigate the feasibility, acceptance and side effects of blood pressure self-measurement and ambulatory blood pressure measurement.

Methods. The subjects were 122 borderline hypertensive outpatients who participated in a comparative, prospective study. They performed self-measurements of blood pressure according to a schedule and underwent two ambulatory blood pressure measurements. They reported the discomfort associated with the measurement procedures in a diary/questionnaire.

Results. One hundred fourteen patients performed the self-measurements according to the schedule. A small number of patients reported problems associated to the measurement procedure. Almost 30\% of the patients who underwent ambulatory measurement reported moderate to severe discomfort during daily activities. In 40 to $45 \%$ of the patients the ambulatory blood pressure monitoring interfered seriously with sleep.

Conclusions. Both measurement procedures are feasible in borderline hypertensive primary care patients, but ambulatory blood pressure measurement led to more problems, especially during the night. Self-measurement is a less expensive, more easily available alternative to ambulatory measurement. The precise role of blood pressure self-measurement in clinical practice should be settled in future research.

Keywords: feasibility, acceptance, blood pressure self-measurement, ambulatory blood pressure monitoring, general practice

\subsection{Introduction}

There is increasing evidence that the diagnosis and management of hypertensive patients can be improved by blood pressure self-measurement and ambulatory blood pressure measurement. ${ }^{1}$ The feasibility of both measurement procedures has been described as good. 2.3 Ambulatory blood pressure measurement is tolerated quite well during the day, though it interferes with sleep in a considerable percentage of patients. ${ }^{3}$ Side effects of ambulatory measurement are relatively rare: case studies have reported the Rumpel-Leede sign, upper arm thrombophlebitis, and local dermatitis from the cuff, $4-6$

The aim of the present study was to investigate the acceptance and side effects of both blood pressure measurement procedures in borderline hypertensive primary care patients.

The data were derived from a prospective, comparative study on diagnosing hypertension in general practice. 


\subsection{Methods}

The background and design of the study as a whole have been described in a recently published article.?

The practice nurses trained the participating patients in performing selfmeasurements, storing the readings, and using a special diary. The patients were asked to record 16 blood pressure readings in the diary, according to the schedule of 2 measurements in the morning and 2 in the evening on 4 working-days during 2 weeks. In addition to this, they noted special events and activities of that day, and problems or side effects associated with the measurements. Measurements by the patient were made using a BOSO-Oscillomat. The BOSO-Oscillomat (Bosch LTD, Jungingen, Germany) is a battery-powered cuff-oscillometric measuring device which is triggered by the patient. It is driven by an automatic internal pump. The apparatus has been validated and has been described as an acceptable alternative to the conventional sphygmomanometer. $^{7-9}$

All patients underwent ambulatory blood pressure measurements in week 4 and month 7. Ambulatory blood pressure was measured using a Spacelabs 90207 (Spacelabs Inc., Hillsboro, Oregon, USA) automatic cuff-oscillometric monitor. This monitor received a $B$ rating for both systolic and diastolic blood pressure according to the criteria of the British Hypertension Society protocol and satisfies the criteria of the Association for the Advancement of Medical Instrumentation. ${ }^{10,11}$ Blood pressures were recorded automatically every 15 minutes from $6.00 \mathrm{am}$ till $10.00 \mathrm{pm}$, and every 30 minutes during the night. At the end of the measurement they were asked to fill in a questionnaire and to record the amount of discomfort they had experienced from the ambulatory blood pressure measurement. For this purpose we used two scales: one for the day (none, mild, moderate or severe discomfort) and the other for the night (slept normally, woke up 1 or 2 times, woke up often, hardly slept).

The stored data from self-measurements were printed out at the GP's office. All printed and written data were compared by the investigator.

A list was made of those problems experienced by the patients which were associated with self-measurement and ambulatory monitoring.

\subsection{Results}

One hundred and twenty two patients were included in the study, 63 men and 59 women, with a mean age of 49 years. Mean initial systolic blood pressure was $162 \mathrm{mmHg}$, while mean initial diastolic blood pressure was 102 $\mathrm{mmHg}$. 


\section{Blood pressure self-measurement}

Eight patients did not perform self-measurements: three because of reasons related to the apparatus (one patient did not understand the instructions, one patient experienced too much pain from cuff inflations above $200 \mathrm{mmHg}$, one patient became highly irritated by the apparatus), and five patients because of other reasons (dropped out during the first or second week of the study).

One hundred and fourteen patients performed the self-measurements according to the schedule. The following problems were reported. Two patients had to return to the GP's office because their apparatus for blood pressure self-measurement was out of order; they were given a new apparatus. Two patients recorded pain during inflation of the cuff, while one patient had a feeling of anesthesia in the measured arm, which disappeared soon after completion of the measurement, and one patient registered tingling sensations in the arm and hand during the measurement. There was one patient who felt that the self-measurement values were too low. The averaged self-measurement values of this patient were found to be $127 / 71 \mathrm{mmHg}$, whereas the average daytime ambulatory blood pressure was $123 / 74 \mathrm{mmHg} .107$ patients did not report any problems associated with the measurement procedure.

\section{Ambulatory blood pressure measurement}

Eight patients did not undergo ambulatory blood pressure measurement at all; four of them because they started drug treatment in week 1,2 or 3 of the study, and one because of serious co-morbidity. Two patients gave up further participation in the study. In one patient, ambulatory blood pressure measurement was found to be impossible, probably due to severe arrhythmia.

Twelve patients underwent only one ambulatory blood pressure measurement: 4 started drug treatment before month 7 of the study, one patient had a heart attack, two patients were too anxious to continue their participation, one patient refused a second ambulatory measurement because the first was too painful, and four patients refused further participation because they felt the study was too long.

One hundred and two patients underwent two ambulatory blood pressure measurements, the first in week 4 and the second in month 7 . Considering all 216 ambulatory blood pressure measurements eleven patients reported technical problems: slip of the tube (7), slipping down of the cuff (2), low battery power (1) and technical defect of unknown origin (1). Two patients complained about the noise during the inflation of the cuff, and one patient complained of a swollen hand, maybe as part of the Rumpel-Leede sign.

The discomfort associated with the ambulatory monitoring is presented in figures 1 (in the daytime) and figure 2 (during sleep). Ambulatory measurements were tolerated quite well during the day by most patients, though $10 \%$ of patients reported severe discomfort and almost 20\% noted moderate discomfort during their daily activities. ABPM interfered with sleep in a considerable percentage (40-45) of patients. 


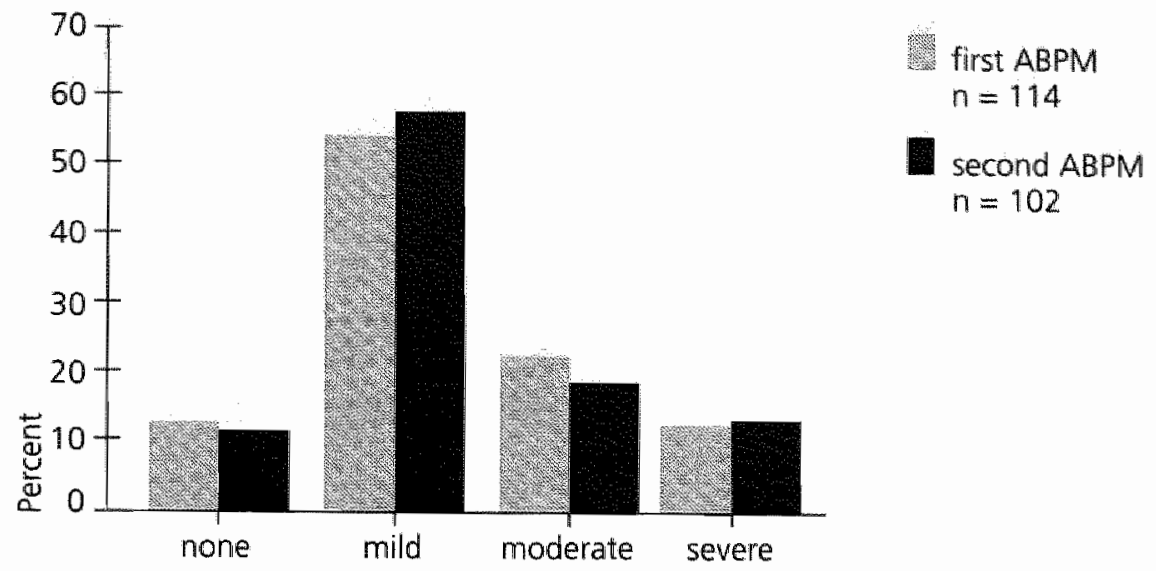

Figure 1. Discomfort associated with ambulatory blood pressure measurement in the daytime.

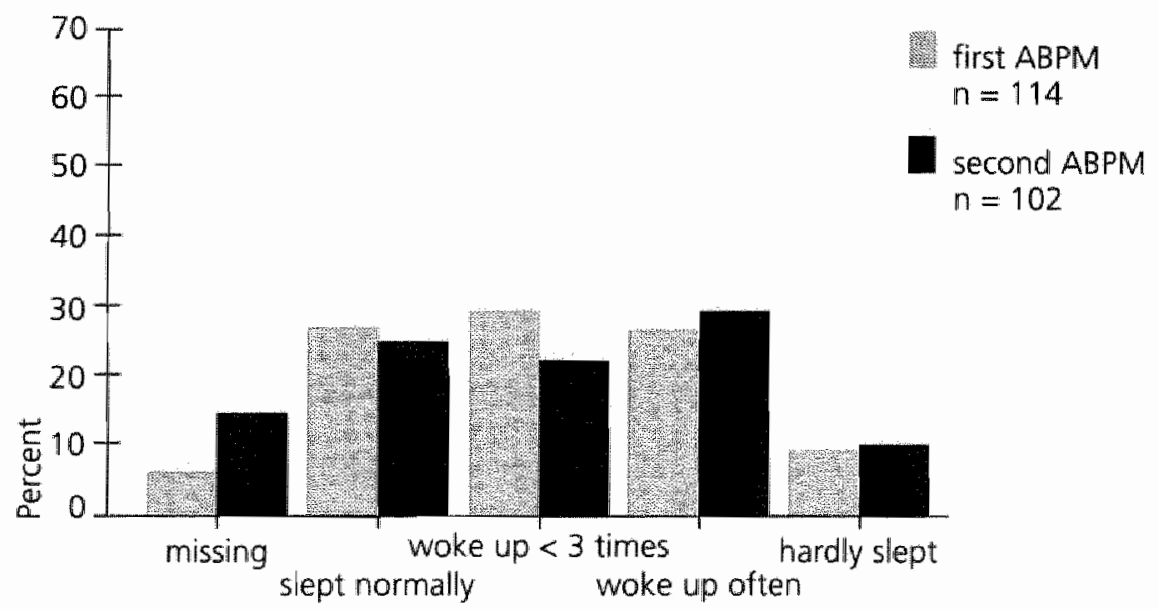

Figure 2. Discomfort associated with ambulatory blood pressure measurement during sleep. missing: patients putted off the apparatus in the evening because they experienced too much discomfort. 
The discomfort reported after the first and second ambulatory measurement was quite good reproducible: $42 \%$ (in the day) and $45 \%$ (during the night) of the patients reported the same amount of discomfort on both ambulatory measurements. In most other patients the amount of discomfort reported in relation with both measurements differed only slightly.

\subsection{Discussion}

We studied the feasibility, acceptance and side effects of ambulatory blood pressure measurement and blood pressure self-measurement. The data were derived from a prospective, comparative study in borderline hypertensive primary care patients.

Both measuring procedures were tolerated quite well during daytime, although ambulatory measurement led to more problems being reported. The acceptance of ambulatory monitoring during sleep was only moderate. Approximately $25 \%$ of the patients did not experience any discomfort during sleep, whereas $40-45 \%$ reported that the measurement interfered seriously with sleep. These results are in accordance with those from earlier studies, 2,3,13,14 Using polygraphic sleep recordings, Degaute et al, found only modest sleep disturbances during ambulatory monitoring at night. ${ }^{15}$ However, their study was done among healthy, normotensive volunteers, and the relatively good sleep recorded in this study might be associated with lower, less painful, inflations of the cuff.

We conclude that, provided clear and detailed instructions are given, self-measurement and daytime ambulatory blood pressure measurement are practicable in general practice. Both procedures were tolerated fairly well by borderline hypertensive patients. Problems may occur in patients with arrhythmias, and ambulatory monitoring may interfere with car driving or manual labor. Since the reproducibility of a series of self-measurements is comparable to that of ambulatory blood pressure measurement, we recommend self-measurements as a reliable, less expensive and more easily available alternative to ambulatory measurement. ${ }^{7}$ Our data support the suggestion of Aylett that self-measurement is a practical alternative to ambulatory measurement. ${ }^{16}$ In order to improve the diagnosis and management of hypertensive patients self-measured blood pressure should be integrated with office measurements. ${ }^{17}$ The precise role of self-measurement of blood pressure in general and clinical practice (in addition to or instead of office measurement) should be settled by future research. 


\section{References}

1. Appel $\sqcup$. Stason WB. Ambulatory blood pressure monitoring and blood pressure self-measurement in the diagnosis and management of hypertension. Ann intern Med 1993: 118: $867-82$

2. Welin $L$, Swärdsudd $K_{*}$ Tibblin $G$. Home blood pressure measurements. Feasibility and results compared to office measurements. Acta Med Scand 1982; 211:275-9.

3. Van de Weijgert EHMM, Braun JJ. Experience with noninvasive ambulatory 24-hour blood pressure recording in a community hospital. Neth J Med 1992; 40: 175.82

4. White WB. The Rumpel-Leede sign associated with a noninvasive ambullatory blood pressure monitor, JAMA 1985; 253: 1724.

5. Creevy PC, Burris JF, Mroczek WJ. Phlebitis associated with noninwasive 24-hour ambulatory blood pressure monitor. JAMA 1985; 254: 2411.

6. Burris JF, Brinkley RR, Riggs MC, et al. Adverse events assaciated with 24-hour ambulatory sphygmomanometry. JAMA 1988; 260: 2508-9.

7. Brueren MM, Van Limpt P. Schouten HIA, et all. Is a series of blood pressure measurements by the general practitioner or the patient a reliable alternative to ambulatory blood pressure measurement? Am J Hypertens 1997; 10: 879-85.

8. Imai $Y$, Abe $K$, Sasaki S, et al. Clinical evaluation of semiautomatic and automatic devices for home blood pressure measurement: comparison between cuff-oscillometric and microphone methods. J Hypertens 1989; 7: 983-90.

9. Johnston DW, Shah D. An evaluation of the Takeda UA-751 semiautomated cuff-oscillometric sphygmomanometer. J Hypertens 1990; 8:377-81

10. Jamieson MJ. Webster J, Witte $K$, et al. An evaluation of the A\&D UA-75.1 semi-automated cuff-oscil ometric sphygmomanometer. J Hypertens 1990; $8: 377-81$.

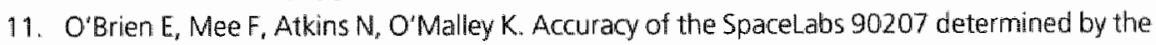
British Hypertension Society Protocol. J Hypertens 1991; 9(suppl 5): \$24-531.

12. Association for the Advancement of Medical instrumentation. American National Standard for Electronic or Automated Sphygmomanometers. Washington DC, AAMI. 1987.

13. Coope G, Coope I" Roberts D. Ambulatory blood pressure measurement [letter]. Bif J Gen Pract 1993; 44:83

14. Beltman FW, Heesen WF, Smit AJ, et al. Acceptance and side effects of ambulatory blood pressure monitoring: evaluation of a new technology. I Hum Hypertens 1996; 10(suppl 3): \$39-542.

15. Degaute JP, Van de Borne $P$. Kerkhofs $M$, et al. Does non-invasive ambulatory bload pressure monitoring disturb sleep? J Hypertens 1992; 10:879-85.

16. Aylett MJ. Ambulatory or self blood pressure measurement? Improving the diagnosis of hypertension. Fam Pract 1994; 11: 197-200.

17. Sheps SG, Canzanello VI. Current role of automated ambulatory blood pressure and self-measured blood pressure determinations in clinical practice. Mayo Clin Proc 1994; 69: $1000-5$. 

CHAPTER 8

A series of self-measurements by the patient is a reliable alternative to ambulatory blood pressure measurement 


\section{Abstract}

Objectives. To compare blood pressures measured by doctor practice nurse and patient with ambulatory blood pressures.

Design. Comparative, prospective study over 7 months.

Setting. Primary care.

Subjects. 99 primany care patients with initially elevated blood pressures.

interventions none.

Main outcome measures. Mean differences and standard deviations of these differences between series of blood pressures measured by genera practitioner (6 and 12 measurements), practice nurse ( 6 measurements) and patient ( 8 measurements) on the one hand and ambulatory blood pressure on the other, and the influence of age and sex on these differences.

Results. Mean differences (systolic blood pressure) between different measurement procedures and ambullatory measurement ranged from $+10 \mathrm{mmHg}$ (doctor) to $-1 \mathrm{~mm}-\mathrm{lg}$ (patient), and (diastolic) from $+4 \mathrm{mmHg}$ (doctor) to -2 mmHg (patient). Standard deviations of mean differences ranged from 12 $\mathrm{mmHg}$ (doctor/systolic) to $10 \mathrm{mmHg}$ (patient/systolic), and from $8 \mathrm{mmHg}$ (doctor/diastolic) to $7 \mathrm{mmHg}$ (patient/diastolic). White coat effect was more pronounced in older women ( $>40$ years) than in older men, both in measurements by the doctor as in measurements by the nurse.

Conclusions. Self-measurements by the patient appear to be a reliable alternative to ambulatory blood pressure measurement. In diagnosing and managing mild hypertension, we recommend the use of a validated selfmeasuring device for home-measurement. The white caat effect was more pronounced in older women ( $>40$ years) than in older men.

\subsection{Introduction}

Considering the diagnosis of hypertension, the physician is forced to take into account the large within-person variability of blood pressure, the phenomenon of regression to the mean and the risk of diagnosing 'white coat hypertension". Accurate diagnosis of hypertension is especially difficult in mild or moderate essential hypertensives, since the closer a subject's pressure is to the cutoff point, the larger the likelihood of classification in the wrong category. "In many countries, detection, diagnosis and treatment of mild to moderate hypertension are considered to be the work of general practitioners. Accurately diagnosing hypertension and withholding or starting drug treatment are important tasks in general practice.

Ambulatory blood pressure monitoring is becoming a popular method for blood pressure determination and diagnosing hypertension. ${ }^{2}$ Nevertheless, there is still discussion about widespread introduction of ambulatory monitors in general and dinical practice. . $^{3-8}$ 
Ambulatory blood pressure monitoring has many advantages over clinica! measurements. Measurements take place at the patient's work or home, so that the "white coat effect" is avoided. The large number of measurements reduces the confidence interval of the estimated mean, thereby reducing the risk of misclassification. The influence of interpersonal observer factors is eliminated, and due to the large number of measurements, there is regression to the mean to a lesser degree. Besides, the correlation with target organ damage and cardiovascular mortality is better than that in clinical measurement. $^{9}$

However, its use is relatively expensive, and the reproducibility appears to be only moderate. ${ }^{10-13}$ In addition to this, the procedure may interfere with daily activities and sleep.

Apart from ambulatory measurement, the literature mentions two alternatives to clinical measurements by the doctor. The first is home measurements by the patient, as an easily available and cheap method. The second is measurements by the practice nurse. It has been shown that these methods reduce the white coat effect relative to doctor's measurements. ${ }^{14-15}$

The aim of the present study is to compare series of blood pressure measurements by the general practitioner and the practice nurse, and series of home measurements by the patient with daytime ambulatory blood pressure as a reference measurement. In addition, we studied the influence of age and sex on differences between measurements by the general practitioner and the practice nurse on the one hand and ambulatory blood pressure measurement on the other (white coat effect).

\subsection{Methods}

Seventeen general practitioners and their practice nurses participated in the study. All of them were given instructions, on adequate techniques of blood pressure measurement. ${ }^{16}$ Phase $V$ of the Korotkoff sounds was recorded as the level of diastolic pressure.

\section{Patients}

Patients were selected on the basis of an initially elevated office blood pressure.

Inclusion criteria were:

- mean of two systolic values (measured in one visit) between 160 and 200 $\mathrm{mmHg}$ and/or mean of two diastolic measurements between 95 and 195 $\mathrm{mmHg}$

- age between 20 and 75 .

Exclusion criteria were:

- known hypertension or antihypertensive treatment in the year preceding the study 
- suspicion of secondary hypertension

- congestive heart failure or unstable angina

- pregnancy.

\section{Measurement procedures}

After inclusion by the general practitioner, all patients underwent four procedures of blood pressure measurement:

Procedure 1 consisted of duplicate measurements in one visit by the general practitioner in his office in weeks 2,3 and 4 and months $2,3,4,5,6$ and 7.

Procedure 2 consisted of duplicate measurements in one visit (on other days than the measurements by the general practitioner) by the practice nurse in weeks 2,3 and 4 .

Procedure 3 consisted of home-measurements by the patient (two measurements in the morning and two in the evening on two working-days) in week 2 and week 3.

Procedure 4 consisted of ambulatory blood pressure measurements on one working day in week 4 and month 7 .

In week 4 and month 7 of the study the weight $(\mathrm{kg})$ of all patients was measured.

\section{Measurement instruments}

The general practitioner and the practice nurse measured blood pressures with a calibrated mercury sphygmomanometer, provided with a standard-sized cuff $(12 \times 35 \mathrm{~cm})$. Home-measurements by the patient were made using a BOSO-Oscillomat. The BOSO-Oscillomat (Bosch LTD, Jungingen, Germany) is a battery-powered cuff-oscillometric measuring device which is triggered by the patient. It is driven by an automatic internal pump. The apparatus has been extensively validated and has been described as an acceptable alternative to a conventional sphygmomanometer. ${ }^{17-19}$ The patients were asked to record 16 blood pressure readings according to the schedule as mentioned earlier. In addition the blood pressure values were stored in the memory of the apparatus (maximum capacity 14 readings). The stored readings were printed out at the GPS office and compared with the values written down by the patient. Ambulatory blood pressure was measured using a Spacelabs 90207 (SpaceLabs Inc., Hillsboro, Oregon, USA) automatic cuff-oscillometric monitor. This monitor received a $\mathrm{B}$ rating for both systolic and diastolic blood pressure according to the criteria of the British Hypertension Society protocol and satisfies the criteria of the Association for the Advancernent of Medical Instrumentation. ${ }^{20-21}$ Blood pressures were recorded automatically every 15 minutes from 6.00 AM till 10.00 PM and every 30 minutes during the night.

\section{Data analysis}

In the present study, the reference value was defined as the average of two ambulatory blood pressure measurements ( 6 months interval). Only daytime 
values were used, as we compared the ambulatory blood pressure values with daytime measurements by the general practitioner, the practice nurse and the patient. We used the average of two ambulatory measurements, since the reproducibility of a single ambulatory measurement is only moderate, but can be augmented by increasing the number of measurements. ${ }^{22}$ An average of two or more ambulatory blood pressure measurements on different days has been advocated in a study by Reeves et al. ${ }^{23}$ In general, the accuracy of the estimated mean blood pressure will increase (reducing the $95 \%$ confidence interval of the estimated mean) by augmenting the number of measurements. ${ }^{24}$

Means, standard errors of mean and standard deviations of systolic and diastolic measurements by the general practitioner, practice nurse, patient and ambulatory monitoring were computed. Mean differences and standard deviations of procedures 1,2 and 3 versus the reference measurement were computed. ${ }^{25}$ Since the incidence of white coat hypertension might be increased if observer and observed are of different gender, a multiple linear regression analysis was used to investigate how the differences between ambulatory measurement on the one hand and general practitioner's and practice nurse's measurements on the other hand depend on age and sex. ${ }^{26}$ In case of significant interaction $(p<0,05)$ between age and sex, the term age*sex was included in the model. All participating practice nurses were female, whereas nearly all (94\%) general practitioner's measurements were made by male physicians.

All data were computerized and analyzed using SPSS (Statistical Package Social Sciences).

The study was approved by the local ethics committee. All subjects gave written informed consent for participation in the study.

\subsection{Results}

One hundred and twenty two patients were included in the study. Twenty three dropped out: seven were excluded because they started hypotensive drug treatment during the study, one patient had a heart attack, one patient refused a second ambulatory measurement (the first measurement had been too painful), six patients had missing values, and eight withdrew for personal reasons (heart attack of husband, study too long, nervousness because of home measurements, lack of understanding of the instructions).

Characteristics of the dropouts were as follows: 14 men and 9 women, mean initial systolic blood pressure $167 \mathrm{mmHg}$ (SD 20), mean initial diastolic blood pressure $104 \mathrm{mmHg}$ (SD 6), mean age 51 years (range 28 to 71).

Ninety nine patients completed the study: 49 men and 50 women, with a mean age of 48 years (range 21 to 72 ); mean initial systolic blood pressure was $161 \mathrm{mmHg}$ (SD 18), mean initial diastolic blood pressure $102 \mathrm{mmHg}$ (SD 6). 
There was no weight reduction in the course of the study $(75.6 \mathrm{vs} 75.3 \mathrm{~kg}$, $P=0.3)$.

The relatively small standard deviation of initial diastolic pressures, compared to the standard deviation of initial systolic pressures, suggests that most patients were included on the basis of diastolic blood pressure.

The reference value was defined as the mean of two daytime ambulatory measurements (mean number of measurements 84 , standard deviation 11 , minimum 44 , and maximum 101).

Table 1 shows the means, standard errors of meanis and standard deviations of doctor-measured blood pressures (three respectively six visits), nursemeasured blood pressures (mean of three visits), home measurements (four duplicate measurements), and means of two ambulatory measurements. On average, nurse-measured systolic and diastolic blood pressures were lower than blood pressures measured by the doctors, but both procedures revealed higher blood pressures than ambulatory and home measurements. Mean differences and standard deviations of differences between procedures 1, 2 and 3 on the one hand and ambulatory measurement on the other are given in table 2. Mean differences between the reference value and the various procedures ranged from +10 (doctor/systolic) to $-1 \mathrm{mmHg}$ (home/systolic), and from +4 (doctor/diastolic) to $-2 \mathrm{mmHg}$ (home/diastolic). Procedure 3 (four duplicate measurements by patient) showed the smallest standard deviations of differences: $10 \mathrm{mmHg}$ (systclic blood pressure) and $7 \mathrm{mmHg}$ (diastolic biood pressure).

A white coat effect, defined as a difference of $10 \mathrm{mmHg}$ or more between diastolic office measurements and ambulatory blood pressure, was found in $27 \%$ of participating subjects ( 14 men and 13 women) when blood pressures were measured by the doctor, and in $18 \%$ of subjects ( 7 men and 11 women) when measured by the practice nurse.

Figure 1a presents the differences between systolic doctor measured and ambulatory blood pressures (male and female patients) against age. There is significant influence of age $(p=0.001)$ and sex $(p=0.001)$ : the white coat effect is more pronounced in older women ( $>40$ years) than in older men ( $>40$ years). Diastolic differences between doctor-measured and ambulatory blood pressure plotted against age reveal significant interaction of age and sex $(P=0.03)$ : regression lines for men and women have different slopes. There is a slight white coat effect in older women, which is absent in older men (figure 1b). In figure 2 a differences between systolic nurse-measured and ambulatory blood pressures are plotted against age. There is statistically significant interaction, indicating that the regression lines have different slopes $(P=0.049)$. Figure $2 \mathrm{~b}$ shows the differences between diastolic nurse measured and ambulatory blood pressure plotted against age. There is significant influence of age ( $P=0.005)$, whereas the influence of sex was not significant $(P=0.06)$. Measurements by the practice nurse reveal a white coat effect in older women, which is less pronounced in older men. 
Table 1. systolic and diastolic means and standard deviations of ambulatory blood pressure measurement (ABPM), 3 duplicate $(n=6)$ and 6 duplicate $(n=12)$ measurements by general practitioner (GP), 3 duplicate $(n=6)$ measurements by practice nurse (PN), and 4 duplicate $(n=8)$ measurements by patient.

\begin{tabular}{lll}
\hline & mean & Std Dev \\
\hline ABPM systolic & 142 & 11 \\
measurements by GP systolic $(n=6)$ & 152 & 15 \\
measurements by GP systolic $(n=12)$ & 152 & 14 \\
measurements by PN systolic $(n=6)$ & 148 & 14 \\
home measurements systolic $(n=8)$ & 141 & 14 \\
ABPM diastolic & 91 & \\
measurements by GP diastolic $(n=6)$ & 95 & 8 \\
measurements by GP diastolic $(n=12)$ & 95 & 7 \\
measurements by PN diastolic $(n=6)$ & 95 & 9 \\
home measurements diastolic $(n=8)$ & 89 & 9 \\
\hline
\end{tabular}

$n=$ number of measurements

Table 2. mean differences and standard deviations of differences (SDD) between ambulatory blood pressure (ABPM) on the one hand, and 3 duplicate measurements by the general practitioner $(G P, n=6), 6$ duplicate measurements by the general practitioner (GP, $n=12), 3$ duplicate measurements by the practice nurse $(P N, n=6)$, and 4 duplicate measurements by the patient at home $\left(H P_{n} n=8\right)$.

\begin{tabular}{lcc}
\hline & mean & SDD \\
\hline GP $(n=6)-A B P M(S B P)$ & 10 & 12 \\
GP $(n=12)-A B P M(S B P)$ & 10 & 11 \\
$P N(n=6)-A B P M(S B P)$ & 6 & 11 \\
$H P(n=8)-A B P M(S B P)$ & -1 & 10 \\
GP $(n=6)-A B P M(D B P)$ & 4 & \\
GP $(n=12)-A B P M(D B P)$ & 4 & 7 \\
$P N(n=6)-A B P M(D B P)$ & 4 & 8 \\
$H P(n=8)-A B P M(D B P)$ & -2 & 7 \\
\hline
\end{tabular}

n: number of blood pressure measurements; SBP: systolic blood pressure; DBP: diastolic blood pressure. 


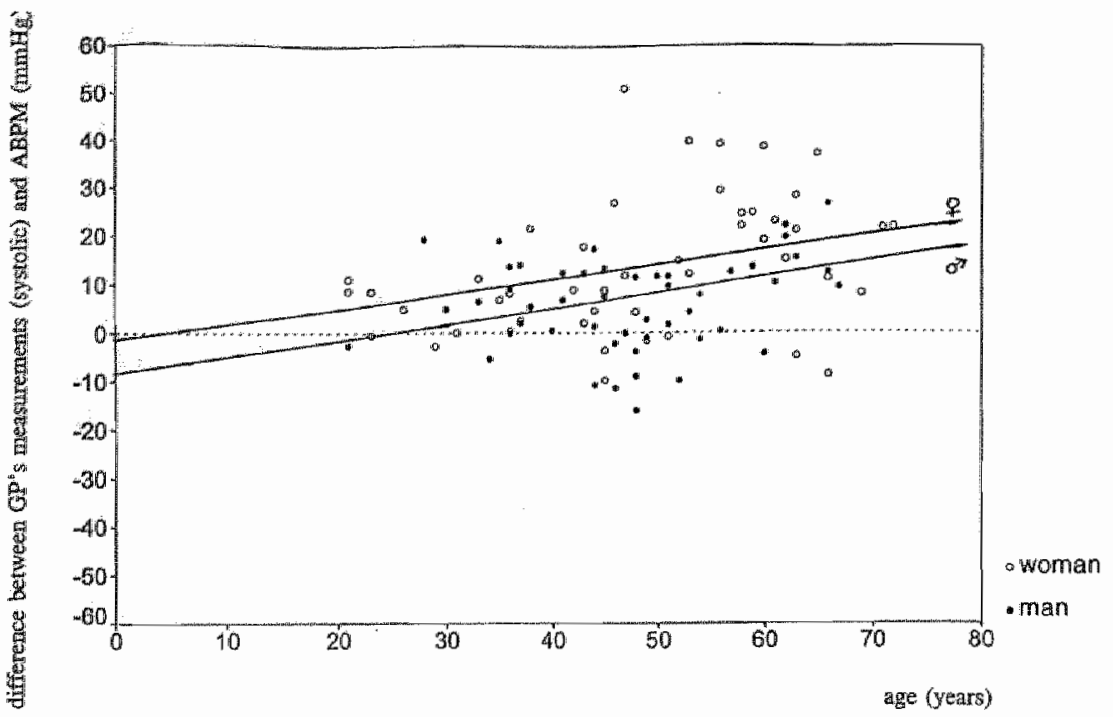

Figure 1a. differences (systolic) between the means of 3 duplicate measurements by GP (general practitioner) and ABPM (ambulatory measurement, $y$-axis) against age ( $x$-axis). Regression equation: $y=-8.59+7.495 E X+0.31 \mathrm{AGE}$ (man $=0$, woman $=1$, in years).

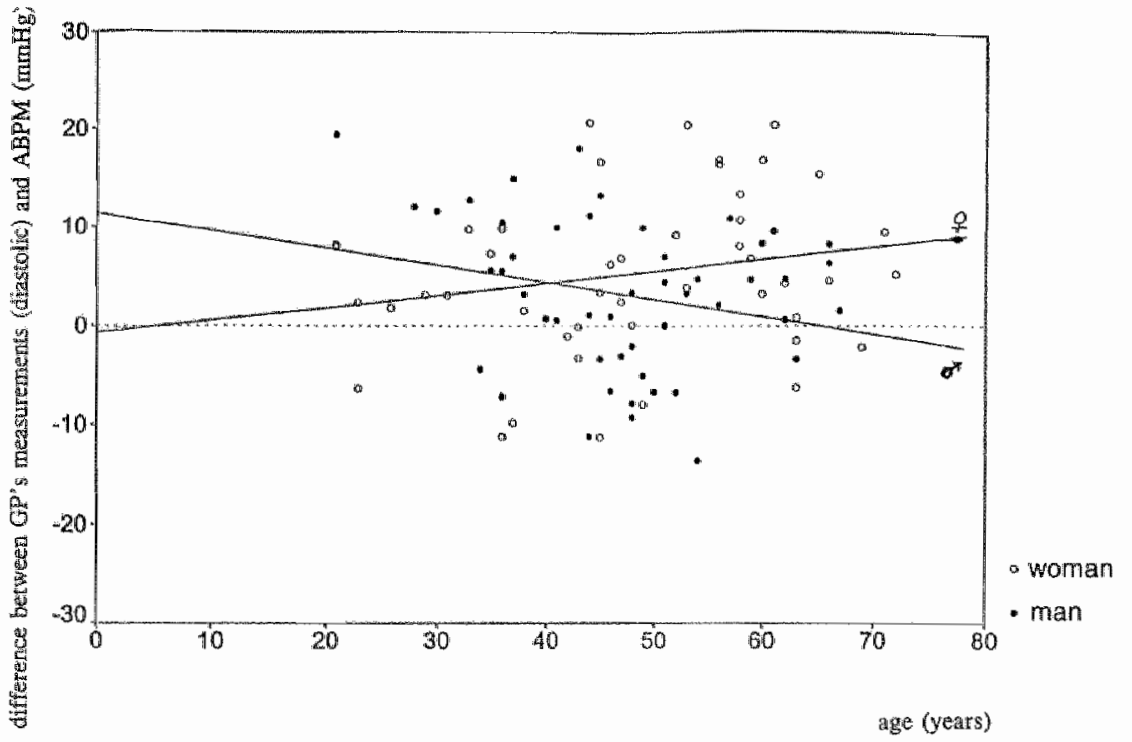

Figure 1b. differences (diastolic) between the means of 3 duplicate measurements by GP (general practitioner) and $A B P M$ (ambulatory measurement, $y$-axis) against age. Regression equation: $y=$ $11.57-12.29$ SEX -0.176 AGE $($ mann $=0$, woman $=1$, in years $)+0.299$ SEXXAGE... 


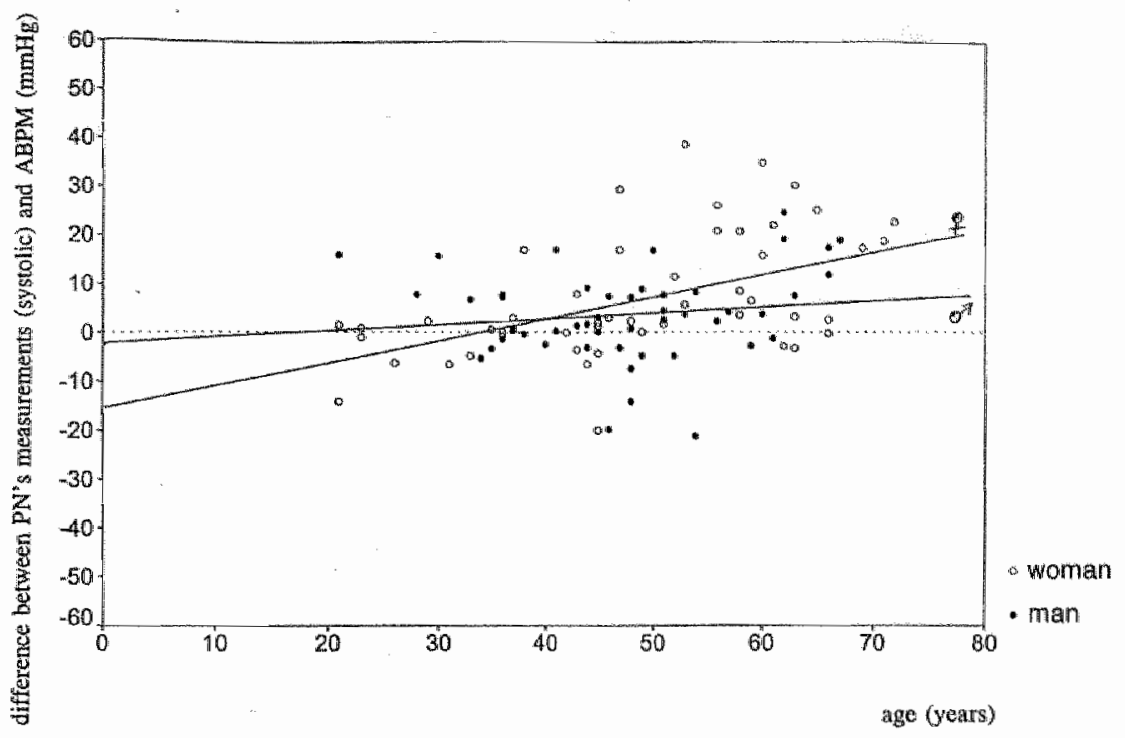

Figure 2a. differences (systolic) between the means of 3 duplicate measurements by PN (practice nurse) and ABPM (ambulatory measurement, $y$-axis) against age ( $x$-axis). Regression equation: $y=$ $-2.23-13.29 \mathrm{SEX}+0.123$ AGE $($ man $=0$, woman $=1$, in years $)+0.347 \mathrm{SEXXAGE}$.

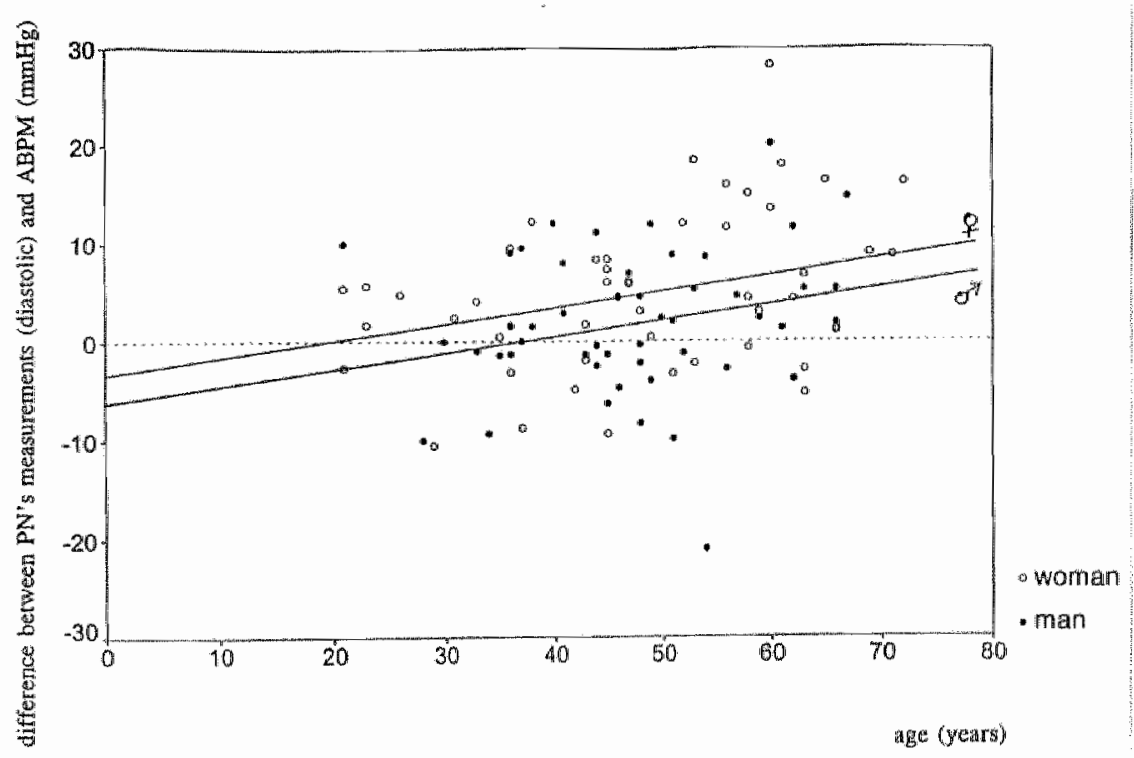

Figure 2b. differences (diastolic) between the means of 3 duplicate measurements by PN (practice nurse) and $A B P M$ (ambulatory measurement, $y$-axis) against age ( $x$-axis). Regression equation: $y=$ $-6.19+2.865 E X+0.17$ AGE (man = 0, woman = 1, in years $)$. 


\subsection{Discussion}

The aim of this study was to compare a series of blood pressure measurements by doctor, practice nurse and patient with the mean of two daytime ambulatory blood pressure measurements. On theoretical grounds, and because of the improved reproducibility of two ambulatory blood pressure measurements on different days, we consider this as a better reference value than a single ambulatory measurement. ${ }^{22-23}$ We compared the reference values with the means of six and twelve (in three and six visits) measurements by the general practitioner, the means of six measurements in three visits by the practice nurse and the means of eight measurements (on four occasions) by the patient. The Fifth Report of the Joint National Committee on Detection, Evaluation, and Treatment of High Blood Pressure recommends at least two subsequent visits during one to several weeks. ${ }^{27}$

In accordance to the study of Veerman et al. nurse measured blood pressure appeared to be more in accordance with ambulatory blood pressure than blood pressure measurements by a doctor. ${ }^{15}$ However, both procedures distinctly overestimated ambulatory blood pressure. On the contrary, series of blood pressures measured by the patient at home agreed quite well with ambulatory blood pressures. The slightly lower systolic and diastolic means of home measurements may be due to the more standardized measurements at home (patients were sitting and probably performed their measurements preferably on quiet moments). Mean differences and standard deviations of differences of home-measurements versus ambulatory measurements appeared to be within the ranges of these values found in studies on the reproducibility of ambulatory blood pressure measurement. ${ }^{11,13,22}$ Our results confirm the conclusions from earlier studies 28.29

Twelve instead of six measurements by the doctor provided an only minimally better agreement with ambulatory blood pressure measurement. This does not agree with the results of Watson et al. who investigated percentages of misclassification on the basis of different numbers of office measurements, using the 'notional stable blood pressure' ( = mean of twelve measurements in six visits) as a reference value ${ }^{30}$ In our study, there seems to be a systematic difference between office blood pressure and ambulatory blood pressure, which scarcely can be reduced by augmenting the number of measurements above a certain critical number.

The results of this study do not confirm Comstock's speculation that 'a subject's blood is tending to be higher when the examiner is of the opposite $\operatorname{sex}^{\prime 26}$

In accordance with earlier studies the white coat effect was more pronounced in women. ${ }^{15,31}$ Like Pearce and co-workers, we did not detect a clear white coat effect in older men, nor in doctor-measured, nor in nursemeasured blood pressures. ${ }^{32}$ However, Pearce studied a general, normotensive population, and the absence of white coat hypertension in these subjects was 
not surprising: white coat hypertensives are a subgroup of hypertensives, and not of normatensives.

Our study reveals better agreement between home measurements by the patient and ambullatory measurements than the study of Stergiou et al. but they used different types of instruments for home measurements. ${ }^{33}$ In addition, in their conclusions the authors did not take into account that measurements by the patient are much cheaper and more available than measurements by a doctor, whereas the one measurement procedure appeared to be as good as the other. Using at least six home measurements, Chatellier et al. demonstrated the improvement of the measurement precision as compared to office measurements. $^{34}$

A limitation of our study concerns the non-optimal standardization of measurements, but this always will be a limitation of research done in large numbers of general practices. We consider the achieved standardization in this multi-centered study as sufficient.

In conclusion, a series of eight blood pressure measurements (on four occasions) by the patient appeared to be a good and reliable alternative to ambulatory blood pressure measurement. In diagnosing mild to moderate hypertension in general practice, cheap, easy available and accurate self-measurements by the patient have the priority above ambulatory measurements. In contrast with Cox et al. we reject widespread use of ambulatory blood pressure measurement in general practice. ${ }^{3}$ Ambulatory monitoring of blood pressure should be restricted to scientific research, and in tracing white coat hypertension in patients unable to perform self-measurements. ${ }^{35}$

\section{References}

1. Perry HM, Miller Ph.J. Difficulties in diagnosing hypertension: implications and alternatives. I Hypertens 1992; 10: 887-96.

2. Aylett MJ. Ambulatory or self blood pressure measurement? Improving the diagnosis of hypertension? Fäm Pract 1994; 1 : $197-200$.

3. Cox JP, OMalley K, O'Brien E. Ambulatory bllood pressure measurement in generai practice Br J Gen Pract 1992: 42: 402-3.

4. Silagy C. Lawrence M, Ebbs $D$, et al. Monitoring ambulatory blood pressure in general practice. BMJ 1992: 305: 181-2 (18 July).

5. Webb DI, Stewart MJ, Padfield PL. Monitoring a mbulatory blood pressure in general practice. BMI 1992: 304: 1442 (30 May).

6. Webb DJ, Stewart M, Padfield PL. Monitoring ambulatory blood pressure in general practice BM॥1992; 305: 716-7 (19 September).

7. Appel LJ, Stason WB. Ambulatory blood pressure monitoring and blood pressure self-measurement in the diagnasis and management of hypertension. Ann Intern Med 1993: 118: $876-82$. 
8. Automated ambulatory blood pressure and seffomeasured blood pressure monitoring devices: their role in the diagnosis and managenent of hypertension. Ann Intern Med 1993; 118: $889-92$

9. Perloff D, Sokolow M, Cowan R. The prognostic value of ambulatory biood pressure. JAMA 1983; 249: 2792-8.

10. Jacot des Combes $B$, Porchet $M$, Waeber $B$, et al. Ambulatory blood pressure recordings. Reproducibility and unpredictability. Hypertension 1984; 6: 110-4.

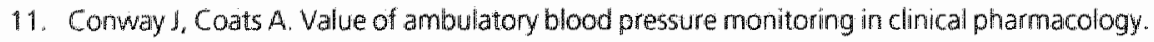
J Hypertens 1989: 7 (suppl 3): \$29-\$32.

12. Gerin W, Rosafsky M. Pieper $C$, et al. A test of reproducibility of blood pressure and heart rate variability using a controlled ambulatory procedure. J Hypertens 1993; 11: 1127-31.

13. Mansoor 6 A, MCC abe E), White WB. Long-term reproducibility of ambulatory blood pressure. J Hyperters 1994; 12:703-8.

14. Mancia $G$, Parati $G$, Pomidossi $G$, et al. Alerting reaction and rise in blood pressure during measurement by physician and nurse. Hypertension 1987; 9: 209-215.

15. Veerman DP, Van Montfrans GA. Nurse-measured or ambulatory blood pressure in routine hypertension care.J Hypertens 1993; 11: 287-92.

15. British Hypertension Society recommendations on blood pressure measurement, in: O'Brien E. O'Malley K. Handbook of Hypertension. Volume 14. Elsevier, Amsterdam, 1991, pp $387-95$

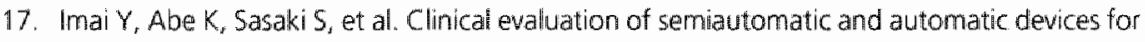
home blood pressure measurement: comparison between cuff-oscillometric and microphone methods. J Hypertens 1989; $7: 983-90$.

18. Johnston DW, Shah D. An evaluation of the Takeda UA-751 automatic sphygmomanometer. Behav Res Ther 1989; $27: 203-4$.

19. Iamieson MJ, Webster J, Witte K, et al. An evaluation of the A\&D UA-751 semi-automated cuff-oscillometric sphygmomanometer. J Hypertens 1990; 8: 377-81.

20. O'Brien E, Mee F. Atkins N, O'Malley K. Accuracy of the Spacelabs 90207 determined by the British Hypertension Society Protocol. 1 Hypertens 1.991: 9 (suppj 5 ) 525.531.

21. Association for the Advancement of Medical Instrumentation. American National Standard for Electronic or Automated Sphygmomainometers. Washington DC, AAMI, 1987.

22. Fotherby MD. Potter IF. Reproducibility of ambulatory and clinic blood pressure measurements in elderly hypertensive subjects. J Hypertens 1993; 11:573-9.

23. Reeves RA, Myers MG. Reproducibility of ambulatory blood pressure and assessing treatment withdrawal in hypertension trial. Am J Hypertens 1993: 6 (6 Pt 2): 2295-2325.

24. Ingelfinger JA, Mosteller $F$. Thibodeau LA, et al. Biostatistics in Clinical Medicne. New York, Macmillan 1987: chapter 5, p 85-112.

25. Bland M. Altman DG. Statistical methods for assessing agreernent between two methods of clinical measurement. Lancet 1986; it: 307-10.

26. Comstock GW. An epidemiological study of blood pressure levels in a biracial community in the southern United States. Am J Hyg 1957; 65: 271-315.

27. Fifth Report of the Joint National Committee on Detection. Ewaluation, and Treatment of High Blood Pressure. Airch Intern Med 1993; 153: 154-83. 
28. Marolf AP, Hany B, Bättig, el al. Comparison of casual, ambulatony and self-determined blood pressure measurement. Nephron 1987; 47 (suppl 1): pp. 1422145.

29. Flapan AD, Stewart SE, MCDougal F, et al. Is self home-monitoring of blood pressure as good as 24 hour ambulatory monitoring? I Hypertens 1987: 5; (suppl 5): $5491-5493$.

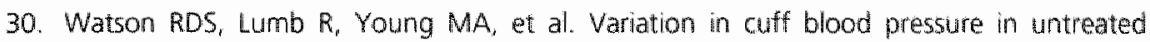
outpatients with mild hypertension. Implications for initiating antihypertensive treatment. J Hypertens 1987; 5: 207-11.

31. Myers MG. Reeves RA. White coat effect in treated hypertensive patients: sex differences. I Hum Hypertens 1995; 9: 729-33:

32. Pearce KA, Grimm RH, Rao S, et al. Population-derived comparisons of ambulatory and office blood pressures. Implications for the determination of usual blood pressure and the concept of white coat hypertension. Arch Intern Med 1992; 152:750-6.

33. Stergiou GS, Malakos 15, Voutsa AV, et al. Home monitoring of blood pressure: limited wallue in general practice. J Hum Hypertens, 1996; 10, 219-23.

34. Chatellier $G$, Dutrey-Dupagne $C$, Vaur $L$, et al. Home self blood pressure measurement in general practice. The SMART Study. Am \Hypertens 1996; 9:644-52.

35. Brueren M. Ambulatory monitoring of blood pressure should be restricted to scientific research. BMJ 1996; 313: 1334 (23 November). 

CHAPTER 9

\section{No relevant seasonal influences on office and ambulatory blood pressure}

Data from a study in borderline hypertensive primary care patients

Accepted for publication as: Brueren MM, Schouten BS, Schouten HJA, Van Weel C, De Leeuw PW, Van Ree JW. No relevant seasonal influences on office and ambulatory blood pressure: data from a study in borderline hypertensive primary care patients. Am J Hypertens 1998; ii. 


\section{Abstract}

Objective: To study seasonal influences on office and ambulatory blood pressure.

Design: Prospective study over 7 months.

Setting: Primary care.

Patients: 47 borderline hypertensive patients.

interventions: None.

Main outcome measures. Differences between 'summer' and 'winter' office and ambulatory blood pressures and $95 \%$ confidence intervals.

Results: Winter minus summer differences ranged from 0 to $3 \mathrm{mmHg}$. Only one significant difference was found: ambulatory systolic daytime pressure was significantly higher ( $3 \mathrm{mmHig}$ ) in winter than in summer.

Conclusion: Our results do not confirm the data of earlier studies in hypertensives. In view of the small and clinically irrelevant winter-summer differences, it seems unnecessary to modify antihypertensive treatment of borderline hypertensives according to the season.

Keywords: mild hypertension, ambulatory blood pressure monitoring, office blood pressure, seasonal effects.

\subsection{Introduction}

Several studies suggest that there are seasonal influences on blood pressure in hypertensive patients, blood pressures being higher in winter than in summer. ${ }^{1-5}$ The seasonal variation in blood pressure appeared to be larger in older than in younger subjects and was related to outdoor temperature. ${ }^{2}$ No seasonal differences were found in normotensive subjects. ${ }^{3}$ Table 1 presents the main data from a number of these studies.

We wanted to find out whether these differences also exist in borderline hypertensive primary care patients, since it is especially in this group of patients that there is a considerable risk of misclassification and unjustified drug treatment. ${ }^{6,7}$

The data presented here were derived from a 7 months comparative, prospective study in borderline hypertensive primary care patients. Participating patients did not receive antihypertensive treatment, neither at the start, nor in the course of the study.

\subsection{Methods}

Seventeen general practitioners participated in the study. All were given instructions on adequate techniques of blood pressure measurement. ${ }^{8}$ Phase $V$ of the Korotkoff sounds was recorded as the level of diastolic pressure. 
Table 1. Siudies of seasonal differences in systolic blood pressure (SBP), diastolic blood pressure (DBP), and anbulatory bood pressure (ABPM).

\begin{tabular}{lllllll}
\hline$N$ & SBP/summer & SBP/winter & DBP/summer & DBPAnter & reference & AT \\
\hline 56 & $144-145$ & $145-146$ & $86-88$ & $87-88$ & 1 & - \\
$*$ & $143-145$ & $146-148$ & $90-91$ & $92-93$ & 2 & - \\
9 & 154 & 147 & 103 & 96 & 34 & 24 \\
22 & nochange & no change & 84 & 89 & 4 & 13 \\
& 121 & 125 & 81 & 86 & 4 (ABPM) & \\
50 & 144 & 148 & 85 & 89 & 5 & 16 \\
& 133 & 138 & 83 & 86 & 5 (ABPM) & \\
\hline
\end{tabular}

*Placebagroup/routine follow-up examinations. Number of patients in this subgroup not presented; \#Borderline hypertensives/measurements in upright position; $\Delta$ T Difference between summer and winter temperature $\left({ }^{\circ} \mathrm{C}\right)$.

\section{Patients}

Patients were selected on the basis of an initially elevated office blood pressure measured by the general practitioner.

Inclusion criteria were:

- mean of two systolic values (measured in one visit) between 160 and 200 $\mathrm{mmHg}$ and/or mean of two diastolic measurements between 95 and 115 $\mathrm{mmHg}$

- age between 20 and 75 .

Exclusion criteria were:

- known hypertension or antihypertensive treatment in the year preceding the study

- suspicion of secondary hypertension

- congestive heart failure or unstable angina

- pregnancy.

\section{Measurement procedures}

After inclusion by the general practitioner, all patients underwent four procedures of blood pressure measurement. Since the aim of the study was to detect seasonal influences on office and ambulatory blood pressure, only two of these were relevant for the present analysis. One procedure consisted of duplicate measurements in one visit by the general practitioner in his office in weeks 2,3 and 4 and months $2,3,4,5,6$ and 7 . The other procedure consisted of ambulatory blood pressure measurements during one working day in week 4 and month 7. 


\section{Measuring devices}

The general practitioner measured blood pressure with a calibrated mercury sphygmomanometer, provided with a standard-sized cuff (12 2 35 cm). Ambulatory blood pressure was measured using a Spacelabs 90207 (SpaceLabs Inc, Hillsboro, Oregon, USA) automatic cuff-oscillometric device. This instrument received a $B$ rating for both systolic and diastolic blood pressure according to the criteria of the British Hypertension Society protocol, and satisfies the criteria of the Association for the Advancement of Medical Instrumentation. 9.10 Blood pressures were recorded automatically every 15 minutes from 6.00 AM till 10.00 PM and every 30 minutes during the night.

\section{Data analysis}

The months of December, January and February were defined as 'winter", the months of June, July and August as 'summer'. Only data from patients who had their first ambulatory measurement during the winter period and their second ambulatory measurement during the summer period, or vice versa, were analyzed. Office and ambulatory blood pressures of all included patients were amallyzed in a way analogous to a twa-period crossover design. ${ }^{11} 95 \%$ confidence intervals were computed for the differences between "summer" and "winter" blood pressures. P-values $<0.05$ were regarded as statistically significant.

\section{Results}

Data collection started in the autumn of 1991 and ended in the autumn of 1994. Outdoor temperatures in the months of data collection, defined as the mean temperatures over one month, ranged from 1.5 to $5.2^{\circ} \mathrm{C}$ in the winter months, and from 15.0 to $21.4^{\circ} \mathrm{C}$ in the summer months. ${ }^{12}$

Forty seven patients were selected for amalysis of seasonal differences: 25 of them had their first blood pressure measurements during summer, whille 22 had their first measurements in winter. Eight patients suffered too much discomfort from the ambulatory blood pressure measurement during sleep and turned off the monitor during the night. They were excluded from the analysis of 24 hour ambulatory blood pressures.

Characteristics of the 'summer-winter subgroup' were as follows: 7 men and 18 women, mean systolic blood pressure at entrance into the study 159 mmHtg (standard deviation 17), mean diastolic blood pressure at entrance into the study $99 \mathrm{mmHg}$ (standard deviation 5), mean age 54 (range 33-69), and mean BMI (Body Mass Index) 26 (range 19-37). Characteristics of the "wintersummer subgroup' were: 15 men and 7 women, mean systolic blood pressure at entrance into the study $166 \mathrm{mmHg}$ (standard deviation 17), mean diastolic blood pressure at entrance $103 \mathrm{mmHg}$ (standard deviation 6), mean age 49 (range 28-71), and mean BMI 27 (range 22-36). Table 2 presents means, 
Table 2. Means (mmHg), number of patients ( $\mathrm{N}$ ), mean differences ( $\mathrm{mmHg}$ ), and $95 \%$ confidence intervals ( $C$ ) of mean differences. Mean numbers of office measurements 6 (summen) and 5 (winter).

\begin{tabular}{|c|c|c|c|c|c|}
\hline & & \multirow[b]{2}{*}{ mean } & \multirow[b]{2}{*}{$N$} & \multicolumn{2}{|c|}{ winter minus summér } \\
\hline & & & & difference & $95 \% \mathrm{Cl}$ \\
\hline daytime & SBP & 142 & 47 & 3 & 0106 * \\
\hline ABPM & DBP & 90 & 47 & 1 & 0 to 3 \\
\hline 24 hour & $\operatorname{SBP}$ & 138 & 39 & 2 & -1 to 4 \\
\hline ABPMII & $D B P$ & 87 & 39 & 0 & -1 to 2 \\
\hline \multirow[t]{2}{*}{ OBP } & SBP & 153 & 47 & 2 & -2 to 6 \\
\hline & DBP & 95 & 47 & 1 & -1 to 3 \\
\hline
\end{tabular}

ABPM: ambulatory blood pressure measurement; OBP: office blood pressure, measured by the general practitioner; SBP: systolic blood pressure; DBP: diastolic blood pressure; *Statistically significant $(p<0.05)$.

winter-summer differences and $95 \%$ confidence intervals of daytime ambulatory blood pressures, 24 hour ambulatory blood pressures $(N=39)$, and office blood pressures. Only one significant difference was found: systolic ambulatory daytime pressure was significantly higher in winter than in summer.

\section{Discussion}

Several studies have described seasonal influences on blood pressure, reporting higher levels in winter than in summer. The aim of the present study was to investigate whether these differences are also apparent in borderline hypertensive primary care patients. The data presented here were derived from a prospective study in primary care patients.

Analyzing the data in a way analogous to a two-period crossover design, the only statistically significant seasonal influence found was in systolic daytime ambulatory blood pressure. The difference we found ( $3 \mathrm{mmHg}$ ) is probably not clinically relevant. Our results do not agree with those of earlier studies in hypertensives. With reference to seasonal influences, borderline hypertensives seem to take an intermediate position between normotensives (no seasonal influences) and hypertensives (significant seasonal influences). Winter-summer differences may be related to the extent of blood pressure variability which is known to be larger in hypertensives than in borderline hypertensives and normotensives. ${ }^{13.14}$ The larger variability of blood pressure in hypertensives may be related to a lower resistance to external stimuli, such as outdoor temperature. However, further research is needed to test this hypothesis. 
Our results do not confirm the data of Minami et al. ${ }^{5}$ However, their study population was not homogeneous, consisting of treated as well as non-treated hypertensive patients. As far as we know, our study is the only one in this field using a two period crossover analysis. Moreover, the study comprised borderline hypertensives, a group which is particularly prone to misclassification, overdiagnosis and overtreatment.

In view of the small and clinically irrelevant winter-summer differences, it seems unnecessary to modify antihypertensive treatment of borderline hypertensive patients according to the season.

\section{References}

1. Rose G: Seasonal variation in blood pressure in man. Nature 1961;189:235.

2. Brennan $P J_{,}$Greenberg $G$, Miall WE, et al. Seasonall variation in arterial blood pressure. BMIl 1982; $285 ; 919-23$.

3. Hata $T$, Ogihara T, Maruyama $A_{x}$ et al. The seasonal variation of blood pressure in patients. with essential hypertension. Clin Exp Hypertens 1982; 4: $341-54$.

4. Giaconi S. Palombo C, Genovesi-Ebert $A$, et al. Longuterm reproducibility and evaluation of seasonal influences on blood pressure monitoring. I Hypertens 1988; 6 (suppl 4): 564-566.

5. Minami J Kawano $Y_{*}$ Ishimitsu $T$, et al. Seasonal wariations in office, home and $24 \mathrm{~h}$ ambulatory blood pressure in patients with essential hypertension. J Hypertens 1996; 14: $1421-5$.

6. Perry $H M$, Miller JP. Difficulties in diagnosing hypertension: implications and alternatives. I Hypertens 1992; 10: 887-96.

7. Brueren MM, Petri H, Van Weel C, Van Ree JW. How many measurements are necessary in diagnosing mild to moderate hypertension? Fam Pract 1997; 14: 130-5.

8. British Hypertension Society recommendations on blood pressure measurement, in: O'Brien E, OMalley $K$ (eds): Handbook of Hypertension. Vol. 14: Blood pressure measurement. Elsevier, Arnsterdam, 1991, pp 387-95.

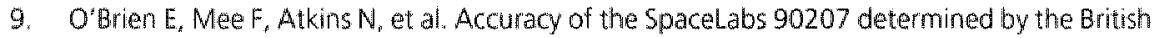
Hypertension Society Protocol. J Hypertens. 1991; 9 (suppl 5): 525-531.

10. Association for the Advancement of Medical Insirumentation. American National Standard for Electronic or Automated Sphygmomanometers. Washington DC, AAMI, 1987.

11. Semn S. Cross-over trials in clinical research. Wiley, New York, 1993.

12. Winkler Prins. Encyclopedisch Jaarboek. Uitgeverij Bonaventura/Het Spectrum/Kluwer Editorial, de jaren 1992, 1993. 1994 en 1995.

13. Millar $-C$ raig $M$, Bishop $C N$, Raftery $E B$. Circadian variations of blood pressure. Lancet 1978: i: $107-9$.

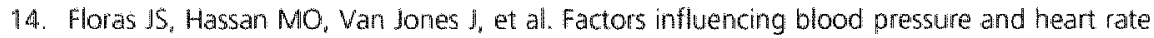
variability in hypertensive humans. Hypertension 1988; $14: 273-81$. 


\section{CHAPTER 10}

\section{General discussion}

\subsection{Introduction}

Diagnosis and treatment of hypertensive patients are considered to be the task of general practitioners, at least in the Netherlands. "Given the impact of within-person variability of blood pressure, the phenomenon of regression to the mean, 'white coat hypertension', and measurement errors, there is a considerable risk of misclassification. This may result in unjustified drug treatment or incorrectly withholding of treatment. Especially blood pressures near the clinically relevant threshold, in the borderline region between high and low blood pressure, may easily lead to misclassification. ${ }^{2}$ The risk of misclassification is particularly present in general practice where the majority of hypertensive patients are diagnosed and where many patients have blood pressures which are hovering near the threshold level for treatment. Three studies have shown that 40 to 50 percent of patients on antihypertensive drug treatment were able to stop using medication without their blood pressure rising above the level regarded as the threshold for treatment. ${ }^{3-5}$

Ambulatory blood pressure measurement is becoming a popular method for blood pressure determination and diagnosing hypertension. ${ }^{6}$ Ambulatory monitoring has many advantages over measurements at the doctor's office. Measurements take place at home or work, so that the 'white coat effect' is avoided. Furthermore, the large number of measurements reduces the confidence interval of the estimated mean and the risk of misclassification. Another advantage is that the influence of observer factors is eliminated, and due to the large number of measurements, there is regression to the mean to a lesser degree. ${ }^{7}$ Moreover, the correlation with target organ damage and cardiovascular morbidity and mortality is better than that in conventional measurements by the physician. ${ }^{8}$ There is discussion about introduction of ambulatory monitors in routine clinical care. ${ }^{9-14}$

The aim of the present study was to assess a blood pressure measurement procedure that would allow diagnosing hypertension with sufficient certainty. The questions were:

1. How many blood pressure measurements by the general practitioner are necessary for a diagnosis of hypertension?

2. What is the reproducibility of a series of measurements by the general practitioner and self-measurements by the patient in comparison to that of an ambulatory blood pressure measurement? 
3. What are the feasibility, acceptance and side effects of blood pressure self-measurement and ambulatory blood pressure measurement?

4. Is the white coat effect less pronounced when blood pressure is measured by the practice nurse instead of the doctor?

5. Is a series of measurements by the general practitioner or the patient a reliable alternative to ambulatory blood pressure measurement?

6. Are there seasonal influences on blood pressure in borderline hypertensive primary care patients, necessitating caution in diagnosis and adaptation of treatment according to the season?

\subsection{Main results}

How many blood pressure measurements by the general practitioner are necessary for a diagnosis of hypertension?

The number of four duplicate measurements on four separate days, recommended by international guidelines, was proven to be too low and resulted in a considerable amount of misclassification. ${ }^{15,16}$ After four duplicate remeasurements, there was misclassification in $56 \%$ (systolic) and $38 \%$ of all patients. These results were even worse than those found by Watson et al (50\% misclassification after four remeasurements for systolic, $32 \%$ for diastolic blood pressure). ${ }^{17}$ Our advise for values in the borderline hypertensive region is to be reticent in starting antihypertensive drug treatment.

What is the reproducibility of a series of measurements by the general practitioner and self-measurements by the patient in comparison with that of ambulatory blood pressure measurement?

In our study the reproducibility of ambulatory blood pressure measurement was not found to be better than that of a series of four duplicate measurements by the general practitioner or the patient. ${ }^{18}$ These findings are in contrast with those from the study of Conway and Coats, but they compared multiple ambulatory measurements with single conventional measurements. ${ }^{19}$ Mansoor and co-workers found a comparable reproducibility of ambulatory blood pressure measurement and noted that the less reproducible office blood pressure they had found might be caused by the small number of office measurements. ${ }^{20}$ Our study supports this assumption.

What are the feasibility, acceptance and side effects of blood pressure self-measurement and ambulatory blood pressure measurement?

A small number of patients reported problems associated to self-measurement of blood pressure. Pain during inflation of the cuff and a feeling of anesthesia in the measured arm were serious complaints.

Almost 30 percent of the patients who underwent ambulatory measurement reported moderate to severe discomfort during daily activities. A large 
proportion of the patients reported that the ambulatory monitoring interfered seriously with sleep. Our results quite well agree with the findings from other studies. ${ }^{21-24}$

We can conclude that both measurement procedures are feasible and acceptable in primary care, but that ambulatory measurement leads to more problems, especially during the night.

Is the white coat effect less pronounced when blood pressure is measured by the practice nurse instead of the doctor?

Nurse measured blood pressures appeared to be slightly more in accordance with ambulatory blood pressure than measurements by a doctor. This result is in accordance with the findings from a study of Veerman and Van Montfrans. ${ }^{25}$ However, both procedures distinctly overestimate ambulatory blood pressure. Only from the viewpoint of cost-effectiveness, blood pressure measurements by the practice nurse would be a good alternative to measurements by the general practitioner.

Is a series of blood pressure measurements by the general practitioner or the patient a reliable alternative to ambulatory measurement?

More than measurements by the general practitioner or the practice nurse, a series of 8 blood pressure measurements (on four occasions) by the patient proved to be a reliable aiternative to ambulatory blood pressure measurement. In a comparative study of blood pressure self-measurements by the patient with office measurements, Chatellier recommended at least six self-measurements as a good and reliable alternative. ${ }^{26}$ Our study revealed better agreement between home measurements by the patient and ambulatory measurements than the study of Stergiou and associates, but in the latter study the patients used different types of self-measuring devices and specific instructions regarding the self-measurement procedure were lacking. ${ }^{27}$

Are there seasonal influences on blood pressure in borderline hypertensive primary care patients, necessitating caution in diagnosis and adaptation of treatment according to the season?

We did not find relevant seasonal influences on blood pressure in borderline hypertensive patients. The only statistically significant seasonal difference ('winter' minus 'summer") was in systolic daytime ambulatory blood pressure, but the difference we found $(3 \mathrm{mmHg}$ ) is probably not clinically relevant. Our results do not agree with the findings from earlier studies in hypertensives. ${ }^{28-32}$ Borderline hypertensives seem to take an intermediate position between normotensives (no seasonal influences) and hypertensives (significant seasonal influences). Winter-summer differences may be related to the extent of blood pressure variability which is known to be larger in hypertensives than in borderline hypertensives and normotensives. ${ }^{33-34}$ The larger variability of blood pressure in hypertensives may be related to a lower resistance to external 
stimuli, such as outdoor temperature. However, further research is needed to test this hypothesis.

\subsection{Limitations of the study}

Since our study covered a large time space (1990-1997), an important, but unresolvable limitation of the study was the progress of scientific reasoning, based upon new research findings. At that time, ambulatory blood pressure measurement seemed to be the solution of many, maybe even all, problems with regard to the precise and accurate diagnosis of hypertension. In a number of studies a single ambulatory blood pressure measurement was used as the 'gold standard'. A shadow of this way of thinking is presented in chapter 3 of this thesis, which comprises the first analyses of our study. But time goes on, and in later studies (chapters 5, 6,8 and 9) the data were amalyzed in a radical different way.

The second limitation is related to the one mentioned above. With borderline abnormalities, for instance borderline hypertension, which is the subject of this study, there are generally two different approaches. The first is a clinical, qualitative approach: there is illness or health, hypertension or normotension. The second is a quantitative, more or less mathematical approach: there is more or less illness, mild/moderate/severe hypertension etc. This problem is clearly verbalized by G.W.Pickering: '...It is apparently difficult for doctors to understand because it is a departure from the ordinary process of binary thought to which they are brought up. Is it normal or abnormal, physiological or pathological, health or disease, good or bad? Quantity is not an idea that is as yet allowed to intrude. Medicine in its present state can count up to two but not beyond. ${ }^{35}$ The chapters 3 and 4 departed from a clinical. qualitative viewpoint, with dichotomization of the data and the use of different cutoff points. The chapters 5, 6, 8 and 9 on the other hand, were based on quantitative, statistical analyses of data. The relatively high prevalence of white coat hypertension found in chapter 3 is partly caused by the definition we used (hypertension according to the doctor's measurements and normotension according to the ambulatory measurements) and the qualitative analysis. White coat hypertension, in chapter 8 defined as a difference of $10 \mathrm{mmHg}$ or more between diastolic office measurements and ambulatory blood pressure was found in $27 \%$ ( 1.4 men and 13 women) when blood pressures were measured by the doctor and in $18 \%$ ( 7 men and 11 women) when measured by the practice nurse.

The third limitation of our study relates to the apparatus for self-measurement of blood pressure. In 1991, we decided to use the BOSO-Oscillomat for self-measurement, at that time one of the best instruments. The apparatus was validated and was described as an acceptable alternative to a conventional sphygmomanometer. ${ }^{36-38}$ Given the results from a study of the validity of a 


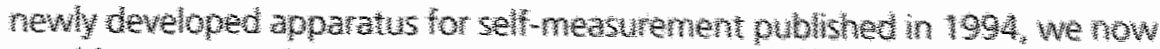

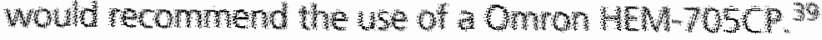

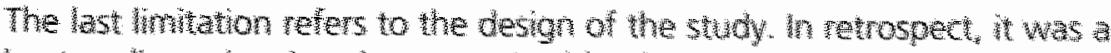

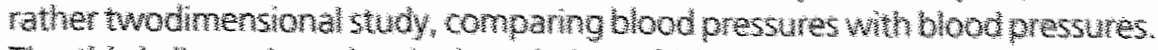

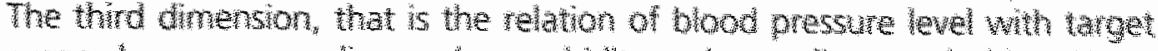

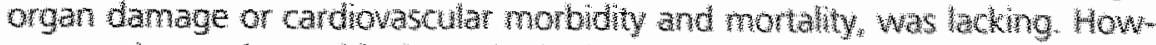

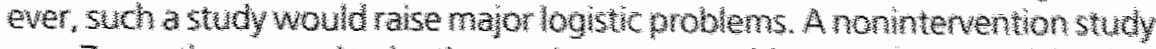

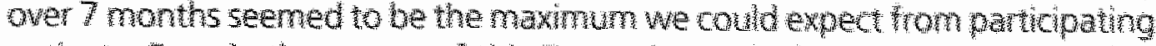

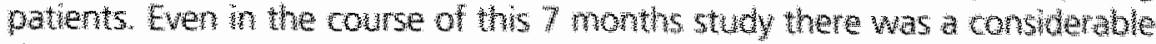
dropout rate.

\subsection{Fecommendations for clinical practice}

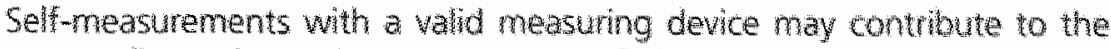
accurate dogncss and management of hypertensive patients boo

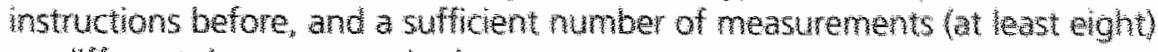
on different days, are requited.

The number of chical bood pressue measurements as recommended by intemational guidehnes four duplicate measurements on sepatate days in

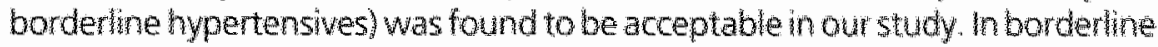
hypertenswe blood pressure values, thet is bood pressues hovering the theshold for diagnosis and dug treatment there sulu is ansiderable risk ot misclassfication, even after tout duplucte remeasurements. Fon thason. and to race white coat hypetension, we recommind self measurements in patients with borderlne blood pressure values. The introduction of a vald, easky avalable and inexpensive device for he selt-ineasurement of blood pressure permits a broad application in ganeral practice ${ }^{30}$

Like lackson et al. we advocate that in bonderhe hypertenswes, other cardiovascular risk factors should be taken into account in the decision whether to treat or not. ${ }^{40}$ in our opinion, our results and conclusions contribute to the supposition by Reeves: 'In the future, individualized assessments of absolute risk incorporating other relevant information, such as age, sex, concomitant risk factors, and co-existing target organ damage, along with the patient's tolerance for risk and history of drug side effects may replace arbititary cut points in determining when blood pressure elevation becomes treatable. 41 Ambulatory blood pressure measurement should be restricted to scientific research, to the study of factors influencing the short-term variability of blood pressure (with help of a diary), and in tracing white coat hypertension in patient who are unable to perform self-measurements. 


\subsection{Recommendations for further research}

In our study, blood pressure self-measurement revealed to be a reliable alternative to ambulatory blood pressure measurement. Since self-measurements are more available and less expensive than ambulatory measurement. clinical threshold values for home blood pressure should be determined. Moreover, the cost-effectiveness of self-measurement should be assessed.

In the past two decades, many studies on validity and reproducibility of (semi-)automatic self-measuring devices (ambulatory or not) have been published. However, studies on the validity and reproducibility of conventional blood pressure measurements by the doctor, the practice assistant or someone else are llacking. Further research is needed to compare the validity, predictive value for cardiovascular risk and cost-effectiveness of self-measurements and conventional, sphygmomanometric measurements. Self-measurement could prove to be more accurate, more predictive and less expensive than conventional measurements. In connection with this, more research must be done with reference to the phenomenon of white coat hypertension. What is the validity of this concept? What is the within-subject reproducibility of white coat hypertension? Is it an innacent condition or do white coat hypertensives have an elevated cardiovascular risk?

\section{References}

1. Gezondheidsraad. Advies inzake hypertensie. Den Haag: Staatsuitgeverij, 1983.

2. Perry HM, Miller JP. Difficulties in diagnosing hypertension: implications and alternatives. J Hypertens 1992; 10: 887-96.

3. Management Committee of the Australian therapeutic trial on mild hypertension. Untreated mild hypertension. Lancet 1982; i: 185-91.

4. Medical research council working party. MRC trial on treatment of mild thypentension: principal results. BMI 1985: 291: 97-104

5. Van Kruijsdijk MCM. Hypertensie opnieuw gemeten [proefschrift]. Krips Repro, Meppel. 1991. Nijmegen: Unwersiteit wan Nijmegen, 1991.

6. Aylett M. Ambulatory or self blood pressure measurement? Improving the diagnosis of hypertension? Fam Pract 1994; 11: 197-200

7. Reeves RA, Myers MG. Reproducibility of ambulatory blood pressure and assessing treatment withdrawal in hypertension trial. Am J Hypertens 1993; 6: 22.5 -2325.

8. Perloff $\mathrm{D}$, Sokolow $M$, Cowan $\mathrm{R}$. The prognostic value of ambulatory blood pressure. JAMA 1983; 249: 2792-8.

9. Cox JP, O'Malley $K_{\text {, }} \mathrm{O}^{\prime}$ Brien E. Ambulatory blood pressure measurement in general practice. Br J Gen Pract 1992; 42: 402-3.

10. Webb DJ, Stewart MJ, Padfield PL. Monitoring ambulatory blood pressure in general practice. BMJ 1992; 304: 1442 (30 May). 
11. Sillagy $C$, Lawrence $M$, Ebbs $D$, et al. Monitoring ambulatory blood pressure in general pracice. BMJ 1992; 305: 181-2 (18 July)

12. Weob DJ, Stewart MJ, Padfield PL. Monitoring ambulatory blood pressure in general practice. BMJ 1992; 305: 716-7 (19 September).

13. Appel U. Stason WB. Ambulatory blood pressure monitoring and blood pressure self-measurement in the diagnosis and management of hypertension. Ann intem Med 1993; 118: $876-82$.

14. Automated ambulatory blood pressure and self-measured blood pressure monitoring device: their role in the diagnosis and management of hypertension. Amn Intern Med 1993: 118: 889-92.

15. Brueren MM, Petri H, Van Weel C, et al. How many measurements are necessary in diagnosing mild to moderate hypertension? Fam Pract 1997; 14: 130-5.

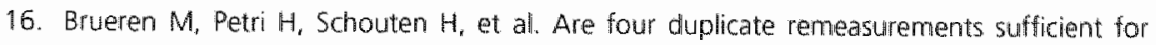
diagnosing milld hypertension? J Hum Hypertens 1996; 10: 3.49.52.

17. Watson RDS, Lumb $R_{*}$ Young MA, et al. Variation in cuff blood pressure in untreated outpatients with mild hypertension: implications for initiating anthypertensive treatment. I Hypertens 1987; 5: 207-11.

18. Brueren MM, Van Limp: $P$, Schouten HJA, et al. 15 a series of blood pressure measurements, by the general practitioner or the patient a reliable alternative to ambulatory blood pressure measurement? Am I Hypertens 1997; 10:879-85.

19. Conway J, Coats A. Value of ambulatory blood pressure monitoring in clinical pharmacology. J Hypertens 1989; 7 (suppl 3): 529-532.

20. Mansoor $\mathrm{GA}$, MCCabe El, White WB. Long-term reproducibility of ambulatory blood pressure." 1 Hypertens 1994; 12: 703-8.

21. Welin L, Swärdsudd K, Tibblin G. Home blood pressure measurements. Feasibility and results compared to office measurements. Acta Med Scand 1982; $211: 275$-9.

22. Van de Weijgert EJHM, Braun IJ. Experience with noninvasive ambulatory 24-hour blood pressure recording in a community hospital. Neth J Med 1992; 40: 175-82.

23. Coope $G$, Coope J. Roberts D. Ambulatory blood pressure measurement [letter]. Br J Gen Pract 1993; 44:83.

24. Beltman FW, Heesen WF, 5 mit A), et al. Acceptance and side effects of ambulatory blood pressure monitoring: evaluation of a new technology. I Hum Hyperteris 1996; 10(5uppl 3): 539-542.

25. Veerman DP, Van Montfrans GA. Nurse-measured or ambulatory blood pressure in routine hypertension care. Hypertens 1993; 11:287-92.

26. Chatellier G, Dutrey-Dupagne C, Vaur L, et al. Home self blood pressure measurement in general practice. The SMART Study. Am J Hypertens 1996; 9: 644-52

27. Stergiou GS, Malakos IS, Voutsa AV, et al. Home monitoring of blood pressure: limited value in general practice. J Hum Hypertens 1996; 10: $219-23$.

28. Rose $G$. Seasonal variation in blood pressure in man. Nature 1961; 189: 235 .

29. Brennan PJ, Greenberg G, Miall WE, et al. Seasonal variation in arterial biood pressure. BMJ $1982 ; 285: 919-23$.

30. Hata T, Oghara T, Maruyama $A_{\text {, }}$ et al. The seasonal variation of blood pressure in patients with essential hypertension. Clin Exp Hypertens 1982; $4: 341-54$ 
31. Gaconi 5 , Palombo C. Genovesi-Ebert A, et al. Long-1erm reproducibility and evaluation of seasonal intuences on blood pressure monitoring. J Hypertens 1988; 6 (suppl 4): 564 -S66.

32. Minami I, Kawano $Y$, lstimitsu $T$, et al. Seasonal variations in office, home and $24 \mathrm{~h}$ ambulatony blood pressure in patients with essential hypertension. I Hypertens 1996; 14 : $1421-5$

33. Foras J5, Hassan MO, Van Jones J, et al. Factors influencing blood pressure and heart rate variability in hypertensive humans. Hypertension 1988; 11: 273-81.

34. Millar-Craig M, Bishop CN, Raftery EB. Circadian variations of blood pressure. Lancet 1978; i: $107-9$

35. Pickering GW. High Blood Pressure, Churchill, London, 1968 , pp 4-5.

36. Imai $Y$, Abe $K$, Sasaki $S$, al. Clinical evaluation of semiautomatic and automatic devices for home blood pressure measurement: comparison between cuff-oscillometric and microphone methods. J Hypertens 1989; 7: 983-90

37. Johnston DW, Shah D. An evaluation of the Takeda UA-751 automatic sphygmomanometer. Behav Res Ther 1989; $27: 203-4$.

38. Jamieson MJ, Webster , Witte $K$, et al. An evaluation of the A\&D UA-751 semiautomated cuff-oscillometric sphygmomanometer. J Hypertens $1990 ; 8: 377-81$.

39. O'Brien E, Mee F, Atkins $N$. An accurate automated device for home blood pressure measurement at last! The Omron HEM-705CP. J Hypertens 1994; 12: 1317-8.

40. Jackson R, Barham P. Bills J, et al. Management of raised blood pressure in New Zealand: a discussion document. BMJ 1993; 307: 107-10.

41. Reeves. RA. Does this patient have hypertension? How to measure blood pressure. JAMA 1995; $373: 1211-8$. 


\section{CHAPTER 11}

\section{Summary}

Detection, diagnosis and treatment of mild to moderate hypertension, which is a risk factor for cardiovascular pathology, are considered to be the tasks of general practitioners. Given the large within-person variability of blood pressure, as well as the phenomena of regression to the mean and white-coat effect, and the risk of measurement errors, there is a non-negligible risk of misclassification. Misclassification can result in incorrect initiation or withholding of drug treatment. In a number of studies in patients diagnosed as mild hypertensives, one third to one half of all those taking placebo were later found to have diastolic pressures below $90 \mathrm{mmHg}$.

The aim of the present study was to detect which blood pressure measurement procedures, feasible in general practice, reduce the risk of misclassification to an acceptable level.

The general background of the study is presented in chapter 1. A brief history of blood pressure measurement over the last century highlights the problems of performing these measurements and adequately diagnosing hypertension. From the studies referred to, regression to the mean, a methodological artefact, appears to have been strongest in patients with the highest initial blood pressure values. Studies in (borderline) hypertensive patients have shown the prevalence of white coat hypertension to range from 21 to $38 \%$. Much remains unknown about factors causing the large withinperson variability of blood pressure, even more so among hypertensive than among normotensive subjects. Blood pressure changes during physical activity and breathing, and depends on the position of the body. In most people, blood pressure drops during sleep, and in temperate climates, blood pressures have been shown to be about $5 \mathrm{mmHg}$ higher in winter than in summer.

In diagnosing hypertension there is a considerable risk of misclassification. This problem is particularly experienced in general practice, where many patients have blood pressures near the threshold value.

The design and methods of the study are described in chapter 2. A prospective, diagnostic, comparative study was undertaken in primary care patients with elevated blood pressures detected at the first visit. Seventeen general practices participated in the study. All patients underwent four blood pressure measurement procedures: measurements by the general practitioner, measurements by the practice assistant, self-measurements by the patient and ambulatory measurements.

Chapter 3 compares measurements according to the guideline published by the Dutch College of General Practitioners with ambulatory blood pressure 
measurements. Measurements according to the guideline correlated much better with ambulatory measurements for patients with 'high' initial values (diastolic pressure $105-115 \mathrm{mmHg}$ ) than for those with 'low' initial values. (diastolic pressure 95-105). The white coat effect was also found in general practice.

Chapters 4 and 5 discuss a study investigating the number of blood pressure measurements by the general practitioner which is necessary for diagnosing mild hypertension with certainty. Blood pressure measurements by the general practitioner were compared with the 'conceptual average blood pressure', defined as the average of ten measurements taken during the last five visits. In chapter 4 the data are analyzed qualitatively, after dichotomization (hypertension/hormotension) at different cutoff points. Chapter 5 presents a quantitative, statistical analysis of the same data, without dichotomization. A linear regression analysis proved that the 'conceptual average blood pressure' was a stable reference value.

Both the qualitative and the quantitative analysis led to the same conclusion: in borderline hypertensives, a considerable percentage of misclassification remained even after four duplicate measurements. Analysis of subgroups revealed what can be intuitively grasped: the proportion of misclassification greatly depended on the initial value and the accepted threshold. The proportion of misclassifications was low at relatively low initial values and higher threshold values, and the same was true for relatively high initial values and lower threshold values.

Chapter 6 shows the reproducibility of a series of blood pressure measurements by the general practitioner or the patient to be as good as that of an ambulatory measurement. This result contrasts with those of other studies. The less reproducible office blood pressures found in a number of studies might be caused by (too) low numbers of office measurements.

Chapter 7 discusses the feasibility, acceptance and side effects of ambulatory blood pressure measurement and blood pressure self-measurement. Almost $30 \%$ of the patients who underwent ambulatory measurement reported moderate to severe discomfort during daily activities. In 40 to $45 \%$ of the patients, ambulatory monitoring interfered seriously with sleep. A small number of patients reported problems associated with the self-measurement procedure. We recommend self-measurement as a less expensive and more easily available alternative to ambulatory measurement. However, the precise role of blood pressure self-measurement should be settled in future research investigating its relation with cardiovascular pathology, clinically relevant cutoff points and cost-effectiveness.

Chapter 8 compares blood pressure measurements by the general practitioner, the practice nurse and the patient with daytime ambulatory blood pressure (mean of two days) as a reference value. On average, nurse-measured blood pressures were lower than blood pressures measured by the doctors, but both procedures revealed higher blood pressures than ambulatory mea- 
surements and self-measurements. A series of eight self-measurements on four occasions appeared to be a reliable alternative to ambulatory measurement. The white coat effect was more pronounced in older women ( $>40$ years) than in older men.

Chapter 9 discusses a study which attempted to find out whether seasonal influences on blood pressure, as found in other studies, also existed in borderline hypertensive primary care patients. In our study, differences between winter and summer ranged from 0 to $3 \mathrm{mmHg}$. Only one significant difference was found: systolic ambulatory daytime pressure was higher ( 3 $\mathrm{mmHg}$ ) in winter than in summer.

Finally, chapter 10 presents a general discussion and recommendations for clinical practice and further research. 



\section{CHAPTER 12}

\section{Samenvatting}

De opsporing, diagnosestelling en behandeling van lichte tot matige hypertensie, een risicofactor voor het optreden van hart- en vaatziekten, zijn taken van de huisarts. Tegen de achtergrond van de grote intra-individuele variabiliteit van bloeddruk, de mogelijke aanwezigheid van regressie naar het gemiddelde en 'witte-jashypertensie', en de kans op meetfouten, is er een aanzienlijke kans op verkeerde classificatie. Verkeerde classificatie kan leiden tot een onjuiste beslissing bij het verdere beleid. In een aantal studies bleek dat bij eenderde tot de helft van patiënten, gediagnostiseerd als licht hypertensief, na overschakeling van behandeling met bloeddruk verlagende medicijnem op placebo of stoppen met de medicatie, de diastolische bloedoruk lager dan 90 $\mathrm{mmHg}$ bleef.

Hoofdstuk 1 beschrijft de algemene achtergrond van het onderzoek. In een beknopt overzicht over bloeddrukmeting gedurende de laatste honderd jaar wordt de problematiek van de bloeddrukmeting en de juiste diagnosestelling hypertensie in kaart gebracht. De onderzochte literatuur geeft aan dat regressie naar het gemiddelde, een methodologisch artefact, het duidelijkst aanwezig is bij patiënten met de hoogste bloeddrukken tijdens de eerste meting. De prevalentie van witte-jas-hypertensie bij patiënten met 'borderline' hypertensie blijkt in studies tussen 21 en $38 \%$ te liggen. De oorzaken van de grote intra-individuele bloeddrukvariabiliteit, die bij mensen met hypertensie nog groter is dan bij degenen met normale bloeddrukwaarden, zijn slechts ten dele bekend. De bloeddruk verandert onder invloed van lichamelijke inspanning en tijdens de ademhaling, en is onder meer afhankelijk van de lichaamshouding. Bij de meeste mensen is de bloeddruk lager tijdens de slaap, en in landen met een gematigd klimaat bleek de bloeddruk ' 5 winters ongeveer $5 \mathrm{mmHg}$ hoger te zijn dan 's zomers.

Bij de diagnosestelling hypertensie bestaat een aanzienlijke kans op verkeerde classificatie. Dit probleem doet zich met name voor in de huisartspraktijk met relatief veel patiënten met bloeddrukken in de buurt van de grenswaarden.

De opzet en methoden wan het onderzoek worden in hoofdstuk 2 beschreven. Het betreft een prospectief, diagnostisch, vergelijkend onderzoek bij patiënten uit huisartspraktijken die bij het eerste consult een verhoogde bloeddruk bleken te hebben. Er namen zeventien huisartspraktijken deel aan het onderzaek. Alle deelnemende patiënten ondergingen vier procedures van bloeddrukmeting: metingen door de eigen huisarts, metingen door de 
praktijkassistente, metingen door de patiënt zelf, en ambulante 24-uursmetingen.

In hoofdstuk 3 worden de uitkomsten van de diagnostische procedure uit de NHG-Standaard Hypertensie vergeleken met de uitkomsten van de ambulante metingen. Met betrekking tot de klinische beslissing hypertensie of normotensie stemde de NHG-procedure bij 'hoge' uitgangsmeting (diastolische bloeddruk tussen 105 en $115 \mathrm{mmHg}$ ) aanzienlijk beter overeen met de ambulante meting dan bij 'lage' uitgangsmeting (diastolische bloeddruk tussen 95 en $105 \mathrm{mmHg}$ ). Het witte-jaseffect bleek ook aanwezig bij metingen door de huisarts.

In de hoofdstukken 4 en 5 wordt onderzocht hoeveel bloeddrukmetingen de huisarts moet uitvoeren alvorens met zekerheid de diagnose lichte of matige hypertensie te stellen. De bloeddrukmetingen door de huisarts werden vergeleken met de "naar redelijkheid veronderstelde gemiddelde bloeddruk" gedefinieerd als het gemiddelde van tien bloeddrukmetingen tijdens de laatste vijf consulten. In hoofdstuk 4 zijn de onderzoeksgegevens kwalitatief, dat wil zeggen na dichotomisering (hypertensie/nomotensie), geanalyseerd bij verschillende afkappunten. Hoofdstuk 5 doet verslag van een kwantitatieve, statistische analyse van dezelfde onderzoeksgegevens, zonder dichotomisering. Met behulp van een lineaire regressie analyse werd aangetoond dat de "naar redelijkheid aangenomen gemiddelde bloeddruk" een stabiele referentiewaarde was.

De verschillende analyses leidden tot dezelfde conclusie: zelfs na acht bloeddrukmetingen tijdens vier consulten blijft er bij 'borderline' hypertensieve patiënten een aanzienlijke kans op verkeerde classificatie. De analyse van subgroepen wees uit wat vanuit theoretisch gezichtspunt valt te verwachten: de kans op een verkeerde classificatie hangt grotendeels af van de beginbloeddruk en de gehanteerde grenswaarde. De kans op een verkeerde classificatie is laag bij lage uitgangswaarden en hoge grenswaarden, en bij relatief hoge uitgangswalarden en lage grenswaarden.

Hoofdstuk 6 lat zien dat de reproduceerbaarheid van een aantal bloeddrukmetingen door de huisarts of de patiënt even goed is als die van een ambulante bloeddrukmeting. Deze bevinding is in strijd met die van andere studies. De geringere reproduceerbaarheid van metingen door de arts, zoals gevonden in een aantal andere onderzoeken, is waarschijnlijk het gevolg van een (te) gering aantal metingen.

De uitvoerbaarheid, verdraaglijkheid en bijwerkingen van ambulante bloeddrukmetingen en metingen door de patiënt worden beschreven in hoofdstuk 7 . Ongeveer $30 \%$ van de patiënten die een ambulante meting ondergingen hadden tamelijk veel of heel veel last van de meting tijdens hun dagelijkse activiteiten. Bij 40 tot $45 \%$ van de patiënten belemmerde de ambulante meting in ernstige mate de slaap. Met betrekking tot de metingen door de patiënt werden slechts weinig problemen genoemd. Metingen door de patiënt blijken een goedkoop en minder belastend alternatief te zijn voor 
ambulante bloeddrukmeting. De plaats van zelf-metingen bij de diagnostiek en het beleid bij mensen met een verhoogde bloeddruk is echter nog niet exact aan te geven. Op dit moment staan slechts geëxtrapoleerde grenswaarden ter beschikking. Nieuwe grenswaarden, gerelateerd aan cardiovasculaire eindpunten, zijn nodig, naast onderzoeksresultaten met betrekking tot de kosten-effectiviteit van thuismetingen.

In hoofdstuk 8 worden bloeddrukmetingen door de huisarts, de praktijkassistente en de patiënt vergeleken met het gemiddelde (overdag) van twee ambulante bloeddrukmetingen. Metingen door de praktijkassistente zijn gemiddeld lager dan metingen door de dokter, maar beide meetprocedures leveren bloeddrukken op die hoger zijn dan ambulante metingen en metingen door de patiënt. Acht metingen door de patiënt bij vier gelegenheden bleken een betrouwbaar alternatief voor ambulante meting. Het witte-jaseffect was meer uitgesproken aanwezig bij oudere vrouwen ( $>40$ jaar) dan bij oudere mannen.

In hoofdstuk 9 is onderzocht of de seizoensinvloeden op bloeddruk, gevonden in andere onderzoeken, eveneens aanwezig zijn bij 'borderline' hypertensieve patiënten in huisartspraktijken. De verschillen die wij vonden lagen tussen 0 en $3 \mathrm{mmHg}$. Er was slechts éen statistisch significant verschil: de ambulante systolische bloeddruk overdag was 's winters hoger ( $3 \mathrm{mmHg}$ ) dan 's zomers.

De algemene discussie, en aanbevelingen voor de praktijk en verder onderzoek zijn te vinden in hoofdstuk 10. 



\section{Dankwoord}

Het verrichten van wetenschappelijk onderzoek wordt wel geassocieerd met een eenzame worsteling waarbij de, soms nog jonge, onderzoeker geacht wordt zich wast te bijten in een probleem dat door voorgangers niet of onvoldoende werd opgelost.

Bij het lezen van dit dankwoord zal spoedig een andere indruk ontstaan. In de snel veranderende wereld die de onze is, is veel onderzoek onmogelijk zonder de hulp van velen. En, op het gevaar af dat ik deze of gene vergeet, maak ik graag van de gelegenheid gebruik om de voor dit onderzoek belangrijke personen te noemen. Zij die menen dat ik hen ten onrechte ben vergeten: laat het me weten, dan kan ik beoordelen of het zo is en het wellicht op een andere manier rechtzetten.

Jan van Ree stond aan de wieg van dit onderzoek. Als eerste indiener van het onderzoeksvoorstel werd hij de projectleider en tevens de begeleider bij de dagelijkse gang van zaken. Van zijn praktische tips heb ik vaak gebruik gemaakt, maar verreweg het belangrijkst waren voor mij de rust, het vertrouwen en de vrijheid die hij me gaf. Mede daardoor kan ik terugkijken op een heerlijke tijd.

André Knottnerus was degene die me eind 1989 benaderde met de vraag of $i k$ interesse had in dit onderzoek. Na aanvankelijke aarzeling ben ik eraan begonnen, en ik heb er geen spiijt van gekregen. Gedurende de looptijd van het project heeft hij verschillende keren waardevolle adviezen gegeven die me verder hielpen.

Berna Schouten was als onderzoeksassistente bij alle fasen van het project betrokken: de literatuurstudie, de opzet, het benaderen van huisartsen en praktijkassistenten, de gegevensverzameling en -verwerking, de analyses en de vormgeving van de artikelen en voordrachten. Vanaf het begin was er bij haar ook duidelijk een inhoudelijke interesse, die haar onder andere aanzette tot een cursus Statistiek bij de Open Universiteit. Wanneer ik hier schrijf dat zij vaak als een rots in de branding was, dan zeg ik niets te veel. Archiveren is nog altijd niet mijn sterkste eigenschap. Het was daarnaast vooral heel plezierig om met haar samen te werken.

Peter de Leeuw heeft me telkens weer verbaasd door zijn brede en diepe kennis op het gebied van bloeddrukmeting, bloeddruk en hypertensie. En dat terwijl hij toch ook de algemene interne geneeskunde een warm hart toedraagt. De keren dat ik met hem kon overleggen heeft hij aan zijn 'promotor-zijn' letterlijk inhoud gegeven.

Chris van Weel heeft met name in de eindfase, en bij het schrijven van enkele artikelen, bijgedragen. Zijn stilistische talent en redactionele ervaring waren in die fase uitermate welkom. 
De leden van de beoordelingscommissie, Prof.dr. P. Pop (voorzitter), Prof.dr. P. van den Brandt, Prof.dr. J.A. Knottnerus, Prof.dr. B. Meyboom-de Jong en Prof.dr. Th. Thien, dank ik voor de tijd en aandacht die ze aan het manuscript hebben willen geven. Waar mogelijk en nodig heb ik hun commentaren zo goed mogelijk verwerkt.

Van de co-auteurs wil ik met name Hubert Schouten bedanken. Bij de statistische onderbouwing van de conclusies in de hoofdstukken die naar mijn mening niet de minste zijn uit dit proefschrift, was zijn hulp onontbeerlijk. Gaandeweg heb ik veel wan hem geleerd.

Het onderzoek had nooit kunnen plaatsvinden zonder de inzet van de deelnemende huisartsen en de praktijkassistenten. Ik weet hoeveel een

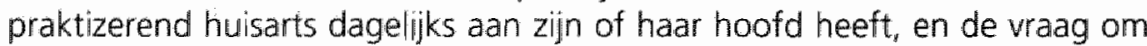
deelname aan weer een onderzoek 'vanuit Maastricht' komt niet altijd gelegen. Tegen deze achtergrond mijn dank en waardering voor de volgende huisartsen en praktijkassistenten: Charles Phaff, Bert Zonneveld, Marja Mommers, Petra Saparuwé, J. Screever-Delahaye, A. Screever, Maud Haemers (allen Maastricht), Gerard Benthem, Martin den Heyer, Marjolein Janssen, Diana de Raad-Weckx, Philo Kroon, P. van Esser, G. Sampers, A. de Vries, Marie-José Hasselmann, Jacqueline Reyners, J. Welzen, M. Snijders, J. Boots (allen Roermond), G. Saes, Carmen Rouing, Fianne Wenteler (Horn), Peter Jordans, Anita Bongers (Swalmen), A. Visschedijk, Trees Kuyper, Mirjam Maessen (Heel), F. Donders, Karin Frijns (Nuth), R. Panhuyzen, Melanie van der Veeke (Voerendaal), H. Berendsen, L. Bongenaar en Maud Rens (Urmond). Michiel Cornel en Machteld Langenberg droegen als huisartsen in dienstverband bij aan de gegevensverzameling.

Zeer dankbaar ben ik de patiënten die belangeloos aan dit onderzoek hebben deelgenomen. De door en aan hen verzamelde gegevens waren de basis van deze studie.

In de beginfase heb ik veel gehad aan de commentaren van Jos Diederiks, Pieter Leffers en Jacques Lenders.

De volgende mensen hebben als lid van stuur- of projectgroep, of door overleg binnen de afdeling, hun bijdragen geleverd: Luc van Bortel, Henk van den Hoogen, Jos van den Hoogen, Jan-Willem de Jonge, Hans Petri, Peter Pop, Piet Portegijs, Jelle Stoffers en Wim van Zutphen, die het vervolg van het onderzoek helaas niet heeft kunnen meemaken. Geert-Jan Dinant heeft me goed begeleid bij de opzet en het schrijven van het eerste artikel.

Een speciaal woord van dank gaat uit naar Gert van Montfrans die verschillende keren bereid was tot nadere informatie en overleg.

Jan Klerkx vertaalde hoofdstuk 3 in het Engels en redigeerde mijn Engelse teksten op deskundige wijze.

De heer Hueber droeg zorg voor ijking en, waar nodig, reparatie van de in het onderzoek gebruikte kwikmeters, en voorzag alle apparaten van een standaard manchet. 
Enkele mensen die niet tot het onderzoek, maar wel tot een voor mij plezierige werksfeer bij de Vakgroep Huisartsgeneeskunde hebben bijgedragen, will ik hier graag noemen: Henk Goettsch, mijn compagnon 'door dik en dun' bij de Huisartsopleiding. Paul Höppener, Frans van der Horst, Jim Tatipata, Trudy van der Weijden, tot voor kort mijn sympathieke kamergenote, en George Wolfs.

I would like to thank a number of experts who have contributed much to my knowledge of the subject of this study. First of all I want to thank Dr G.W. Pickering. The problem of diagnosing hypertension and its relation to the large variability of blood pressure were already described in his handbooks from 1955, 1961 and 1968. I also learned much from the studies by Armitage and Rose, published in 1966. They tried to solve the problems of regression to the mean, measurement errors and blood pressure variability from a statistical/ mathematical viewpoint. Drs Perry and Miller elaborated the concepts of earlier studies and presented the implications and alternatives for clinical practice. Their illustration of the problem, clearly visualized in their study, is something I have used in oral presentations. Finally, I would like to thank Dr Reeves, who was one of the first investigators to recognize 24 hour ambulatory blood pressure measurement for what it actually is, a large number of measurements. Moreover, I have enjoyed Reeves' detailed review of blood pressure measurement and diagnosing hypertension.

Na dit 'uitstapje overzee' kom ik dichter bij huis. De twee mensen waar voor mij alles mee begon, mijn ouders, wil ik bedanken voor de waarden en waardigheden die ze aan mij hebben doorgegeven, en voor de mij geboden mogelijkheid om te studeren. Mijn vader kan het jammer genoeg niet meer meemaken. Hij is nog vaak in mijn gedachten.

Een proefschrift afronden is een vorm van thuiskomen. Lieve Annemiek, bedankt voor je relativerende en nuchtere houding bij mijn activiteiten van de afgelopen jaren. Je zette me soms weer met de voeten op de grond wanneer aanwaaiende ideeën en toevallige impulsen met me aan de haal dreigden te gaan. Met jou en onze 'knubuskes' Pim, Pauke en Kasper kan ik alleen maar zeggen: 'het is goed zo'. 



\section{Curriculum vitae}

Mark Brueren (Venlo, 1954) behaalde in 1972 het diploma gymnasium B aan het St.Thomascollege in Venlo. Daarna studeerde hij een jaar Psychologie aan de Katholieke Universiteit Nijmegen (KUN). In 1973 begon hij aan deze universiteit met de studie Geneeskunde en behaalde in 1982 het arts-examen. In 1985 voltooide hij de éénjarige huisartsopleiding aan de KUN (opleider: E. Gerrits, Afferden, Noord-Limburg). Na de huisartsopleiding nam hij waar in huisartspraktijken in Gelderland, Noord-Brabant, Limburg en in het Duitse Sauerland. In 1986 en 1987 werkte hij als projectleider bij het Nijmeegs onderzoeksbedrijf Farma Research. Daarna was hij, tot 1989, stafmedewerker bij wat toen nog de Rijksuniversiteit Limburg heette, op de afdeling WTS (Wetenschapswinkel, Transferbureau, Science Park). Sinds 1989 werkt hij bij de Vakgroep Huisartsgeneeskunde in Maastricht, eerst als eindredacteuri coördinator nascholing voor huisartsen (PAOG-H), en van 1990 tot 1995 als huisarts-onderzoeker, In 1995 begon hij als huisartsbegeleider bij de huisartsopleiding van de Universiteit Maastricht. Hij maakte deel uit van de werkgroep die de NHG-Standaard 'Depressie' voorbereidde, en was namens het NHG (Nederlands Huisartsen Genootschap) lid van de CBO-werkgroep 'Depressie bij volwassenen'. Van 1989 tot 1993 werkte hij in deeltijd in een huisartspraktijk, eerst in Landgraaf en later in Maastricht. In 1994 startte hij met Wilma Bijloo-de Graaff een duo-praktijk in Helmond-Stiphout. Hij woont met Annemiek Buijs en hun kinderen Pim, Pauke en Kasper in Maastricht. 